\title{
Phosphodiesterase-4 in the Brain: Effects of Pharmacological Inhibition and Mutation of DISC1
}

Lan Xiao

West Virginia University

Follow this and additional works at: https://researchrepository.wvu.edu/etd

\section{Recommended Citation}

Xiao, Lan, "Phosphodiesterase-4 in the Brain: Effects of Pharmacological Inhibition and Mutation of DISC1" (2011). Graduate Theses, Dissertations, and Problem Reports. 4818.

https://researchrepository.wvu.edu/etd/4818

This Dissertation is protected by copyright and/or related rights. It has been brought to you by the The Research Repository @ WVU with permission from the rights-holder(s). You are free to use this Dissertation in any way that is permitted by the copyright and related rights legislation that applies to your use. For other uses you must obtain permission from the rights-holder(s) directly, unless additional rights are indicated by a Creative Commons license in the record and/ or on the work itself. This Dissertation has been accepted for inclusion in WVU Graduate Theses, Dissertations, and Problem Reports collection by an authorized administrator of The Research Repository @ WVU.

For more information, please contact researchrepository@mail.wvu.edu. 
Phosphodiesterase-4 in the Brain: Effects of Pharmacological Inhibition and Mutation of DISC1

\section{Lan Xiao}

Dissertation submitted to the

School of Pharmacy

at West Virginia University

in partial fulfillment of the requirements

for the degree of

Doctor of Philosophy

in

Pharmaceutical and Pharmacological Sciences

James M. O'Donnell, Ph.D., Chair

Patrick S. Callery, Ph.D.

Han-Ting Zhang, M.D., Ph.D.

James O'Callaghan, Ph.D.

Jason D. Huber, Ph.D.

Department of Basic Pharmaceutical Sciences

Morgantown, West Virginia

2011

Keywords:phosphodiesterase-4, cyclic adenosine monophosphate, protein kinase A, cyclic AMP response element binding protein, forced-swim test, high-affinity rolipram binding state, low-affinity rolipram binding state, disrupted in schizophrenia 1, upstream conserved region

Copyright 2011 Lan Xiao 


\title{
$\underline{\text { Abstract }}$
}

\section{Phosphodiesterase-4 in the Brain: Effects of Pharmacological Inhibition and Mutation of DISC1}

\author{
Lan Xiao
}

The effects of treatment with PDE4 inhibitors on cAMP/pCREB signaling, hippocampal neurogenesis and immobility in forced-swim test and the effects of DISC1 mutation on cAMP/pCREB signaling, PDE4 subtypes and PDE4 activity and highaffinity rolipram binding state were determined. Acute treatment with PDE4 inhibitors increased cAMP and pCREB transiently, as determined by ELISA and Western blotting, respectively. Repeated treatment with PDE4 inhibitors for 16 days produced antidepressant-like effect as evidence by decreased immobility in forced-swim test, increased cAMP/pCREB signaling and enhanced hippocampal neurogenesis. PDE4 inhibitors which preferentially interact with the high-affinity rolipram binding state, such as rolipram and piclamilast, produced greater effects than CDP840, which preferentially interacts with the low-affinity rolipram binding state.

PDE4 exerts its normal functions by interacting with a variety of binding proteins. The effects of mutation of one of the most important binding proteins DISC1, a risk factor gene for mental disorders, were determined. In this study, DISC1 mutant mice that carried truncated DISC1 proteins were used. DISC1 mutation increased cAMP and pCREB levels, and decreased PDE4 activity in prefrontal cortex, hippocampus and striatum. The PDE4B1, B3 and B4 splice variants were decreased in these three brain regions, while the $\mathrm{D} 3$ and $\mathrm{D} 5$ variants were decreased only in the hippocampus; PDE4A1 and A5 splice variants were not affected by the DISC1 mutation. Previous work has shown greater DISC1 association with the PDE4B subtype than the other subtypes. Radioligand binding assays showed that the high affinity rolipram binding state was decreased in brain regions of DISC1 mutant mice, suggesting high affinity rolipram binding state is functionally associated with DISC1.

Overall, PDE4 inhibitors which preferentially interact with the high-affinity rolipram binding states produced greater effects on cAMP/pCREB and behavior, as well as for increasing hippocampal neurogenesis. In addition, DISC1 mutation decreased PDE4 activity and upregulated cAMP/pCREB levels. These suggest DISC1 is important for the normal function of PDE4 and downstream cAMP signaling. Mutation of DISC1 also induced a decrease in PDE4B and PDE4D, but not PDE4A splice variants. The studies shed light on the understanding of the function of high-affinity rolipram binding state in the central nervous system and may provide a new target for antidepressant drug discovery and development. 


\section{Acknowledgements}

I would like to sincerely thank my mentor Dr James M. O’Donnell for his advice, support, and guidance throughout my graduate studies, research and writing of this dissertation.

I would also like to thank my committee members, Dr Han-Ting Zhang, Dr Patrick S. Callery, Dr James O'Callaghan and Dr Jason D. Huber for their suggestions in the course of my dissertation.

I would also like to thank all of the laboratory members in Dr O'Donnell's lab for their help and assistance.

I want to thank the faculty, staff and graduate students in the department of Basic Pharmaceutical Sciences for their help and assistance.

I would also like to thank my parents and all my friends for their love, support and encouragement in everything I did. 


\section{Table of Contents}

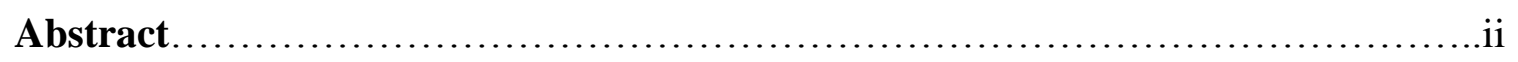

Acknowledgements.........................................................

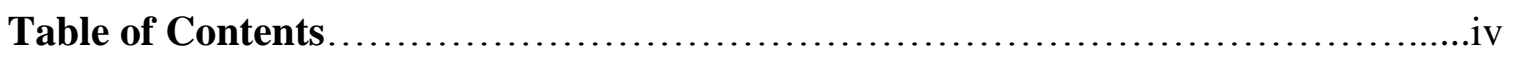

List of Tables...........................................................

List of Figures.........................................................

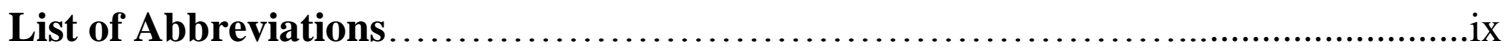

\section{Chapter 1. Introduction}

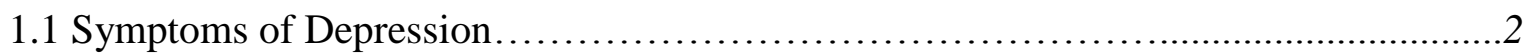

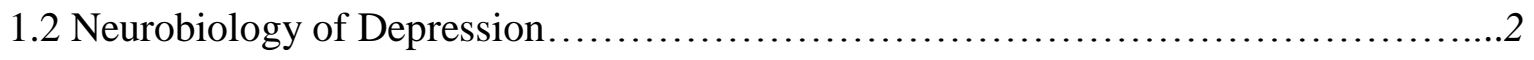

1.3 Animal Models of Depression...........................................6

1.4 Treatment of Depression................................................

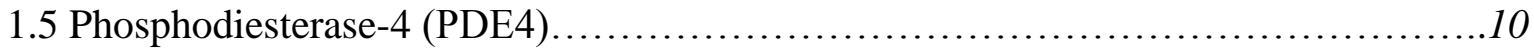

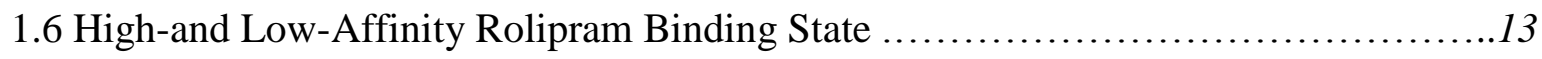

1.7 PDE and Antidepressant Effects.......................................... 14

1.8 Genetic Linkage Studies of Disrupted in Schizophrenia 1 (DISC1)................18

1.9 DISC1 Expression in Developing Brain and Adult Brain.........................19

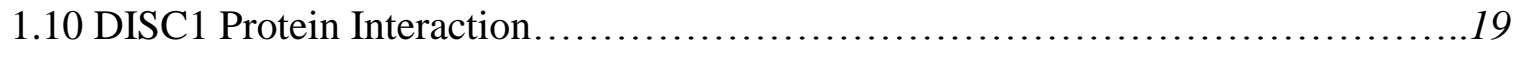

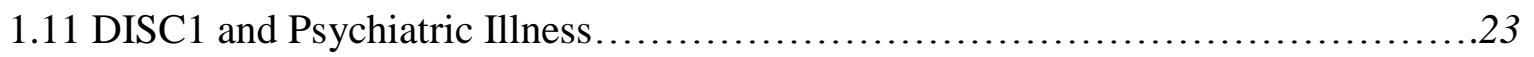


Chapter 2. Effects of repeated treatment with phosphodiesterase-4

inhibitors on cyclic AMP signaling, hippocampal neurogenesis, and behavior in the forced-swim test

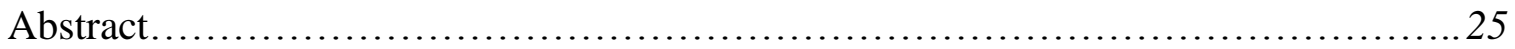

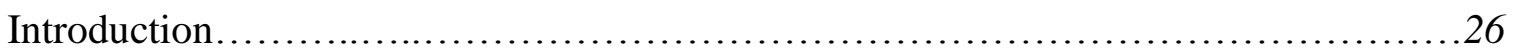

Materials and Methods...............................................................

Results.................................................................. 34

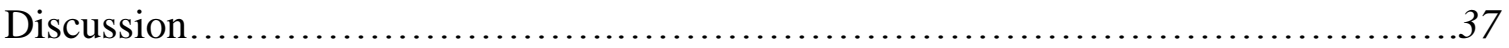

Chapter 3. Effect of DISC1 mutation on CAMP/pCREB signaling and

\section{PDE4 isoforms}

Abstract...................................................................... 49

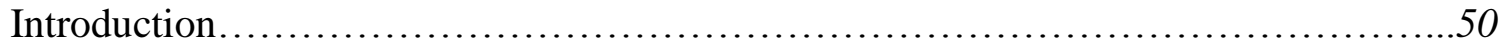

Materials and Methods................................................................

Results.................................................................. 55

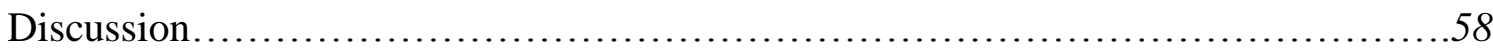

Chapter 4. Overall discussion and conclusion......................80

List of references............................................. 87

Curriculum Vitae...............................................120 


\section{List of Tables}

\section{Table}

1.1 Animal models use for depression/antidepressant research.........................7

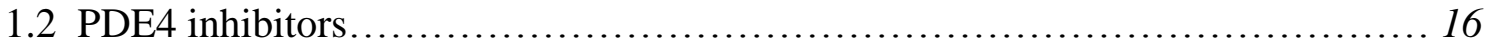

2.1 Effects of acute treatment with PDE4 inhibitors on cyclic AMP

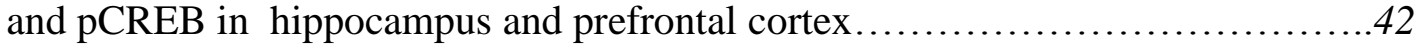

2.2 Effects of acute treatment with PDE4 inhibitors on

immobility in the forced-swim test......................................43 


\section{List of Figures}

\section{Figure}

1.1 Structure of PDE4 enzymes................................................

1.2 Modulation of the cAMP/CREB signaling

pathway by PDE4 inhibitors.......................................... 17

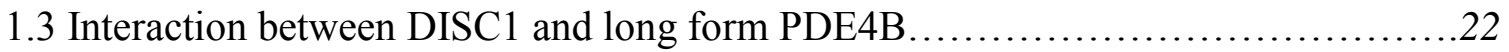

2.1 Effects of repeated treatment with rolipram, piclamilast, or CDP840 on cyclic AMP in rat brain.....................................44

2.2 Effects of repeated treatment with rolipram, piclamilast, or CDP840 on pCREB in rat brain.......................................... 45

2.3 Effects of repeated treatment with rolipram, piclamilast, or CDP840 on cell proliferation and survival in rat hippocampus.................46

2.4 Effects of repeated treatment with rolipram, piclamilast, or CDP840 on immobility of rats in the forced-swim test.......................47

3.1 Cyclic AMP levels in the hippocampus, prefrontal cortex and striatum of wild type (Wt) and DISC1 mutant mice.

3.2 Phospho-CREB levels in the hippocampus, prefrontal cortex and striatum of wild type (Wt) and DISC1 mutant mice... .68

3.3 PDE4 activity in the hippocampus, prefrontal cortex and striatum of wild type (Wt) and DISC1 mutant mice.

3.4 PDE4B1 levels in the hippocampus, prefrontal cortex and striatum of wild type (Wt) and DISC1 mutant mice...

3.5 PDE4B2 levels in the hippocampus, prefrontal cortex and striatum of wild type (Wt) and DISC1 mutant mice

3.6 PDE4B3 levels in the hippocampus, prefrontal cortex and striatum of wild type (Wt) and DISC1 mutant mice. 
3.7 PDE4B4 levels in the hippocampus, prefrontal cortex and striatum of wild type (Wt) and DISC1 mutant mice..........................73

3.8 PDE4B mRNA levels in the hippocampus, prefrontal cortex and striatum of wild type (Wt) and DISC1 mutant mice....................74

3.9 PDE4D3 levels in the hippocampus, prefrontal cortex and striatum of wild type (Wt) and DISC1 mutant mice..........................75

3.10 PDE4D5 levels in the hippocampus, prefrontal cortex and striatum of wild type (Wt) and DISC1 mutant mice...........................76

3.11 PDE4A1 levels in the hippocampus, prefrontal cortex and striatum of wild type (Wt) and DISC1 mutant mice.........................77

3.12 PDE4A5 levels in the hippocampus, prefrontal cortex and striatum of wild type (Wt) and DISC1 mutant mice..........................78

3.13 HARBS levels in the hippocampus, prefrontal cortex and striatum of wild type (Wt) and DISC1 mutant mice. .79 


\section{List of Abbreviations}

PDE4: Phosphodiesterase-4

cAMP: Cyclic adenosine monophosphate

PKA: Protein kinase A

CREB: Cyclic AMP response element binding protein

FST: Forced-swim test

HARBS: High-affinity rolipram binding state

LARBS: Low-affinity rolipram binding state

DISC1: Disrupted in schizophrenia 1

UCR: Upstream conserved region 
Chapter 1

Introduction 


\subsection{Symptoms of Depression}

Depression was first termed as melancholia, which means black bile in Greek, by Hippocrates (Akiskal, 2000). To date, depression is one of the most prevalent forms of mental illness in the world. Severe form of depression influences about $2 \%-5 \%$ of the U.S. population and mild form of depression affects up to $20 \%$ of the population (Nestler et al., 2002). In addition, due to the high risk of suicide, depression is a very life threatening disease (Blazer, 2000). Though the symptomatology of depression has been described, the pathophysiology of this disorder was not understood very well until the middle of the $19^{\text {th }}$ century (Nestler et al., 2002). In 1960, depression was defined as major depression based on the symptomatic criteria of Diagnostic and Statistical Manual and this categorization has continued (DSMIV, 2000). This criteria include: depressed mood; irritability; low self esteem; feelings of hopelessness, worthlessness, and guilt; decreased ability to concentrate or think; change of appetite or weight; change of sleep habits; low energy; fatigue or increased agitation; decreased interest in pleasurable activities; and recurrent thinking of death or suicide. When a number of symptoms last for longer than 2 weeks and normal social and occupational functions are impaired, major depression is diagnosed (DSMIV, 2000).

\subsection{Neurobiology of Depression}

Current thinking is that genetic and non-genetic factors contribute to the development of depression. Though no single genes have been identified to be highly related to depression in a conclusive manner, approximately $40-50 \%$ of the risk for 
depression is genetic (Fava and Kendler, 2000). Because a variety of genes contribute to the development of depression, identifying a single risk gene and its effects becomes very difficult. In addition, non-genetic factors such as stress, emotional stimuli, or viral infection might also induce the development of the depression (Burmeister, 1999). Generally, depression is described as a stress-related disorder. However, stress alone is not sufficient to induce depression and most people who experience serious stress do not become depressed. This indicates that interaction between genetic predisposition and environmental factors contribute to the pathogenesis of depression (Nestler et al., 2002).

To date, the neurobiology of depression could be explained by several mechanisms: dysfunction of the hippocampus and hypothalamic-pituitary-adrenal axis; impairment of neurotrophic mechanisms; and impairment of brain reward pathways. In the theory of regulation of the hypothalamus-pituitary-adrenal axis, parvocellular neurons that contain corticotrophin-releasing factor (CRF) of the paraventricular nucleus of the hypothalamus integrate input induced by stress. These inputs include excitatory afferents from the amygdala, inhibitory afferents from the hippocampus, and inputs from the ascending monoamine pathways. CRF is released from neurons located in the hypophyseal portal system and exerts its effects on the anterior pituitary to facilitate the release of ACTH. ACTH increases glucocorticoid levels, while simultaneously, inhibiting the synthesis of CRF and ACTH. However, a high level of glucocorticoids damages hippocampal function, initiating a hypercortisolemic state associated with depression (Nestler et al., 2002). Despite the dysfunction of the hypothalamus-pituitary-adrenal axis having been associated with depression, it is still unknown whether it is the cause for depression or secondary to depression (Nestler et al., 2002). 
Another hypothesis based on the pathologic effects of stress on the hippocampus involves the role of the neurotrophic factor in the etiology of depression. Neurotrophic factors are found to regulate neural growth and differentiation during development, as well as plasticity and survival of adult neurons and glial cells (Duman et al., 1997; Altar, 1999). The neurotrophic hypothesis states that a deficiency of neurotrophic factors contributes to hippocampal pathology during the development of depression (Nestler et al., 2002). Chronic stress decreases BDNF expression in the dentate gyrus and the pyramidal cell layers of the hippocampus (Smith et al., 1995). This decrease may result partly from a reduction in glucocorticoids (Smith et al., 1995) and a change in serotonergic transmission (Vaidya et al., 1997). In addition, chronic antidepressant treatment enhances BDNF expression (Nibuya et al., 1995). Compelling studies reveal that severe stress induces changes in glutamatergic and monoaminergic neurons; these changes include the reduction of dendritic arborizations and BDNF expression. The reduction of BDNF is due to excessive glucocorticoid-induced reduction of transcription via CREB, which controls BDNF expression (Kuroda and McEwen, 1998). Antidepressant treatments produce the opposite effects, i.e., increased dendritic arborization and BDNF expression in the hippocampus via activation of CREB (Conti et al., 2002). In vivo and in vitro, expression of BDNF is increased by CREB (Tao et al., 1998; Conti et al., 2002). Injection of CREB into hippocampal dentate gyrus increases CREB activity, and exerts an antidepressant-like effect in forced swim and learned helplessness tests (Chen et al., 2001).

Most preclinical studies have focused on the hippocampus because of its role in the memory and spatial learning. Recently, brain imaging and autopsy studies indicate 
abnormalities in several other brain regions in patients with depression such as nucleus accumbens, hypothalamus and amygdala (Nestler et al., 2002). Such regions are involved in the brain reward pathway. The nucleus accumbens is part of the mesolimbic dopamine system, which contains dopaminergic neurons. Dopaminergic neurons in the nucleus accumbens play an important role in reward (Nestler et al., 2002). Drugs of abuse exert their rewarding effects via enhancing dopaminergic transmissions (Wise, 1996; Koob et al., 1998). Other drugs such as opiates not only activate dopaminergic neurons, but also $\mu$ opioid receptors in the nucleus accumbens (Nestler et al., 2002). The possible involvement of the nucleus accumbens in the development of depression has been studied for decades. Behavioral studies demonstrate drugs of abuse decrease the stimulation threshold for intracranial self-stimulation (Hall et al., 1977; Wise, 1996). The reinforcing effects of drugs of abuse depend in part on their ability to activate CREB in the nucleus accumbens (Berke and Hyman, 2000; Nestler, 2001; Shaw-Lutchman et al., 2002). An increase of CREB in the region decreases the sensitivity to a variety of aversive stimulants, while a decrease of CREB increases that sensitivity (Carlezon et al., 1998). Acute and chronic stress could increase the CREB-mediated transcription in the nucleus accumbens (Carlezon et al., 1998; Pliakas et al., 2001). Thus, it would appear that CREB in the nucleus accumbens is involved in the behavioral responses to the stimulants (Nestler et al., 2002). Several studies point out that dynorphin is a target gene downstream of the CREB signaling cascade, which may affect sensitivity to aversive stimuli and contribute to some symptoms of depression (Carlezon et al., 1998; Pliakas et al., 2001). In addition, BDNF in the nucleus accumbens significantly enhances drugreward signaling (Horger et al., 1999). 
Besides the nucleus accumbens, the hypothalamus is also regarded as contributing to the pathogenesis of depression. Orexin, which is expressed in the lateral hypothalamus, regulates both sleep and eating activity (Willie et al., 2001). Melanin, which is expressed in the lateral hypothalamus, modulates sexual and anxiety-like behaviors (Gonzalez et al., 1996; Ahima and Osei, 2001; Monzon et al., 2001). Melanocortin, which is expressed in the medial hypothalamus, regulates the anxiety-like behavior (Nestler et al., 2002). Furthermore, the amygdala is also involved in the molecular mechanism of depression due to its role in conditioned fear (Davis, 1998; Cahill et al., 1999), drug abuse, and natural rewards (Everitt et al., 1999; Koob, 1999; Hall et al., 2001; Josselyn et al., 2001; Jentsch et al., 2002).

\subsection{Animal Models of Depression}

Animal models have been important in studying neural factors involved in depression as well as the mechanism of action of antidepressant drugs. However, there is no single animal model that fully captures the various aspects of depression in humans. The cardinal symptoms of depression such as feelings of worthless and suicidal ideation exhibited in humans are difficult or impossible to model in animals (Nestler et al., 2002). Thus, the measurements of depression-related behavior in laboratory animals depend primarily on two criteria, i.e., responses to antidepressants and responses to stress (Willner, 1995; Hitzemann, 2000; Porsolt, 2000; Lucki, 2001). Though there are many limitations with the animal models described as Table 1.1, overall they are useful for studying the effects of new medications and the neurobiological mechanisms underlying depression (Nestler et al., 2002). 
Table 1.1. Animal Models Use for Depression/Antidepressant Research

\begin{tabular}{|c|c|c|}
\hline Model & $\underline{\text { Animals }}$ & Antidepressant effects \\
\hline Forced swim & Rat, Mouse & $\begin{array}{l}\text { Decrease the time of immobility } \\
\text { (Rodgers and Dalvi, 1997; Page } \\
\text { et al., 1999; Zhang et al., 2002) }\end{array}$ \\
\hline Tail suspension & Mouse & $\begin{array}{l}\text { Decrease the time of immobility } \\
\text { (Rodgers and Dalvi, 1997; Zhang } \\
\text { et al., 2002) }\end{array}$ \\
\hline Learned helplessness & Rat, Mouse & $\begin{array}{l}\text { Decrease escape latency and } \\
\text { failures (Hajszan et al., 2009) }\end{array}$ \\
\hline Olfactory bulbectomy & Rat, Mouse & $\begin{array}{l}\text { Partially reverse behavioral } \\
\text { abnormalities induced by lesion } \\
\text { (Breuer et al., 2009) }\end{array}$ \\
\hline Social defeat stress & Rat, Mouse & $\begin{array}{l}\text { Increase the time spent in the } \\
\text { interaction zone (Brown et al., } \\
\text { 2011) }\end{array}$ \\
\hline Chronic mild stress & Rat, Mouse & $\begin{array}{l}\text { Reverse changes in sucrose } \\
\text { consumption, corticosterone } \\
\text { level (Willner et al., 1987; Li et } \\
\text { al., 2007) }\end{array}$ \\
\hline
\end{tabular}




\begin{tabular}{|l|l|l|}
\hline Maternal deprivation & Rat, Mouse & $\begin{array}{l}\text { Decrease the HPA axis } \\
\text { responsiveness, } \\
\text { behaviors and alcohol } \\
\text { consumption (Huot et al., 2001) }\end{array}$ \\
\hline Differential reinforcement of & Rats, Mouse & $\begin{array}{l}\text { Decrease response rate and } \\
\text { low rate (DRL) }\end{array}$ \\
(O'Donnell and Seiden, 1983; \\
van Hest et al., 1992)
\end{tabular}




\subsection{Treatment of Depression}

There are several antidepressant treatments effective for patients with depression. Older treatments include electroconvulsive seizures, tricyclic antidepressants (TCAs), and monoamine oxidase inhibitors (MAOIs). The original tricyclic antidepressants, e.g., imipramine, arose from research on the behavioral effects of antihistamines, while monoamine oxidase inhibitors, e.g., iproniazid, were originally derived from drugs used to treat tuberculosis (Nestler et al., 2002). Both of these classes of drugs relieve the symptoms of depression, but have a very poor tolerability and risk profile (Feighner, 1999). The finding that these drugs can relieve depression shed a light on the molecular mechanism that modulates depressive symptoms in the brain. Over the past 50 years, depression research has been focused on understanding of how these drugs work and on finding better drugs with better tolerability and safety (Dubarek and Kucia, 2007). This led to the development of a number of second-generation antidepressants, which includes selective serotonin reuptake inhibitors (SSRIs), reversible inhibitors of monoamine oxidase A (RIMAs; e.g.,moclobemide), selective norepinephrine reuptake inhibitors (e.g., reboxetine), dual norepinephrine and serotonin reuptake inhibitors (e.g., milnacipram, venlafaxin, duloxetine), and some other drugs with distinct neurochemical actions (Nelson, 1997; Stahl, 1998). Studies in patients and animal models provide clues to how brain function is altered by antidepressant treatment (Pacher and Kecskemeti, 2004). Unfortunately, even the more recently developed antidepressants are still of limited utility due to their incomplete efficacy and side effects (Blier, 2001). Further, their mechanism of action remains incompletely understood. Notably, inhibition of serotonin and 
norepinephrine reuptake enhances the actions of transmitters immediately but antidepressants exert their behavioral effects only after a period of sustained treatment (Blier, 2001). This suggests that adaptation to the increased neurotransmission contributes to antidepressant efficacy.

\subsection{Phosphodiesterase-4}

Cyclic nucleotide phosphodiesterase (PDE) enzymes were first discovered by Thompson and Appleman in a variety of tissues from different species (Thompson and Appleman, 1971a; Thompson and Appleman, 1971b). To date, eleven families have been identified according to their substrate specificity, inhibitor sensitivities, and kinetic properties (Lugnier, 2006). Based on the substrate, the PDE family is divided into three groups: cAMP-specific PDEs, including PDE4, PDE7, and PDE8; cGMP-specific PDEs, including PDE5, PDE6, and PDE9; and dual-substrate PDEs, including PDE1, PDE2, PDE3, PDE10, and PDE11. All the PDE families have the same general structure, which includes a highly conserved catalytic domain within the central to C-terminal region and variable, differentially spliced, N-terminal regions responsible for regulating enzyme activity and intracellular location (Beavo and Brunton, 2002; Houslay and Adams, 2003).

Among PDE families, PDE4 is the most critical enzyme for modulating intracellular cAMP levels in the brain. PDE4 was first described by Reeves using ion-exchange chromatography to separate fractions of PDE activity from heart tissue; the fourth peak of PDE activity was found to be specific for cyclic AMP (Reeves et al., 1987); at the time, it was termed PDE IV. Further study revealed that PDE4 has high affinity for cAMP but not cGMP ( $\mathrm{Km}$ value for cAMP is $1-3 \mathrm{uM}$ ) and that is potently inhibited by rolipram 
(Bolger et al., 1996; Nemoz et al., 1997; Francis et al., 2001). To date, four subtypes of PDE4 have been identified; these are encoded by four genes, PDE4A, B, C, D, which encode 25 different splice variants. These PDE4 splice variants are divided into three groups: long form; short form, and super-short form as shown in Figure 1.1 (O'Donnell and Zhang, 2004; Houslay et al., 2007). Long form PDE4 contains upstream conserved regions UCR1 and UCR2. UCR1 has a conserved domain which can be phosphorylated by cAMP-dependent protein kinase (PKA). This modification enhances the activity for hydrolyzing cAMP (Sette and Conti, 1996; MacKenzie et al., 2002). Short form PDE4 has UCR2 but not UCR1, while the super-short form only has part of UCR2 (Johnston et al., 2004; Houslay et al., 2007; Chandrasekaran et al., 2008; Lynex et al., 2008). All the PDE4 enzymes have a highly conserved catalytic domain in the central to C-terminal region. In addition, PDE4B, $\mathrm{C}$, and $\mathrm{D}$ also contain an ERK phosphorylation site in the catalytic domain, which regulates long, short, and super-short forms differentially (Houslay et al., 2007). 


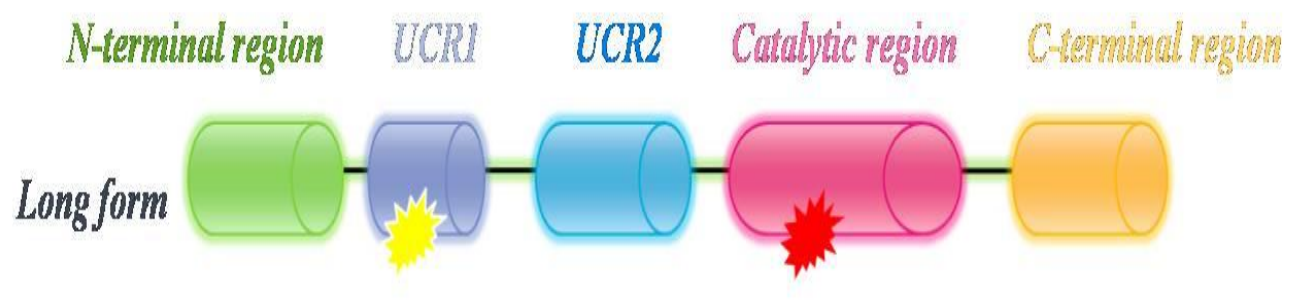

Short form

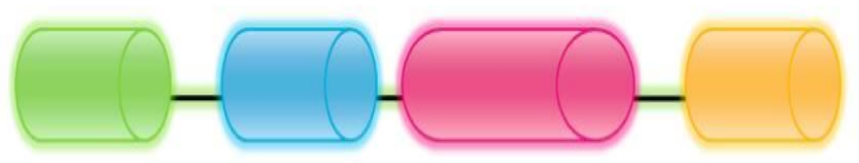

Super-short form

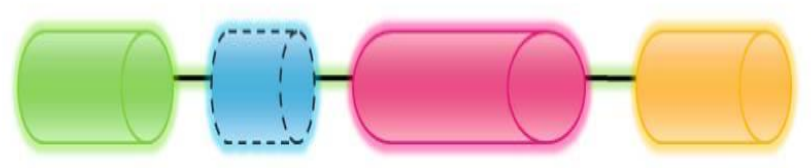

PKA phosphorylation

ERK phosphorylation

Truncated unit

Figure 1.1 Structure of PDE4 enzymes. PDE4 has four genes, PDE4A, B, C and D; each expresses approximately 3-11 alternative spliced variants at $\mathrm{N}$-terminus. According to their structure, PDE4 are classified as long, short and super-short forms (Zhang, 2009) 


\subsection{High and Low Affinity Rolipram Binding States}

Based on the binding of the inhibitor rolipram, PDE4 has two different conformations termed the high-affinity rolipram binding state (HARBS) and the lowaffinity rolipram binding state (LARBS); rolipram exhibits Kd values of approximately 2 nM and $200 \mathrm{nM}$, respectively, for these conformations (Jacobitz et al., 1996; Souness and Rao, 1997). The HARBS is present in the brain, while the LARBS is present in both brain and peripheral tissues (Kaulen et al., 1989; Souness and Rao, 1997; Zhang et al., 2006). Consistent with their distribution, the HARBS is associated with head twitches, tremor, hypothermia, and emesis (Schmiechen et al., 1990), while the LARBS is associated with anti-inflammatory effects (Souness and Rao, 1997). Chronic antidepressant treatment induces an increase in the HARBS but not the LARBS in rat brain (Zhao et al., 2003a).

It has been shown that PDE4 inhibitors, rolipram preferentially binds to the HARBS while CDP840 has some preference for the LARBS; piclamilast binds with equal, high affinity to both the HARBS and the LARBS (Zhao et al., 2003a). All three compounds can penetrate the blood brain barrier after peripheral administration (Zhang et al., 2006). Jacobitz and coworkers have shown that PDE4 inhibitors bind to both the HARBS and LARBS at the catalytic site; the HARBS depends on the presence of $\mathrm{N}$-terminal domain

of the protein (Jacobitz et al., 1996). Overall, all the studies suggest HARBS and LARBS represent inhibitor binding to the same site but to different conformations, resulting in different, inhibitor-specific, binding affinities. It is likely that interactions of PDE4 with other proteins in the brain may stabilize the HARBS (Zhang et al., 2006). 


\subsection{PDE and Antidepressant Effects}

The cAMP signaling pathway is involved in the therapeutic actions of antidepressants and the antidepressant-like effects of PDE4 inhibitors (Table 1.2) (D'Sa and Duman, 2002; Manji et al., 2003). Mice deficient in the PDE4D subtype exhibit increased cAMP signaling in the brain and an antidepressant-like behavioral phenotype effect, as evidenced by decreased immobility time in the forced-swim test (Zhang et al., 2002). Chronic antidepressant treatment increases CREB mRNA and protein levels in rat hippocampus compared with non-antidepressant, psychotropic drug treatment (Nibuya et al., 1996). In addition, repeated treatment with rolipram increases CREB activity and phosphorylation in rat cerebral cortex (Itoh et al., 2004; Monti et al., 2006). Chronic antidepressant treatment also increases cAMP signaling at several levels, including upregulation of the stimulatory GTP-binding protein Gs to adenylyl cyclase, activation of PKA and enhanced expression and function of CREB (Duman and Vaidya, 1998). Animal studies also suggest that electroconvulsive shock, an effective antidepressant treatment, also potentiates cAMP signaling, including CREB (cAMP response element binding protein) and neurotrophic factor BDNF (Nibuya et al., 1996; Frechilla et al., 1998). Other studies demonstrate that over-expression of CREB in the hippocampus exerts antidepressant-like effects in preclinical models (Chen et al., 2001). Further, chronic antidepressant treatment increases the expression of PDE4 in the frontal cortex and nucleus accumbens via a compensatory mechanism (Takahashi et al., 1999). Overall, these findings suggest that induction of CREB function via the cAMP-signaling cascade by PDE4 inhibitors plays a pivotal role in their antidepressant actions. 
Neurogenesis occurs in the adult brain of different species, including humans, rats, mice and monkeys; it is regulated by a variety of neurochemical, endocrine, and environmental factors (van Praag et al., 2005). Exercise and enriched environmental conditions enhance neurogenesis; aging and stress decrease it (Cameron and McKay, 1999). Recent studies have suggested that depression is associated with decreased volume and function of the hippocampus that may result from reduced neurogenesis; antidepressants increase hippocampal function by increasing neurogenesis via the cAMP/CREB signaling pathway as described in figure 1.2 (Takahashi et al., 1998; Nakagawa et al., 2002). Increased neurogenesis is associated with antidepressant-like effects on behavior and enhanced learning and memory (Finkbeiner, 2000; Santarelli et al., 2003). 
Table 1.2 PDE4 inhibitors

\begin{tabular}{|l|l|l|l|}
\hline Rolipram & Piclamilast & $\mathrm{CP} 840$ \\
\hline IUPAC & $\begin{array}{l}\mathrm{C}_{16} \mathrm{H}_{21} \mathrm{NO}_{3} \\
\text { 4-3-cyclopentyloxy-4- } \\
\text { one }\end{array}$ & $\begin{array}{l}\text { 3-cyclopentyloxy-N-3,5- } \\
\text { dichloropyridin-4-yl-4- } \\
\text { methoxybenzamide }\end{array}$ & $\begin{array}{l}\text { 4-[2R-2-3-cyclopentyloxy-4- } \\
\text { methoxyphenyl-2- } \\
\text { phenylethyl]pyridine }\end{array}$ \\
\hline Structure & &
\end{tabular}




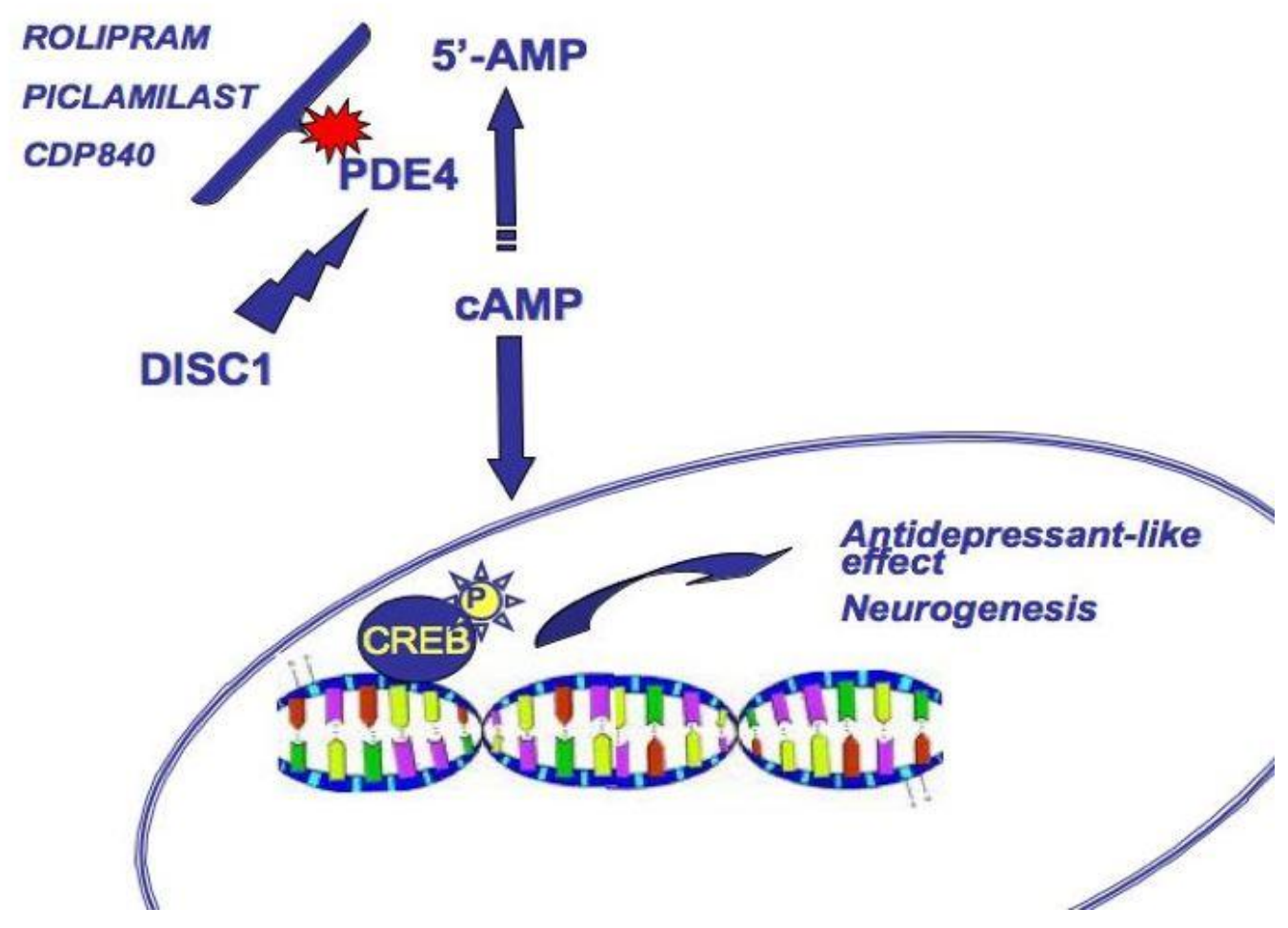

Figure 1.2. Modulation of the cAMP/CREB signaling pathway by PDE4 inhibitors. PDE4 inhibitors, e.g., rolipram, increase cAMP levels by inhibiting PDE4 activity, thus increasing phosphorylation of CREB which initiates transcription of a number of genes. P, phosphate group; CREB, cAMP response element binding protein; DISC1, disrupted in schizophrenia 1. 


\subsection{Genetic Linkage Studies of Disrupted in Schizophrenia 1 (DISC1)}

Major mental diseases consist of schizophrenia, schizoaffective disorder, bipolar disorder and major depression. The incidences of these diseases have increased during the past years and are very devastating in humans (Devon et al., 2001). These diseases share some common symptoms and risk factors and are induced by combination of both genetic and environmental effects (Semple et al., 2001). Current studies have pointed out that environmental factors play an important role in neuronal development which contributes to the pathogenesis of mental diseases (Badner and Gershon, 2002). Mutations in "Disrupted in Schizophrenia 1" (DISC1) have been shown to be a risk factor for mental illness, including schizophrenia, bipolar disorder, and depression (Hodgkinson et al., 2004; Millar et al., 2004).

DISC1 was first reported in a Scottish family. In this family, 34 of the 77 people carried a translocation between chromosome $(\mathrm{t} 1: 11)(\mathrm{q} 43, \mathrm{q} 21)$ by genetic analysis, and 16 of 34 carriers were diagnosed with psychiatric illness compared with 5 out of 43 members without translocation (St Clair et al., 1990). This provides strong evidences for the link between DISC1 and psychiatric illness (Blackwood et al., 2001). Studies of a Finnish population also show a strong linkage between schizophrenia or schizoaffective disorder and the disruption of DISC1 gene (Ekelund et al., 2001). Furthermore, genetic analysis of populations in Taiwan, Scotland, Iceland, and Britain also suggest an association of DISC1 gene with psychiatric illness (Liu et al., 2006). 


\subsection{DISC1 Expression in Developing Brain and Adult Brain}

Studies indicate that DISC1 is distributed in many human tissues such as heart, brain, and placenta at both RNA and protein levels (Millar et al., 2000a). Studies of the postmortem human brain show that DISC1 expression is expressed widely (Lipska et al., 2006). Studies of rodents and primates including African Green Monkeys and Rhesus Monkeys by western blotting and immunohistochemistry also show similar expression patterns of DISC1 as that observed in humans (Austin et al., 2003; Bord et al., 2006). DISC1 plays an important role in early brain development and adult brain function. In the developing mouse brain, DISC1 is distributed throughout the brain, particularly in the bed nucleus of stria terminals, neocortex, limbic system, and thalamic nuclei, and maintained in the hippocampus throughout development (Austin et al., 2004). By immunohistochemistry and western blotting, DISC1 is detected at every stage from embryonic day 10 to 6 months old, with two peaks of expression at E13.5 and P35 (Schurov et al., 2004). These time points are important stages for the mouse brain development, especially neurogenesis in the hippocampus. The pattern and timing of the expression indicates a role of DISC1 in the brain development and maturation (Miyoshi et al., 2003; Ozeki et al., 2003; Austin et al., 2004; Schurov et al., 2004)

\subsection{DISC1 Protein Interaction}

Examination of DISC1 by immunocytochemistry reveals a cytoplasmic location and overlap with F-actin, a-tubulin, MAP2, and gelsolin, indicating that DISC1 interacts with many cytoskeletal proteins (Miyoshi et al., 2003; Brandon et al., 2004; Kamiya et al., 2005). DISC1 localizes to the centrosome via interaction with LIS/NDEL, modulating 
local microtubule dynamics (Morris et al., 2003). Over-expression of C-terminal truncated DISC1 disrupts assembly of LIS1, NDEL, dynein, dynactin, as well as ytubulin and pericentrin $\mathrm{B}$; this mutation of DISC1 also disrupts the organization of microtubules (Kamiya et al., 2005). In addition, kinesin-1 heavy chain KIF5B and 14-3$3 \varepsilon$ are identified by mass spectrometry as interacting with DISC1. Further studies demonstrate that 14-3-3 $\varepsilon$, LIS1 and NDEL1 are necessary for the axonal growth, and this function only exists in the presence of DISC1 and kinesin (Taya et al., 2007). The 14-3-3 gene is decreased in patients with schizophrenia and upregulated in the prefrontal cortex of the monkey by the psychiatric treatment with haloperidol and fluoxetine, which are used to treat schizophrenia and depression, respectively (Middleton et al., 2005; Cecconi et al., 2007). Affinity chromatography has shown that growth factor receptor-bound protein Grb2 also interacts with DISC1 (Shinoda et al., 2007). Studies using RNA interference demonstrate that Grb modulates microtubules assembly and facilitates axon elongation via a DISC1-dependent process (Shinoda et al., 2007). Fasciculation and Elongation Factor Zeta (FEZ1) also has been shown to interacts with DISC1 in rat brain (Honda et al., 2004; Ikuta et al., 2007). Reduced expression of FEZ1 compromises axon growth, while over-expression of FEZ1 increases DISC1 binding and neurite length (Miyoshi et al., 2003). Yeast two-hybrid studies demonstrate that DISC1 interacts with a number of other proteins, including activating transcription factor 4 (ATF4) (Morris et al., 2003; Pletnikov et al., 2007), microtubule-associated protein 1A (MAP1A) (Halpain and Dehmelt, 2006), TNF receptor-associated factor 3 interacting protein 1 (TRAF3IP/MIP-T3 ) (Halpain and Dehmelt, 2006), and DISC1-Binding Zinc-finger protein (DBZ) (Hattori et al., 2007). Compromised binding of these proteins impairs 
cortical development and neurite outgrowth. Taken together, these studies show that DISC1 is involved in the processes that are essential for brain development and that dysfunctions in its function may contribute to the pathogenesis of mental illness (Chubb et al., 2008). 


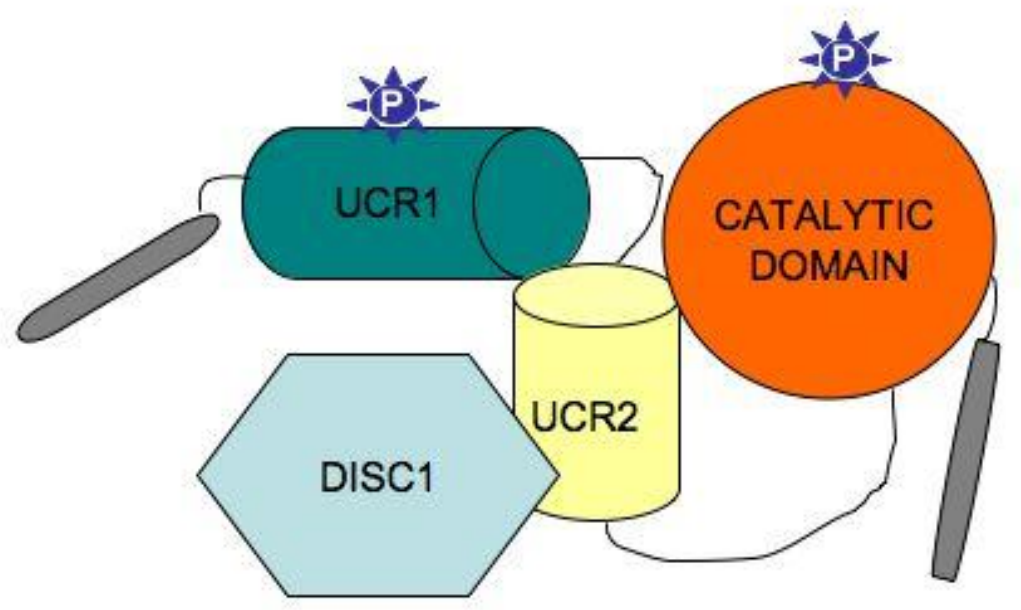

Figure 1.3 Interaction between DISC1 and long form PDE4B. Long form PDE4B contain regulatory domain including UCR1 and UCR2, catalytic domain, and amino-terminal and carboxy-terminal regions. The enzyme can be activated by phosphorylation by PKA on UCR1 and inhibited by ERK phosphorylation of the catalytic domain. DISC1 binds to the UCR2 domain of PDE4B, as well as other PDE4 subtypes, and may induce conformational changes in DISC1 or PDE4B (Mackie et al., 2007). 


\subsection{DISC1 and Psychiatric Illness}

To date, there are only a few studies of DISC1 expression in patients with major mental illness. It has been reported that there are no differences of full length of DISC1 in the postmortem brain samples between schizophrenia and controls, and antipsychotic treatment does not alter its expression (Lika et al., 2006). Two studies of DISC1 have been performed in the lymphoblastoid cell lines from patients with psychiatric illness. In cell lines from patients with $\mathrm{t}(1: 11)$, the expression of DISC1 mRNA and protein are decreased compared with controls (Millar et al., 2005). In cell lines from patients with bipolar disorder, the mRNA of DISC1 also is decreased compared with normal family members (Maeda et al., 2006). In addition, the decreased expression of DISC1 mRNA is also correlated with the manic symptoms in bipolar patients (Maeda et al., 2006). Further studies reveal that antipsychotic treatment in mice up-regulates the DISC1 expression in both the frontal cortex and the hippocampus (Chiba et al., 2006). Though the data on DISC1 in patients with psychiatric illness are limited and controversial due to the differences in samples and method of preparation, extensive studies of DISC1 demonstrate that as a hub protein, DISC1 links a variety of signaling pathways, including the cAMP signaling, kinesin-mediated transportation, neurite growth and elongation (Mackie et al., 2007). Meanwhile, it forms complexes with considerable scaffolding proteins. Therefore, compromised DISC1 function could enhance the risk of developing mental major diseases (Roberts, 2007). 


\section{Chapter 2}

Effects of repeated treatment with phosphodiesterase-4

inhibitors on cyclic AMP signaling, hippocampal neurogenesis, and behavior in the forced-swim test 


\begin{abstract}
The effect of acute and chronic treatment with the phosphodiesterase-4 (PDE4) inhibitors rolipram, piclamilast, and CDP840, which differ in their interactions with highand low-affinity binding conformers, were determined on cyclic AMP signaling, hippocampal neurogenesis, and immobility in the forced-swim test in rats. Acute treatment with rolipram (3 mg/kg), piclamilast ( $1 \mathrm{mg} / \mathrm{kg})$, or CDP840 (30 mg/kg) induced transient increases in cyclic AMP and phosphorylation of cyclic AMP response element binding protein (pCREB) in rat hippocampus and prefrontal cortex. Chronic treatment with rolipram $(1,3 \mathrm{mg} / \mathrm{kg})$, piclamilast $(0.3,1 \mathrm{mg} / \mathrm{kg})$, or CDP840 $(10,30 \mathrm{mg} / \mathrm{kg})$ also increased cyclic AMP and pCREB in hippocampus and prefrontal cortex. In addition, chronic treatment with the PDE4 inhibitors increased proliferation and survival of neurons in the hippocampus and, simultaneously, produced antidepressant-like effects on behavior, as evidenced by decreased immobility in the forced-swim test. Compared with rolipram and piclamilast, CDP840 exerted lesser effects on neural and behavioral measures, likely due to its weak interaction with the high-affinity binding conformer of PDE4. Overall, the PDE4 inhibitors rolipram, piclamilast, and CDP840 exert their antidepressant effects via activation of cyclic AMP/pCREB signaling cascade and increase in hippocampal neurogenesis; this appears to involve inhibitor interaction with the high-affinity binding conformer.
\end{abstract}




\section{Introduction}

Phosphodiesterase-4 (PDE4) plays a critical role in modulating cyclic AMP signaling and is involved in many aspects of cell function (Conti et al., 2003; Houslay and Adams, 2003; O'Donnell and Zhang, 2004). Altered cyclic AMP signaling has been suggested to contribute to the pathophysiology of neuropsychiatric illnesses such as major depression, schizophrenia, and dementia (Tanis and Duman, 2007). Consistent with this idea, it has been found that PDE4 inhibitors such as rolipram, which increase cyclic AMP signaling, exert antidepressant- and antipsychotic-like effects, as well as memory-enhancing effects, on behavior (O'Donnell and Zhang, 2004; Blokland et al., 2006; Siuciak, 2008).

Antidepressant-like effects of PDE4 inhibitors have been demonstrated using a number of preclinical models. Early work demonstrated an antidepressant-like behavioral profile for rolipram, including reversal of the effects of reserpine and potentiation of yohimbine toxicity (Wachtel and Loschmann, 1986; Wachtel and Schneider, 1986). Rolipram and other PDE4 inhibitors also reduce response rate and increase reinforcement rate of rats under a differential-reinforcement-of-low-rate schedule of reinforcement (O'Donnell, 1993); such an effect is indicative of an antidepressant action (O'Donnell et al., 2005). PDE4 inhibitors are active in preclinical antidepressant screens such as the forced-swim and tail-suspension tests (O'Donnell and Zhang, 2004). To the extent they have been examined, the antidepressant-like behavioral effects of PDE4 inhibitors persist with repeated treatment (Li et al., 2009). Finally, clinical studies have demonstrated antidepressant effects of rolipram; however, issues 
related to side effects and toxicity have limited its clinical utility (Zeller et al., 1984; Fleischhacker et al., 1992).

There are four PDE4 subtypes, PDE4A, B, C, and D, which undergo differential splicing resulting in 25 PDE4 isozymes. Through the examination of the behavioral phenotypes of mice deficient in PDE4 subtypes, some understanding of their relative roles has begun to emerge. Mice deficient in PDE4D exhibit an antidepressant-like behavioral phenotype, as evidenced by reduced immobility in the forced-swim and tailsuspension tests, and altered hippocampal LTP and memory (Zhang et al., 2002; Rutten et al., 2008). PDE4B-deficient mice exhibit an anxiogenic behavioral profile, as well as reduced prepulse inhibition of an acoustic startle response, consistent with an antipsychotic-like effect (Siuciak et al., 2007; Zhang et al., 2007). The behavioral effects of rolipram, which is not subtype-selective, are somewhat diminished in both PDE4Dand PDE4B-deficient mice (Zhang et al., 2002). There are no published data as yet on the behavioral consequences of PDE4A deficiency and PDE4C is not expressed in the brain.

While rolipram does not inhibit the PDE4 subtypes with different potencies, its interaction with the enzyme is complex. Using an equilibrium dissociation assay, it was found that $\left[{ }^{3} \mathrm{H}\right]$-rolipram binds to PDE4 with two distinct affinities, which have been termed the high- and low-affinity rolipram binding states (HARBS, LARBS) (Jacobitz et al., 1996). This has been confirmed using $\left[{ }^{3} \mathrm{H}\right]$-piclamilast, a PDE4 inhibitor which binds with equal, high affinity to the HARBS and LARBS; interestingly, while LARBS is found both in the brain and peripheral tissues, the HARBS is only found in the brain (Zhao et al., 2003a). Consistent with this, it has been observed that the HARBS and 
LARBS mediate distinct pharmacological effects (Saccomano et al., 1991; Barnette et al., 1996; Zhao et al., 2003a).

It appears that PDE4 is involved in signaling pathways affected by antidepressant drugs. Repeated treatment of mice with antidepressants or rolipram increases the expression of PDE4 in cerebral cortex and hippocampus, with the PDE4D subtype being affected the most consistently (Dlaboga et al., 2006). There appears to be some species dependence since similar treatment of rats has pronounced effects on PDE4A expression (Takahashi et al., 1999; Ye et al., 2000). It is likely that increased PDE4 expression is a compensatory change in response to increased cyclic AMP signaling that results from antidepressant treatment; prior work demonstrated such regulation of PDE4 in neurons (D'Sa et al., 2002; Hajjhussein et al., 2007). Repeated treatment of rats with antidepressant drugs also increases the HARBS, but not the LARBS in cerebral cortex and hippocampus (Zhao et al., 2003a). Consistent with this finding, comparison of the acute behavioral effects of rolipram, piclamilast, and CDP840, PDE4 inhibitors that differ in their interactions with the HARBS and LARBS (Zhao et al., 2003b), suggests a predominant role for the HARBS in mediating antidepressant-like effects on behaviors (Zhang et al., 2006).

The effects of antidepressants on behavior depend to some degree on increased neurogenesis in the dentate gyrus of the hippocampus. Inhibition of neurogenesis blocks some, but not all, effects of antidepressants on behavior (Santarelli et al., 2003; Holick et al., 2008). Similarly, repeated treatment of mice with rolipram, which increases cyclic AMP signaling, as evidenced by an increase in phosphorylation of cyclic AMP response element binding protein (pCREB), also increases hippocampal neurogenesis; inhibition of 
rolipram-induced neurogenesis reduces antidepressant-like effects on behavior ( $\mathrm{Li}$ et al., 2009). The relationship among the ability of PDE4 inhibitors to interact with the HARBS and LARBS to alter cyclic AMP signaling, increase neurogenesis, and produce antidepressant-like effects on behavior has not been well characterized. Comparison of the effects of rolipram, piclamilast, and CDP840 on these measures should provide some insight, since acutely they affect behavior differently, even though all are potent PDE4 inhibitors (Zhang et al., 2006). In addition, such a comparison will show the extent to which the HARBS and the LARBS contribute to altered cyclic AMP signaling in the brain and increased hippocampal neurogenesis. The present study compared the effects of repeated treatment with these three PDE4 inhibitors on behavior in the forced-swim test, hippocampal neurogenesis measured using flow cytometry, and cyclic AMP signaling assessed by measurement of cyclic AMP and pCREB following euthanasia by focused microwave fixation to prevent post-mortem changes. The results suggest the importance of the HARBS in these measures and a close association among increased cyclic AMP signaling, neurogenesis, and antidepressant-like effects on behavior. 


\section{Materials and Methods}

\section{Animals}

Male Sprague-Dawley rats (Harlan, Indianapolis, IN), weighing 200-250 g, were housed individually in clear plastic cages in a room that was maintained at $22^{\circ} \mathrm{C}$ with a 12-h on/12-h off light cycle lights on at 7:00 a.m. Food and water were freely available. All experiments were carried out according to the "NIH Guide for the Care and Use of Laboratory Animals," revised 1996, and were approved by the Institutional Animal Care and Use Committee of West Virginia University.

\section{Drug Treatments}

Rolipram was purchased from Sigma Aldrich (ST. Louis. MO); piclamilast and CDP840 were provided by Memory Pharmaceuticals (Montvale, NJ). To assess the effects of repeated treatment, rats were injected i.p. with 1 or $3 \mathrm{mg} / \mathrm{kg}$ rolipram, 0.3 or 1 $\mathrm{mg} / \mathrm{kg}$ piclamilast, 10 or $30 \mathrm{mg} / \mathrm{kg}$ CDP840, or the $10 \% \mathrm{DMSO} / \mathrm{saline}$ vehicle once daily for 16 consecutive days. Two hours after the last treatment, separate groups of rats were subjected to the five-minute forced-swim test, used for measurement of cyclic AMP and pCREB, or started on the BrdU treatment regimen for assessment of neurogenesis.

To assess the effects of acute treatment on forced-swim behavior, $0.3,1$, or $3 \mathrm{mg} / \mathrm{kg}$ rolipram, $0.3,1$ or $3 \mathrm{mg} / \mathrm{kg}$ piclamilast, 3,10 or $30 \mathrm{mg} / \mathrm{kg} \mathrm{CDP} 840$, or vehicle was administered to separate groups of rats and the time of immobility assessed either 0.5 or 2 hrs post-treatment. To assess the effects of acute treatment on the neurochemical measures, $3 \mathrm{mg} / \mathrm{kg}$ rolipram, $1 \mathrm{mg} / \mathrm{kg}$ piclamilast, $30 \mathrm{mg} / \mathrm{kg}$ CDP840, or vehicle was 
administered and rats were killed by focused microwave fixation $0.5,1,2,3$, or $4 \mathrm{hrs}$ later.

\section{Measurement of Cyclic AMP and pCREB}

To prevent post-mortem changes in cyclic AMP and pCREB, rats were killed by focused microwave fixation (O'Callaghan and Sriram, 2004) (Muromachi Microwave Applicator, TMW-4012C, 10kW output; Stoelting, Kiel, WI). For cyclic AMP measurement, hippocampus and prefrontal cortex were homogenized in ice-cold $0.1 \mathrm{~N}$ hydrochloric acid and centrifuged at $13,000 \times g$ for $50 \mathrm{~min}$ at $4^{\circ} \mathrm{C}$. Cyclic AMP in the supernatant was measured by ELISA (Assay Designs, Ann Arbor, MI) and normalized to protein content(Smith et al., 1985) (Bio-Rad Laboratories, Hercules, CA).

For CREB and pCREB measurement, hippocampus and prefrontal cortex were homogenized in ice-cold RIPA lysis buffer (Upstate, Temecula, CA) and centrifuged at $10,000 \times g$ for $30 \mathrm{~min}$ at $4^{\circ} \mathrm{C}$. Solubilized samples were mixed with equal volumes of Laemmli sample buffer and heated to $100^{\circ} \mathrm{C}$ for 2 minutes. Equal amounts of sample protein were loaded onto gels for SDS-PAGE. Following separation by electrophoresis, proteins in the gels were transferred to nitrocellulose membranes, which were incubated overnight at $4{ }^{\circ} \mathrm{C}$ with primary antibodies against CREB or pCREB (i.e., phosphorylated at serine-133, Millipore Billerica, MA) and then with Alexa Fluor 680-conjugated secondary antibody for $30 \mathrm{~min}$ at room temperature (Invitrogen, Carlsbad, CA). An Odyssey Infrared Imaging System (LI-COR Bioscience, Lincoln, NE) was used for quantifying fluorescence. Treatment-induced changes in CREB and pCREB were assessed within individual gels/immunoblots by densitometry. 


\section{Measurement of Neurogenesis by Flow Cytometry}

To evaluate the effects of repeated treatment with PDE4 inhibitors on hippocampal cell proliferation, rats were administered $100 \mathrm{mg} / \mathrm{kg}$ BrdU, i.p.,two hours after the last injection of PDE4 inhibitors in order to label dividing cells; rats were killed and BrdU labeling quantified 24 hours later. To evaluate effects on hippocampal cell survival, rats were administered $100 \mathrm{mg} / \mathrm{kg}$ BrdU, i.p., 4 times at 2 hours intervals one day after the last injection of the PDE4 inhibitors; rats were killed and BrdU labeling quantified five weeks later.

Neurogenesis in the hippocampus was measured by flow cytometry as described previously (Bilsland et al., 2006; Balu et al., 2009). Rats were killed by decapitation and hippocampi were dissected, placed in $1.5 \mathrm{ml}$ Eppendorf tubes containing Dulbecco's phosphate-buffered saline (D-PBS; Invitrogen, Carlsbad, CA) and finely minced. An enzymatic cocktail comprised of digestive solution (papain $2.5 \mathrm{U} / \mathrm{ml}$, dispase $1 \mathrm{U} / \mathrm{ml}$, and DNase I $250 \mathrm{U} / \mathrm{ml}$ ) was added to each tube, which was then incubated at $37^{\circ} \mathrm{C}$ for 30 min. The samples were triturated and washed twice with DMEM/10\% fetal bovine serum and then once with D-PBS.

The samples were centrifuged at $500 \mathrm{x} g$ for $5 \mathrm{~min}$ and stained using a FITC BrdU Flow Kit (BD Bioscience, San Jose, CA). Precipitated cells were suspended in BD Cytofix/Cytoperm buffer and incubated for $30 \mathrm{~min}$ on ice. After washing twice with $1 \mathrm{ml}$ of BD perm wash buffer, the cells were further permeabilized by resuspension with Cytoperm Plus buffer on ice for 10 min. After washing, the cells were refixed in Cytofix-

Cytoperm buffer for $5 \mathrm{~min}$ and then incubated with DNase for $1 \mathrm{hr}$ at $37^{\circ} \mathrm{C}$. After 
washing with BD buffer, the cells were labeled with $50 \mu$ l of FITC-conjugated antiBrdU1:50 for 20 min. After another wash, cells were labeled with $20 \mu$ of 7 -AAD at room temperature. The BrdU-positive cells were counted by FACS Calibur and analyzed using Cellquest Prosoftware (Becton Dickinson, BD Bioscience, San Jose, CA).

\section{Forced-Swim Test}

The forced-swim test was performed as described previously (Zhang et al., 2006); this consisted of a 15-min pre-test and a 5-min test $24 \mathrm{hr}$ later. Rats were place individually in a Plexiglas cylinder $45 \mathrm{~cm}$ high $\times 20 \mathrm{~cm}$ diameter filled with water 22$23^{\circ} \mathrm{C}$ to a depth of $30 \mathrm{~cm}$. During the 5 -min test, the time of immobility, defined as floating in an upright position with the only movement being that necessary for an animal to keep its head above water, was recorded.

\section{Data Analysis and Statistics}

Data were analyzed by one-way analysis of variance followed by Dunnett's test. Data are expressed as means \pm SEM. A p value of $<0.05$ was considered statistically significant. 


\section{Results}

Effects of repeated treatment with rolipram, piclamilast, and CDP840 on cyclic AMP and pCREB.

Repeated treatment for 16 days with the PDE4 inhibitors increased cyclic AMP in hippocampus and prefrontal cortex (Fig.2.1). Significant increases were observed only at the higher doses of rolipram (3 mg/kg), piclamilast $(1 \mathrm{mg} / \mathrm{kg})$, or CDP840 (30 mg/kg) that were tested. At the higher doses, rolipram, piclamilast, and CDP840 increased cAMP by $204 \%, 250 \%$, and $145 \%$, respectively, in hippocampus and by $168 \%, 189 \%$, and $112 \%$, respectively, in prefrontal cortex.

Parallel effects of repeated treatment with the PDE4 inhibitors on pCREB were observed (Fig.2.2). However, both the lower and higher doses tested were effective: doses of $1,3 \mathrm{mg} / \mathrm{kg}$ rolipram increased pCREB in hippocampus by $59 \%$ and $75 \%$, respectively; $0.3,1 \mathrm{mg} / \mathrm{kg}$ piclamilast by $58 \%$ and $82 \%$, respectively; and $10,30 \mathrm{mg} / \mathrm{kg}$ CDP840 by $36 \%$ and $55 \%$, respectively. Doses of $1,3 \mathrm{mg} / \mathrm{kg}$ rolipram increased pCREB in prefrontal cortex by $61 \%$ and $70 \%$, respectively, $0.3,1 \mathrm{mg} / \mathrm{kg}$ piclamilast by $59 \%$ and $85 \%$ respectively, and $10,30 \mathrm{mg} / \mathrm{kg}$ CDP840 by $32 \%$ and $60 \%$, respectively. None of these treatments affected CREB expression (data not shown).

\section{Effects of repeated treatment with rolipram, piclamilast, and CDP840 on hippocampal neurogenesis.}

The proliferation and survival of newborn cells in rat hippocampus were measured after repeated treatment with rolipram, piclamilast, or CDP840 (Fig.2.3). Sixteen-day 
treatment with $1,3 \mathrm{mg} / \mathrm{kg}$ rolipram or $0.3,1 \mathrm{mg} / \mathrm{kg}$ piclamilast increased both cell proliferation and survival in the hippocampal samples, but the effects on survival were only significant at the higher doses. Repeated treatment with $30 \mathrm{mg} / \mathrm{kg}$ CDP840 increased cell proliferation but not survival.

Effects of repeated treatment with rolipram, piclamilast, and CDP840 on forcedswim behavior.

Repeated treatment with PDE4 inhibitors for sixteen days produced antidepressantlike effects on the behavior of rats in the forced-swim test in a dose-dependent manner (Fig.2.4). Two hours following the last injection, 1 and $3 \mathrm{mg} / \mathrm{kg}$ rolipram, 0.3 and 1 $\mathrm{mg} / \mathrm{kg}$ piclamilast, and 10 and $30 \mathrm{mg} / \mathrm{kg}$ CDP840reduced the time of immobility. At the doses tested, rolipram and piclamilast tended to produce greater reductions in immobility than did CDP840.

Effects of acute treatment with rolipram, piclamilast, and CDP840 on immobility in the forced-swim test, cyclic AMP, and pCREB.

Acute treatment with $3 \mathrm{mg} / \mathrm{kg}$ rolipram, $1 \mathrm{mg} / \mathrm{kg}$ piclamilast, or $30 \mathrm{mg} / \mathrm{kg}$ CDP840 increased cyclic AMP in prefrontal cortex and hippocampus in a time-dependent manner (Table.2.1). The peak effects of the inhibitors were observed 2 hours post-treatment. Similar effects of the PDE4 inhibitors were observed on pCREB in prefrontal cortex and hippocampus (Table.2.1), with a peak effect also 2 hours post-treatment.

Immobility in the forced-swim test was recorded $30 \mathrm{~min}$ or $2 \mathrm{hr}$ after administration of the PDE4 inhibitors. Doses of $0.3 \mathrm{mg} / \mathrm{kg}$ rolipram, $0.3 \mathrm{mg} / \mathrm{kg}$ piclamilast, and $3 \mathrm{mg} / \mathrm{kg}$ 
CDP840 decreased immobility in the forced-swim test at 30 min after acute treatment, but not 2 hours post-treatment (Table.2.2). Acute treatment with higher doses of the PDE4 inhibitors did not affect immobility in the forced-swim test at either time point. 


\section{Discussion}

Repeated treatment with all three PDE4 inhibitors enhanced cyclic AMP signaling in hippocampus and prefrontal cortex, as evidenced by increased cAMP and pCREB. These inhibitors also increased hippocampal neurogenesis and produced antidepressant-like effects on forced-swim behavior. However, rolipram and piclamilast, which bind to the HARBS with high affinity, were more potent at increasing cAMP/pCREB signaling and hippocampal neurogenesis than CDP840, which has lower affinity for the HARBS (Zhao et al., 2003b). Similarly, rolipram and piclamilast were more potent at decreasing the time of immobility in the forced-swim test.

The HARBS and LABRS were first described in a study that showed that $\left[{ }^{3} \mathrm{H}\right]-$ rolipram binds to recombinant PDE4A with two distinct affinity states with a 500-fold difference in $\mathrm{Ki}$ values (Jacobitz et al., 1996). The HARBS is only observed in the central nervous system, while the LABRS is present in both the brain and peripheral tissues (Zhao et al., 2003b). While, rolipram exhibits different affinities to the HARBS and LARBS, piclamilast exhibits equal high affinity for both (Zhao et al., 2003b), and CDP840, by contrast, interacts with relatively low, but similar affinity with both states (Zhao et al., 2003b). The present findings suggest that inhibitor interactions with the HARBS are important for mediating neurochemical and behavioral effects of rolipram, piclamilast, and CDP840.Repeated treatment with rolipram or piclamilast increased cAMP signaling and neurogenesis and produced antidepressant-like behavioral effects at doses below those of CDP840 that could effective.

Previously, it has been found that repeated treatment with the antidepressant drugs desipramine and fluoxetine increases the HARBS in brain, measured either by $\left[{ }^{3} \mathrm{H}\right]-$ 
rolipram or $\left[{ }^{3} \mathrm{H}\right]$-piclamilast binding (Zhao et al., 2003a). By contrast, such treatment does not alter the LARBS in brain. The effects of fluoxetine and desipramine on the HARBS in the brain are prevented when noradrenergic or serotonergic neurons are lesioned with 6-hydroxydopamine (6-OHDA) or 5, 7-dihydroxytryptamine (5,7-DHT), respectively (Zhao et al., 2003a). This suggests that the neurochemical pathways involved in the mediation of antidepressant activity can influence PDE4 expression and activity. In rats trained to discriminate rolipram from vehicle, only PDE4 inhibitors which have a high affinity for the HARBS generalize to rolipram (Zhang et al., 2006). Similarly, when the effects of acute treatment with PDE4 inhibitors on forced-swim behavior are examined, a potency order of piclamilast $>$ rolipram > CDP840 is observed (Zhang et al., 2006); this is consistent with their relative affinities for the HARBS (Zhao et al., 2003a).

Previous studies have shown that hippocampal neurogenesis plays an important role in some effects of antidepressants that depend on repeated treatment (Santarelli et al., 2003). In addition, the time-course of the change in neurogenesis in hippocampus is consistent with the delayed onset of antidepressant efficacy (Sahay and Hen, 2007). Present studies show that repeated treatment with rolipram and piclamilast also increased hippocampal neurogenesis. Interestingly, repeated treatment with CDP840 at 10 or 30 $\mathrm{mg} / \mathrm{kg}$ decreased immobility in forced-swim test, indicating an antidepressant-like effect, but did not increase hippocampal proliferation. Other studies also have shown that some antidepressant-like behavioral effects do not depend completely on neurogenesis (Airan et al., 2007; David et al., 2007; Wang et al., 2008). This suggests that neurogenesis 
might not be the only mechanism underlying PDE4 inhibitor-mediated antidepressantlike effects on behavior.

When rats were treated acutely with the PDE4 inhibitors rolipram, piclamilast, or CDP840, there was dissociation between neurochemical and behavioral effects. The time- course revealed peak effects at $2 \mathrm{hrs}$ post-acute treatment; by contrast, PDE4 inhibitors decreased immobility in the forced-swim test $30 \mathrm{~min}$ post-treatment, but not at $2 \mathrm{hrs}$ post-treatment. In addition, in contrast to the monotonic dose-response curve for the effects of repeated treatment, acute treatment with higher doses of the PDE4 inhibitors no longer decreased immobility. It is possible that sedative effects of higher doses may confound the results in the forced-swim test following acute treatment, but that some tolerance may develop with repeated treatment.

Previous studies have shown that long-term antidepressant treatment increases cyclic AMP as well as phosphorylation of CREB in specific brain regions. The activated cyclic AMP/pCREB signaling cascade induces increased expression of brain-derived neurotrophic factor (BDNF) in the hippocampus and cerebral cortex (Duman et al., 1997). In addition, chronic administration of either a 5-HT or norepinephrine selective reuptake inhibitor, enhances neurogenesis in adult rodent hippocampus via up-regulation of cAMP/pCREB signaling (Duman et al., 2001). Interestingly, cell proliferation is decreased in transgenic mice that express a dominant negative mutant of CREB in the hippocampus (Nakagawa et al., 2002). Furthermore, electroconvulsive shock, an effective antidepressant therapy, also enhances phosphorylation of CREB in rat hippocampus (Jeon et al., 1997). These studies demonstrate that, like proven antidepressants, PDE4 inhibitors produce persistent, enhanced cAMP signaling, altering 
transcription of neurotrophic factors, increasing hippocampal neurogenesis, and contributing to antidepressant-like effects on behavior.

In a summary, it was found that repeated treatment with PDE4 inhibitors increasedcyclic AMP/pCREB signaling and hippocampal neurogenesis and also produced antidepressant-like effects on behavior. Comparison of the neurochemical and behavioral effects of rolipram, piclamilast, and CDP840 suggests that interaction with HARBS, in contrast to the LARBS, mediates these effects. Improved understanding of molecular mechanisms that contribute to the presence of two PDE4 affinity states in the brain may suggest targets for antidepressant drug discovery; potential candidate includes scaffolding proteins (McCahill et al., 2005; Millar et al., 2005) and unique conserved regions of the N-terminal of PDE4 (Burgin et al., 2010). 


\section{Figure Legends}

Fig. 2.1. Effects of repeated treatment with rolipram, piclamilast, or CDP840 on cyclic AMPin rat brain. Treatment for 16 days with rolipram, piclamilast, or CDP840 increased cyclic AMP in hippocampus and prefrontal cortex. Bars represent means \pm SEM, n=3-4 per group. $* * \mathrm{P}<0.01 ; * \mathrm{P}<0.05$ vs. corresponding control.

Fig. 2.2. Effects of repeated treatment with rolipram, piclamilast, or CDP840 on pCREB in rat brain. Treatment for 16 days with rolipram, piclamilast, or CDP840 increased pCREB in hippocampus and prefrontal cortex; none of the treatments affected CREB. Bars represent means $\pm \mathrm{SEM}, \mathrm{n}=3-4$ per group. $* * \mathrm{P}<0.01 \mathrm{vs}$. corresponding control.

Fig. 2.3. Effects of repeated treatment with rolipram, piclamilast, or CDP840 on cell proliferation and survival in rat hippocampus. Treatment for 16 days with rolipram or piclamilast increased cell proliferation (A) and survival (B). CDP84030mg/kgtreatment increased proliferation (A) but not survival (B). Bars represent means \pm SEM, $n=3-4$ per group. $* * \mathrm{P}<0.01 ; * \mathrm{P}<0.05$ vs. corresponding control.

Fig. 2.4. Effects of repeated treatment with rolipram, piclamilast, or CDP840 on immobility of rats in the forced-swim test. Treatment for 16 days with rolipram, piclamilast, or CDP840 decreased immobility time in a dose-dependent manner. Bars represent means $\pm \mathrm{SEM}, \mathrm{n}=4-5$ per group. $* * \mathrm{P}<0.01 ; * \mathrm{P}<0.05$ vs. corresponding control. 
Table 2.1. Effects of acute treatment with PDE4 inhibitors on cyclic AMP and pCREB in hippocampus and prefrontal cortex

\begin{tabular}{|c|c|c|c|c|c|c|}
\hline & hours post-trea & ment & & & & \\
\hline & Control & 0.5 & 1 & 2 & 3 & 4 \\
\hline Rolipram (3mg/kg) & Hippocampus & & & & & \\
\hline cyclic AMP & $17.5 \pm 1.9^{a}$ & $24.9 \pm 3.5$ & $47.5 \pm 4.5^{*}$ & $68.9 \pm 5.7 * *$ & $47.8 \pm 3.0^{*}$ & $23.5 \pm 5.0$ \\
\hline \multirow[t]{2}{*}{$p C R E B^{b}$} & $100^{a}$ & $101.8 \pm 5.0$ & $131.8 \pm 8.2$ & $182.5 \pm 11.0^{*}$ & $126.3 \pm 8.1$ & $116 \pm 7.8$ \\
\hline & Prefrontal & cortex & & & & \\
\hline cyclic $A M P$ & $18.7 \pm 2.7$ & $24.8 \pm 3.0$ & $44.7 \pm 5.1^{*}$ & $61.0 \pm 7.3 * *$ & $40.3 \pm 4.2 *$ & $25.4 \pm 6.0$ \\
\hline$p C R E B$ & 100 & $103 \pm 5.9$ & $123.5 \pm 7.5$ & $160.8 \pm 10.5^{*}$ & $127.5 \pm 10.9$ & $116 \pm 7.8$ \\
\hline Piclamilast (1mg/kg) & Hippocampus & & & & & \\
\hline cyclic AMP & $21 \pm 1.1$ & $38.5 \pm 4.7$ & $58.8 \pm 6.1 * *$ & $73 \pm 7.9 * *$ & $49.5 \pm 5.5^{* *}$ & $38.5 \pm 3.9$ \\
\hline \multirow[t]{2}{*}{$p C R E B$} & 100 & $102.3 \pm 7.4$ & $117.3 \pm 11.6$ & $157.3 \pm 14.8^{*}$ & $133.0 \pm 8.6$ & $109.8 \pm 7.0$ \\
\hline & Prefrontal & cortex & & & & \\
\hline cyclic AMP & $18.7 \pm 2.7$ & $38.8 \pm 4.9$ & $73.3 \pm 4.5^{* *}$ & $89.3 \pm 6.1 * *$ & $52.3 \pm 11.5^{*}$ & $36.0 \pm 7.1$ \\
\hline$p C R E B$ & 100 & $98.5 \pm 9.2$ & $129.8 \pm 9.8$ & $156 \pm 10.0^{*}$ & $124.3 \pm 5.1$ & $101.3 \pm 6.8$ \\
\hline CDP840 (30mg/kg) & Hippocampus & & & & & \\
\hline cyclic AMP & $22.0 \pm 3.9$ & $30.8 \pm 3.0$ & $42.7 \pm 6.6^{*}$ & $51.5 \pm 4.1^{* *}$ & $42.6 \pm 5.6^{*}$ & $26.1 \pm 2.9$ \\
\hline \multirow[t]{2}{*}{$p C R E B$} & 100 & $111.7 \pm 2.3$ & $135.7 \pm 16.6$ & $141.3 \pm 9.3^{*}$ & $125.3 \pm 7.2$ & $102.3 \pm 3.6$ \\
\hline & Prefrontal & cortex & & & & \\
\hline cyclic AMP & $23.8 \pm 3.7$ & $29.2 \pm 5.6$ & $32.5 \pm 2.1$ & $52.2 \pm 4.1 * *$ & $32.3 \pm 4.1$ & $27.8 \pm 4.0$ \\
\hline pCREB & 100 & $111.7 \pm 2.4$ & $117.0 \pm 8.2$ & $136.3 \pm 12.1^{*}$ & $125.3 \pm 7.0$ & $102.3 \pm 3.5$ \\
\hline
\end{tabular}

\footnotetext{
${ }^{a}$ Values shown are means $\pm S E$ expressed as pmol/mg protein cyclic AMP or percentage of control $p C R E B ; n=6$ per group.

${ }^{b}$ None of the treatments affected CREB.

$* * P<0.01 ; * P<0.05$ vs. corresponding control.
} 
Table 2.2. Effects of acute treatment with PDE4 inhibitors on immobility in the forced-swim test

\begin{tabular}{ccc}
\hline & Immobility (sec) & $2 \mathrm{hr}$ \\
\hline Vehicle & $0.5 \mathrm{hr}^{b}$ & $138 \pm 14.2$ \\
\hline Rolipram $(\mathrm{mg} / \mathrm{kg})$ & $154 \pm 10.2^{a}$ & \\
0.3 & $84 \pm 12.1^{*}$ & $144 \pm 7.4$ \\
1 & $174 \pm 9.2$ & $122 \pm 7.0$ \\
3 & $201 \pm 8.6$ & $127 \pm 10.9$ \\
\hline Piclamilast $(\mathrm{mg} / \mathrm{kg})$ & $58 \pm 6.24^{* *}$ & $132 \pm 5.9$ \\
0.3 & $117 \pm 25.5$ & $122 \pm 5.8$ \\
1 & $129 \pm 25.4$ & $123 \pm 9.3$ \\
3 & & \\
\hline CDP840 (mg/kg) & $91 \pm 6.5^{*}$ & $141 \pm 10.6$ \\
3 & $122 \pm 19.0$ & $126 \pm 12.5$ \\
10 & $125 \pm 15.0$ & $123 \pm 6.1$ \\
\hline 0 & & \\
\hline
\end{tabular}

${ }^{a}$ Values shown are means $\pm S E$ for times of immobility of separate groups of rats tested in the forced-swim test; $n=6$ per group.

${ }^{b}$ Rats were treated with PDE4 inhibitors and tested in forced-swim test 0.5 or 2 hr post-treatment.

$* * P<0.01 ; * P<0.05$ vs. corresponding control. 
Figure 2.1

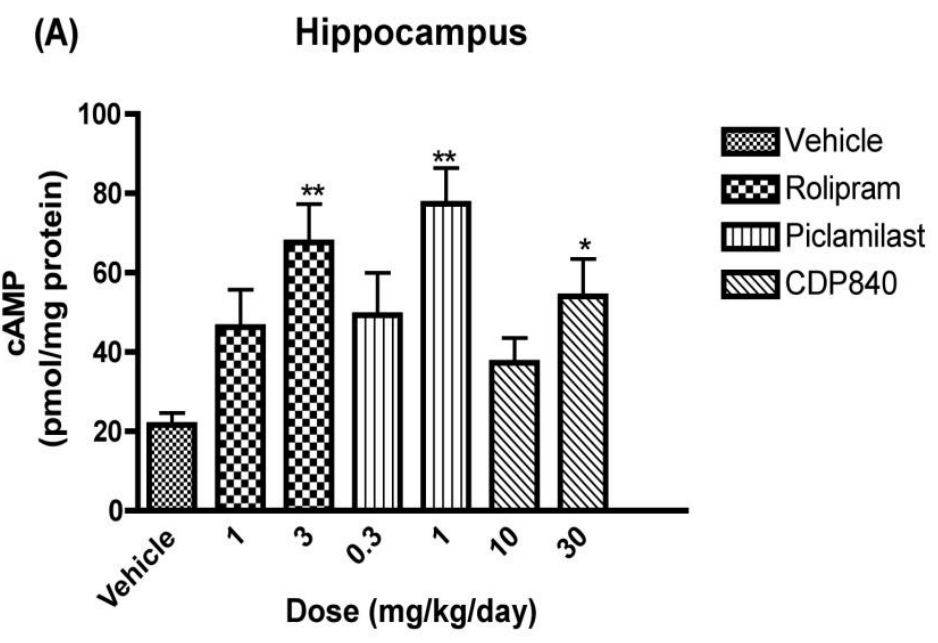

(B) Prefrontal cortex

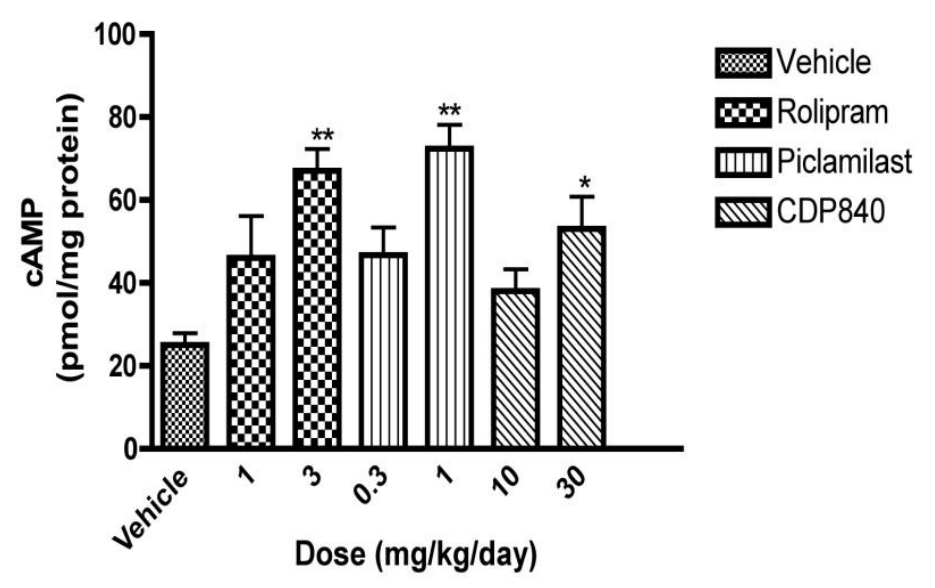


Figure2.2

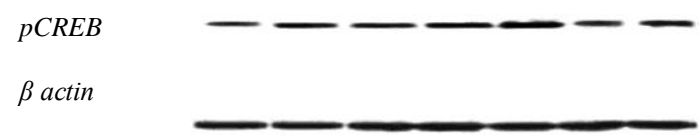

$\begin{array}{llllllll}\text { Vehicle } & 1 & 3 & 0.3 & 1 & 10 & 30 & (\mathrm{mg} / \mathrm{kg} / \text { day }) \\ \text { Rolipram } & \text { piclamilast } & \text { CDP840 }\end{array}$

(A) Hippocampus

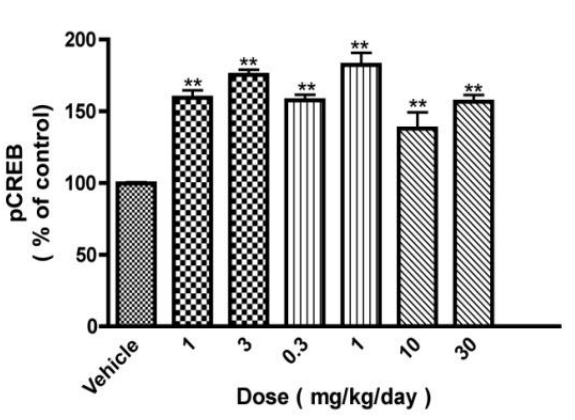

(B)

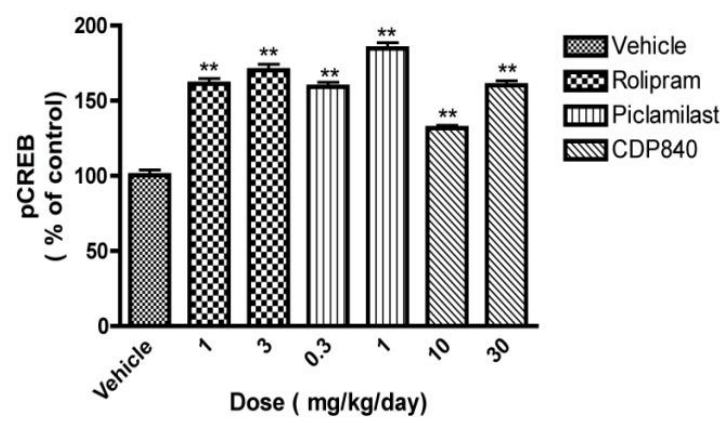

\% Rolipram

InImPiclamilast

CDP840 $\begin{array}{rrrrrrr}\text { Vehicle } & 1 & 3 & 0.3 & 1 & 10 & 30 \\ \text { Rolipram } & \text { piclamilast } & & \text { CDP } 840 & & \end{array}$

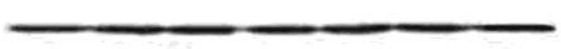


Figure 2.3

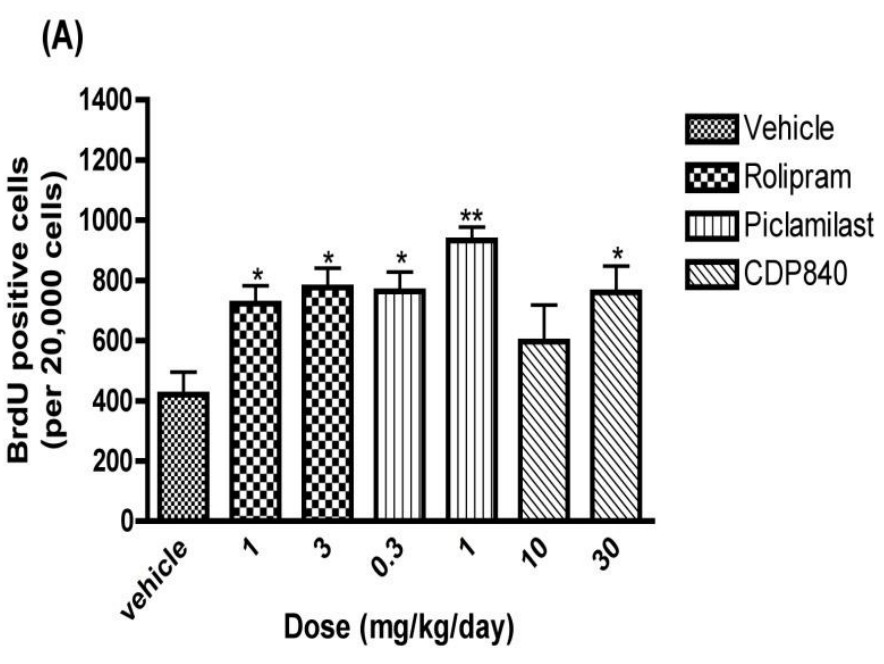

(B)

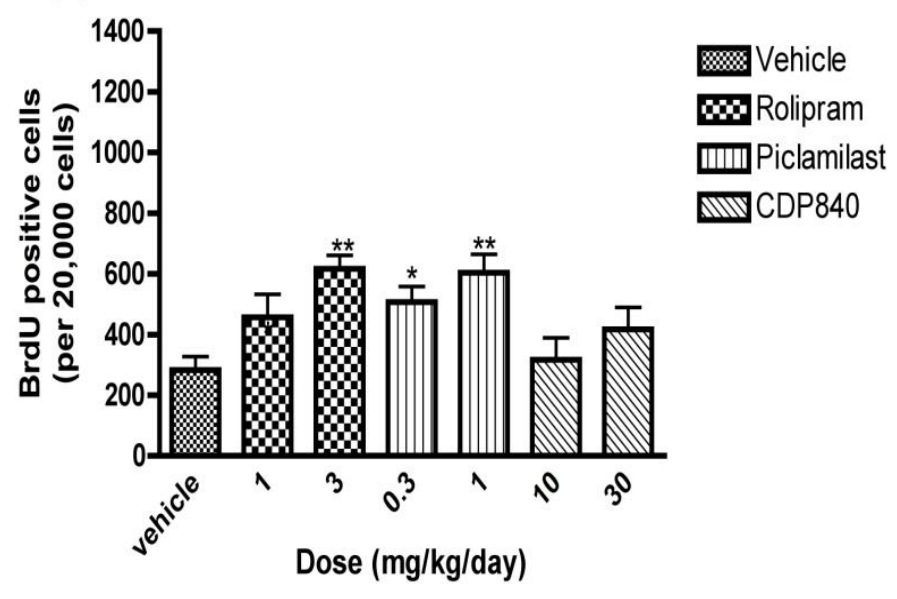


Figure 2.4

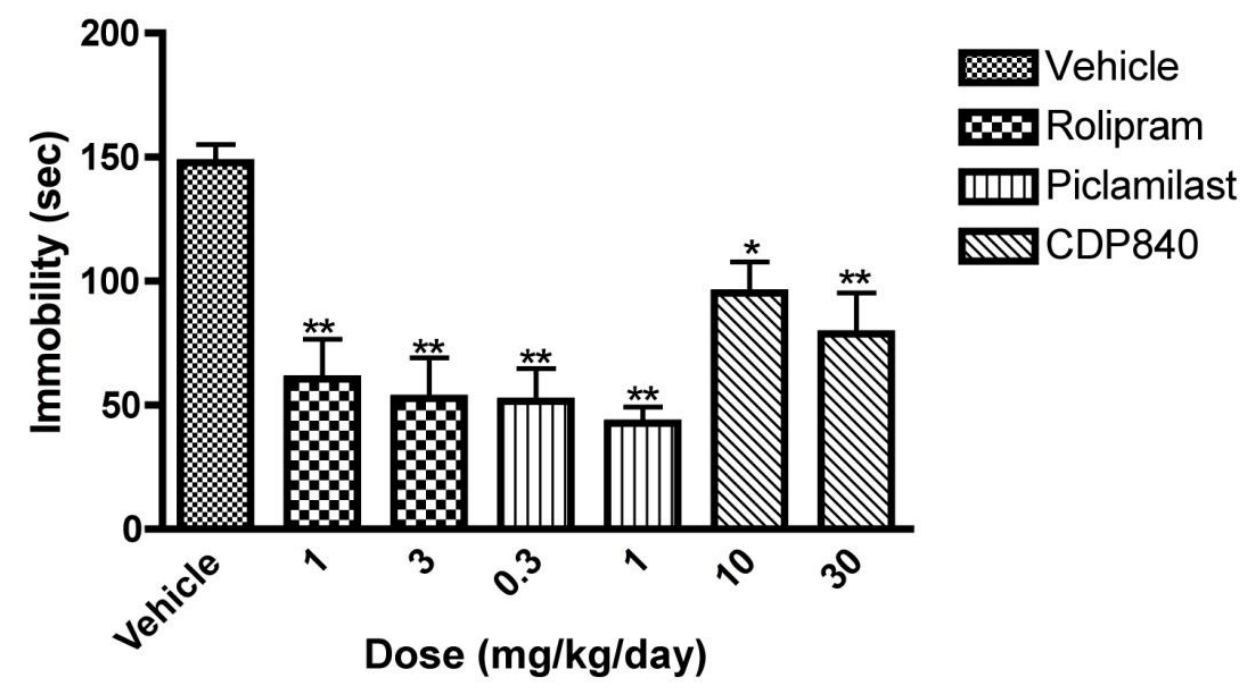


Chapter 3

Effect of DISC1 mutation on cAMP/pCREB signaling and PDE4 isoforms 


\begin{abstract}
Disrupted in schizophrenia 1 (DISC1) is among the most reproducible genetic risk factors that have been identified for psychiatric disorders. Phosphodiesterase-4 (PDE4), notably the PDE4B subtype, which interacts strongly with DISC1, is another identified risk factor. The purpose of this study is to investigate how alterations in DISC1 affect PDE4 using mutant mice expressing mutated DISC1. Using a mouse strain carrying an endogenous DISC1 construct engineered to model the disease-associated chromosomal translocation found in humans, PDE4 expression and activity were examined. In DISC1 mutant mice, it was found that PDE4 activity was reduced and cAMP/pCREB singling was increased in the hippocampus, prefrontal cortex, and striatum. Examination of PDE4 subtypes using SDS-PAGE/immunoblotting showed reduced expression of PDE4B1, PDE4B3, and PDE4B4 in these three brain regions. PDE4D expression was decreased only in the hippocampus and PDE4A was not unchanged. Interestingly, the high affinity rolipram binding state, a conformer of PDE4, found only in brain, also was decreased in DISC1 mutant mice. These data suggest that DISC1 modulates PDE4 expression and function, notably that of the PDE4B subtype, which alters downstream cAMP/CREB signaling, which might be involved in DISC1's role in neuronal function.
\end{abstract}




\section{Introduction}

Schizophrenia and depression are common and debilitating mental disorders characterized by profound emotional and cognitive disturbances (Millar et al., 2007). The onset is determined by multiple factors, and genetic effects are believed to contribute to the pathogenesis. Previous studies have shown that Disrupted-in-Schizophrenia 1 (DISC1), produced by chromosomal translocation t $(1 ; 11)(\mathrm{q} 42.1 ; \mathrm{q} 14.3)$ (Millar et al., 2000b), enhances the risk of developing mental disorders by 50-fold (Blackwood et al., 2001). Furthermore, recent studies demonstrate that DISC1 interacts with a number of proteins in the central nervous system and is involved in compromised cognitive function and behavioral and anatomical changes linked to psychiatric disease (Miyoshi et al., 2003; Brandon et al., 2004; Hayashi et al., 2005). These studies indicate that DISC1 is an important candidate susceptibility gene for mental illness, including schizophrenia, bipolar disorder and major depression (Millar et al., 2000b; Thomson et al., 2005; Chubb et al., 2008).

Phosphodiesterase-4 (PDE4), which is another risk factor for mental disorders, contains four genes (PDE4A-D) and acts to catalyze the hydrolysis of cAMP (Houslay and Adams, 2003; Millar et al., 2007). The PDE4B subtype was identified as risk factor in a family diagnosed as schizophrenia and psychotic disorder, who showed an inherited $\mathrm{t}(1 ; 16)$ chromosomal translocation (Millar et al., 2005; Pickard et al., 2007). Studies revealed that mutations in the fruit fly gene that encodes an orthologous PDE4, i.e., the dunce gene, showed deficits in synaptic plasticity and learning and memory (Davis et al., 1995). In addition, PDE4 inhibitors have antidepressant- and antipsychotic-like effects in animal models (Houslay and Adams, 2003; O'Donnell and Zhang, 2004). Consistent 
with this, mice with deficient in PDE4D or PDE4B show altered behavior in a number of psychopharmacological tests related to anxiolytic, antidepressant, and antipsychotic activity (O'Donnell and Zhang, 2004).

Recent studies show that DISC1 modulates PDE4 activity dynamically by releasing PDE4 in response to increased cAMP levels in a protein kinase A- (PKA) dependent manner in human neuroblastoma cells (Millar et al., 2005). Other studies have demonstrated that DISC1 and PDE4 isoforms are both present at the same neuronspecific regions such as synapses (Kirkpatrick et al., 2006; Clapcote et al., 2007) and are targeted to particular subcellular compartments (Millar et al., 2005; Lynch et al., 2006; Mackie et al., 2007). Both biochemical and clinical studies indicate that the dysregulation of DISC1-PDE4 interaction is likely to contribute to the symptoms of severe psychiatric disorders, but the complexities of the DISC1-PDE4 interaction are not well understood yet.

To examine the association between DISC1 and PDE4, we used a mutant DISC1 mouse strain that carries two termination codons in exons 7 and 8 and a premature polyadenylation site in intron 8 (Koike et al., 2006). In these DISC1 mutant mice, the introduced genetic lesion results in the production of a truncated transcript and the elimination of a major protein isoform of DISC1 (Kvajo et al., 2008). In this study, we found down-regulated PDE4 activity and enhanced cAMP/pCREB signaling cascade in DISC1 mutant mice. The reduction of PDE4 activity was accompanied by decreased expression of PDE4B and high rolipram binding state (HARBS). 


\section{Materials and Methods}

\section{Animals}

Mutant DISC1 mice were genetically engineered in the laboratory of Joseph Gogos at Columbia University, and contained the same DISC1 mutation backcrossed in C57BL/6J, as previously described (Koike et al., 2006). All analyses were performed using littermates produced by mating of heterozygous mice. All animal procedures were approved by the Columbia University Institutional Animal Care and Use Committee.

\section{Measurement of Cyclic AMP}

For cyclic AMP measurement, hippocampus, striatum and prefrontal cortex were homogenized in ice-cold $0.1 \mathrm{~N}$ hydrochloric acid and centrifuged at $13,000 \times \mathrm{g}$ for $50 \mathrm{~min}$ at $4^{\circ} \mathrm{C}$. Cyclic AMP in the supernatant was measured by ELISA (Assay Designs, Ann Arbor, MI) (Li et al., 2009).

\section{Western blotting}

For phospho-CREB measurement, hippocampus and prefrontal cortex were homogenized in ice-cold lysis buffer (Upstate, Temecula, CA) and then centrifuged at $10,000 \times \mathrm{g}$ for $30 \mathrm{~min}$ at $4^{\circ} \mathrm{C}$. Solubilized samples were mixed with equal volumes of Laemmli sample buffer and heated to $100^{\circ} \mathrm{C}$ for 2 minutes. Equal amounts of sample protein were loaded onto gels for SDS-PAGE. Following separation by electrophoresis, proteins in the gels were transferred to nitrocellulose membranes, which were incubated overnight at $4^{\circ} \mathrm{C}$ with primary antibodies against CREB phosphorylated at serine-133 
(Upstate Biotechnology, Lake Placid, NY) and then with Alexa Fluor 680-conjugated secondary antibody for $30 \mathrm{~min}$ at room temperature (Invitrogen, Carlsbad, CA). An Odyssey Infrared Imaging System (LI-COR Bioscience, Lincoln, NE) was used for quantifying fluorescence. Treatment-induced changes in phospho-CREB were assessed within individual gels/immunoblots.

\section{Radioligand Binding Assays}

$\left[{ }^{3} \mathrm{H}\right]$-Rolipram binding was measured as described previously (Zhao et al., 2003a; Scharf et al., 2008). Samples containing $200 \mu \mathrm{g}$ of protein were incubated at $30^{\circ} \mathrm{C}$ in the presence of $250 \mu \mathrm{l}$ of incubation buffer that containing different concentrations of [ $\left.{ }^{3} \mathrm{H}\right]$ rolipram (2-30 nM). Nonspecific binding was determined in the presence of $10 \mathrm{nM}$ unlabeled Ro 20-1724 [4-3-butoxy-4-methoxybenzyl-2-imidazolidinone] for [ ${ }^{3} \mathrm{H}$ ]rolipram binding. Reactions were stopped by addition of $5 \mathrm{ml}$ of ice-cold binding buffer after $1 \mathrm{hr}$ and followed by rapid vacuum filtration through glass fiber filters. The filters were washed twice, and radioactivity measured by liquid scintillation counting.

\section{PDE Activity Assay}

The PDE enzyme assay was performed as described previously (Zhang et al., 2008). Samples were assayed in the presence or absence of $10 \mathrm{uM}$ rolipram. PDE4 activity i.e. rolipram-sensitivity was calculated by subtracting cAMP hydrolysis in the presence of rolipram to that in its absence. 


\section{Real Time-Polymerase Chain Reaction RT-PCR}

Total RNA was isolated from HPC with TRIzol reagent (Invitrogen, Carlsbad, CA) according to manufacturer's instructions, followed by DNase treatment to eliminate contaminated genomic DNA. Conversion of total RNA into cDNA was performed using High Capacity cDNA archive kit (Applied Biosystems, Foster City, CA). Real-time PCR was performed on an ABI PRISM 7300 Detection System Applied Biosystems with Tagman Universal Mastermix Applied Biosystems. The PDE4B primer was purchased from Applied Biosystems. The samples were run in triplicate and amplified for 40 cycles at $50^{\circ} \mathrm{C}$ for $2 \mathrm{~min}, 90^{\circ} \mathrm{C}$ for $10 \mathrm{~min}, 95^{\circ} \mathrm{C}$ for $15 \mathrm{~s}$, extension $60^{\circ} \mathrm{C}$ for $1 \mathrm{~min}$. Beta-actin was used as an endogenous control. The fold difference in expression of target cDNA was determined using the comparative threshold method as previously described (Livak and Schmittgen, 2001).

\section{Data Analysis and Statistics}

Statistical analysis was performed using one-way analysis of variance followed by Dunnett's test. Binding data were analyzed by nonlinear regression (O'Donnell et al., 1984). Data are expressed as means \pm SEM. A p value $<0.05$ was considered significant. 


\section{Results}

Cyclic AMP and pCREB in the hippocampus, prefrontal cortex and striatum of DISC1 mutant mice.

cAMP levels were significantly increased in the hippocampus, prefrontal cortex and striatum of homozygous DISC1 mutant mice compared with wild type mice; no significant changes were observed in the same brain regions of heterozygous DISC1 mutant mice (Fig.3.1). Consistently, pCREB demonstrated a trend to increase in the three brain regions of homozygous DISC1 mutant mice, but no changes were observed in the heterozygous DISC1 mutant mice (Fig.3.2).

PDE4 activity in the hippocampus, prefrontal cortex and striatum of DISC1 mutant mice.

PDE4 activity was significantly decreased in the hippocampus, prefrontal cortex and striatum, by $51 \%, 38 \%$ and $70 \%$, respectively, in the homozygous DISC1 mutant mice compared with wild type mice. In the heterozygous DISC1 mutant mice, PDE4 activity was decreased by $29 \%, 23 \%$ and $40 \%$, respectively, in the hippocampus, prefrontal cortex and striatum (Fig.3.3).

PDE4B levels in the hippocampus, prefrontal cortex and striatum of DISC1 mutant mice.

PDE4B1 was decreased significantly in the hippocampus, prefrontal cortex and striatum by $59 \%, 70 \%$ and $50 \%$, respectively, in the homozygous mutant DISC1 mice compared to wild type mice. In heterozygous mice, PDE4B1 was decreased by $11 \%$, 
$32 \%$ and $38 \%$ (Fig.3.4). In addition, PDE4B3 was also decreased significantly by $49 \%$, $52 \%$ and $38 \%$, respectively, in the same three brain regions of homozygous mutant DISC1 mice, and 11\%, $8 \%$ and $4 \%$ in heterozygous DISC1 mutant mice (Fig.3.6). Similarly, PDE4B4 was decreased by $41 \%, 40 \%$ and $30 \%$, respectively, in the hippocampus, prefrontal cortex and striatum of homozygous mutant DISC1 mice compared to wild type mice. Reductions were 15\%, 19\% and 23\% in PDE4B4 levels in the same brain regions in heterozygous mice (Fig.3.7). No significant changes of PDE4B2 were observed in DISC1 mutant mice compared to wild type mice (Fig.3.5).

Given the marked reductions in protein levels of PDE4B subtypes in DISC1 mutant mice, mRNA for PDE4B was measured using real-time RT-PCR. There were no significant changes in mRNA for PDE4B in DISC1 mutant mice indicating that the changes observed in PDE4B expression were post-transcriptional (Fig.3.8).

\section{PDE4D levels in the hippocampus, prefrontal cortex and striatum of DISC1 mutant} mice.

PDE4D3 was reduced by $40 \%$ in the hippocampus, but only $15 \%$ and $9 \%$ in the prefrontal cortex and striatum of homozygous DISC1 mutant mice compared to wild type mice. In heterozygous DISC1 mice, there were $12 \%, 12 \%$ and $7 \%$ reductions of PDE4D3 in these regions, respectively (Fig.3.9). Similarly, PDE4D5 also was reduced in the hippocampus but not in the prefrontal cortex and striatum of homozygous DISC1

mutant mice. In heterozygous DISC1 mutant mice, PDE4D5 was not reduced significantly (Fig.3.10). 
PDE4A levels in the hippocampus, prefrontal cortex and striatum of DISC1 mutant mice.

To reveal whether the mutation of DISC1 affect the PDE4 variant expression, the subtypes of PDE4A, including PDE4A1 and PDE4A5 were measured. There were no significant alterations in PDE4A1 in either Hom or Het DSIC1 mutant mice (Fig.3.11). Similarly, no changes were found in PDE4A5 in the hippocampus, prefrontal cortex or striatum of mutant DISC1 mice, compared with wild type mice (Fig.3.12).

HARBS levels in the hippocampus, prefrontal cortex and striatum of mutant DISC1 mice.

In order to study whether the mutation of DISC1 alters the HARBS, the index of the HARBS, $\left[{ }^{3} \mathrm{H}\right]$-rolipram binding, was measured in the DISC1 mutant mice. $\left[{ }^{3} \mathrm{H}\right]$-rolipram binding were was significantly decreased in the hippocampus, prefrontal cortex and striatum of DISC1 mutant mice, including Het and Hom group, compared with wild type mice (Fig.3.13). 


\section{Discussion}

DISC1 is involved in multiple neurological signaling cascades, including neuronal proliferation and extension (Ishizuka et al., 2006; Mackie et al., 2007; Mao et al., 2009). As one of the most important and particularly noteworthy binding partners of DISC1, PDE4 is a critical regulator of cAMP. Our studies demonstrate that PDE4 function and downstream cAMP/pCREB signaling cascade were changed by the mutation of DISC1, indicating the altered DISC1-PDE4 interaction results in marked changes in cAMP signaling, most notably that involving PDE4B. Ultimately, this could affect neuronal progenitor proliferation and neurite extension, promotion of axonal transport and neuronal radial migration (Porteous et al., 2003; Ross et al., 2006; Camargo et al., 2007; Shinoda et al., 2007; Taya et al., 2007), and cerebral cortex development (Kamiya et al., 2005).

PDE4 activity is regulated by phosphorylation in the catalytic domain by extracellular signal-regulated kinase (ERK) and in the UCR1 by protein kinase A (PKA), which induces a UCR1-UCR2 interaction (Houslay and Baillie, 2005; Hashimoto et al., 2006). Interestingly, recent data have shown that PDE4 activity is dynamically modulated by DISC1. DISC1 binds to the UCR2 domain, and PDE4B dissociates from DISC1 in response to increased cAMP (Millar et al., 2005). This indicates that DISC1 could exert its effect by modulating PDE4 activity for a variety of biological responses. For instance, PDE4 regulates the compartmentalization of cAMP signaling, which is linked to the learning, memory and mood (O'Donnell and Zhang, 2004; Arguello and Gogos, 2006). Therefore, mutation of DISC1 could disrupt the normal complex interaction, thus interfering with normal learning, memory and cognition, all of which are 
disturbed in patients with schizophrenia. Our studies have shown that the mutation of DISC1 decreases PDE4 activity, resulting in increased AMP/pCREB signaling, probably through the dysregulation of PDE4-DISC1 complex due to the disrupted DISC1 function. Similarly, in another animal model of schizophrenia, which involves a missense mutation by changing leucine to proline at position 100, PDE4B activity also is reduced (Clapcote et al., 2007). Though decreased PDE4 activity might seem contradictory with the model that proposes PDE4B is released from the DISC1-complex in the high activity form, it is implied that the reduced association between DISC1-PDE4 induced by mutation might not be related to the sequence of events that induces PDE4 dissociation from DISC1 and subsequent activation (Millar et al., 2007). Also, studies of the interaction between DISC1-PDE4 are complicated by many factors including studies of differences in cell lines, mouse strains, and methods of DISC1 mutation. Thus, this apparent discrepancy needs further investigation to be fully understood.

Despite these discrepancies, behavioral data offer more evidence of the interaction between PDE4 and DISC1. Mice with a DISC1 mutation demonstrate a schizophrenialike phenotype, including hyperactivity and impaired cognition, and these behaviors are reversed by the treatment with the PDE4 inhibitor, rolipram or an antipsychotic drug (Marx, 2007). In addition, these mice with depression-like phenotype respond to antidepressant treatment in the forced-swim test. Thus, dysfunction of either DISC1 or PDE4 may compromise a variety of signaling cascades and result in distorted neuronal development, which underlies the pathogenesis of mental illness. Additionally, DISC1 modulation of cAMP via PDE4, could be another target for treating schizophrenia and other mental illnesses. 
PDE4 consists of four subtypes including A, B, C and D. PDE4A, PDE4B and PDE4D are widely expressed throughout the central nervous system, whereas PDE4C is expressed only at a minimal level in the brain (O'Donnell and Zhang, 2004). Molecular studies reveal that the association between DISC1 and PDE4 is in a PDE4 isoformdependent manner (Murdoch et al., 2007). Increased cAMP dissociates PDE4C and PDE4D from the $100 \mathrm{kDa}$ DISC1, but not the PDE4A or PDE4B isoform; PDE4B does dissociate from the $71 \mathrm{kDa}$ DISC1 (Millar et al., 2005; Murdoch et al., 2007). This is explained in part by the number of binding sites between DISC1 and the PDE4 isoforms. A peptide array strategy shows that DISC1 has five binding sites for PDE4: two sites for every PDE4 isoform; three more specific sites for PDE4B (Murdoch et al., 2007), explaining the strong bond between PDE4B and DISC1. In our study, mutation of DISC1 induced a decrease in PDE4B1, PDE4B3, PDE4B5, but not PDE4B2 in the prefrontal cortex, hippocampus and striatum, as well as a reduced PDE4D3, PDE4D5 level in the hippocampus, but no changes of PDE4A isoforms. These data indicate that PDE4B is more involved in the interaction with DISC1 and that PDE4A is less susceptible to the regulation by altered DISC1. Consistently, the PDE4B1 isoform was found $50 \%$ reduced in lymphoblastoid cell line in patients with mental disorders (Millar et al., 2005). PDE4B was also found associated with affective disorders and schizophrenia (Pickard et al., 2005).

PDE4D is highly expressed in the hippocampus and the reduction of PDE4D in this region indicates it to have a primary role in the regulation of cAMP signaling; however, PDE4D is mainly regulated by phosphorylation (O'Donnell and Zhang, 2004). Interestingly, other animal models of schizophrenia, which have mutations from 
glutamine to leucine at position $31(31 \mathrm{~L})$ or from leucine to proline at position 100 (100P), decrease binding between DISC1 and PDE4B, particularly for the long isoforms PDE4B1 and PDE4B3 (Clapcote et al., 2007). Clinical studies showed various results due to limited sample resources and variations in lifetime drug treatment in patients. One study showed PDE4B (PDE4B1, PDE4B2, PDE4B3 and PDE4B4) was decreased in the cerebella of patients with autism (Braun et al., 2007). Another study showed PDE4A was reduced in cerebella of patients with bipolar disorder, but not in the patients with schizophrenia or major depression (Fatemi et al., 2008).

One complexity in the understanding of PDE4 is the high-affinity and low-affinity rolipram binding states (HARBS and LARBS). It was first described that $\left[{ }^{3} \mathrm{H}\right]$-rolipram bound to brain tissues with high affinity, while to peripheral tissues with low affinity (Schneider et al., 1986). Further studies using recombinant PDE4A revealed that $\left[{ }^{3} \mathrm{H}\right]-$ rolipram exhibited two distinct affinities with 500-fold differences in Ki (Jacobitz et al., 1996). Interestingly, PDE4 is expressed throughout the body, but HARBS is found in the CNS but not in peripheral tissues. Consistent with its location, current studies indicate that the CNS effects of PDE4 are mediated mainly by HARBS (O'Donnell and Zhang, 2004). In our study, HARBS was decreased in three brain regions of DISC1 mutant mice, including the hippocampus, prefrontal cortex and striatum. Simultaneously, PDE4 activity was also reduced in the same regions, suggesting decreased HARBS might contribute to the reduced PDE4 activity. Previous studies have shown that repeated treatment with desipramine or fluoxetine increases HARBS in cerebral cortex and hippocampus (Zhao et al., 2003a), suggesting an alteration in the component of the signaling cascade involving PDE4. 
In a summary, DISC1 modulates cAMP/pCREB signaling via an interaction with PDE4. DISC1 mutation up-regulates cAMP/pCREB signaling via decreased PDE4 activity, mainly due to reduced PDE4B and PDE4D variants, while simultaneously decreases HARBS. The DISC1-PDE4 interaction may offer a means to selectively reduce the activity of particular PDE4 subtypes, which may offer a unique pharmacological profile for the treatment of psychiatric illnesses. 


\section{Figure Legends}

Fig. 3.1. Cyclic AMP levels in the hippocampus, prefrontal cortex and striatum of wild type (Wt) and DISC1 mutant mice. Cyclic AMP was increased significantly in the hippocampus (A), prefrontal cortex (B) and striatum (C) of homozygous (Hom) DISC1 mutant mice compared with wild type mice. Values are means \pm SEM, $n=3-4$ per group. $* \mathrm{P}<0.05$ vs. corresponding control.

Fig. 3.2. Phospho-CREB levels in the hippocampus, prefrontal cortex and striatum of wild type (Wt) and DISC1 mutant mice. Phospho-CREB was significantly increased in the prefrontal cortex (B) of homozygous (Hom) DISC1 mutant mice compared with wild type mice. A trend toward an increase in phospho-CREB was observed in the hippocampus (A) and striatum (C) in homozygous (Hom) DISC1 mutant mice. Values are means \pm SEM, $\mathrm{n}=3-4$ per group. ${ }^{*} \mathrm{P}<0.05$ vs. corresponding control.

Fig. 3.3. PDE4 activity in the hippocampus, prefrontal cortex and striatum of wild type (Wt) and DISC1 mutant mice. PDE4 activity was significantly decreased in the hippocampus (A), prefrontal cortex (B) and striatum (C) of homozygous (Hom) DISC1 mutant mice compared to wild type mice. In addition, PDE4 activity was also decreased in the striatum of heterozygous (Het) DISC1 mutant mice. Values are means \pm SEM, $\mathrm{n}=3-4$ per group. $* * \mathrm{P}<0.01, * \mathrm{P}<0.05$ vs. corresponding control. 
Fig. 3.4. PDE4B1 levels in the hippocampus, prefrontal cortex and striatum of wild type (Wt) and DISC1 mutant mice. PDE4B1 was decreased in the hippocampus (A), prefrontal cortex (B) and striatum (C) of homozygous (Hom) DISC1 mutant mice compared with wild type mice. There was no significant change of PDE4B1 in the heterozygous (Het) mice. Values are means \pm SEM, $n=3-4$ per group. $* \mathrm{P}<0.05$ vs. corresponding control.

Fig. 3.5. PDE4B2 levels in the hippocampus, prefrontal cortex and striatum of wild type (Wt) and DISC1 mutant mice. PDE4B2 showed a trend toward an increase in hippocampus (A), prefrontal cortex (B) or striatum (C) of homozygous (Hom) DISC1 mutant mice compared with wild type mice. No changes were found in heterozygous (Het) mice. Values are means \pm SEM, $n=3-4$ per group.

Fig. 3.6. PDE4B3 levels in the hippocampus, prefrontal cortex and striatum of wild type (Wt) and DISC1 mutant mice. PDE4B3 was decreased in the hippocampus (A), prefrontal cortex (B) and striatum (C) of homozygous (Hom) DISC1 mutant mice compared with wild type mice. There were no changes in PDE4B3 in the heterozygous (Het) mice. Values are means $\pm \mathrm{SEM}, \mathrm{n}=3-4$ per group. ${ }^{*} \mathrm{P}<0.05$ vs. corresponding control.

Fig. 3.7. PDE4B4 levels in the hippocampus, prefrontal cortex and striatum of wild type (Wt) and DISC1mutant mice. PDE4B4 was decreased in the hippocampus (A), prefrontal cortex (B), but not in the striatum (C) of homozygous (Hom) DISC1 mutant 
mice compared with wild type mice. Values are means \pm SEM, $n=3-4$ per group. $* * \mathrm{P}<0.01, * \mathrm{P}<0.05$ vs. corresponding control.

Fig. 3.8. PDE4B mRNA levels in the hippocampus, prefrontal cortex and striatum of wild type (Wt) and DISC1mutant mice. No significant changes were observed in the DISC1 mutant mice compared with wild type mice. Values are means \pm SEM, $n=3-4$ per group.

Fig. 3.9. PDE4D3 levels in the hippocampus, prefrontal cortex and striatum of wild type (Wt) and DISC1 mutant mice. PDE4D3 was decreased in the hippocampus (A), but not prefrontal cortex (B) or striatum (C) of homozygous (Hom) mice compared to wild type mice. Values are means $\pm \mathrm{SEM}, \mathrm{n}=3-4$ per group. $* * \mathrm{P}<0.01$ vs. corresponding control.

Fig. 3.10. PDE4D5 levels in the hippocampus, prefrontal cortex and striatum of wild type (Wt) and DISC1 mutant mice. PDE4D5 was changed in the hippocampus (A), but not in the prefrontal cortex (B) and striatum (C) of homozygous (Hom) DISC1 mutant mice. Values are means \pm SEM, $\mathrm{n}=3-4$ per group. $* \mathrm{P}<0.05$ vs. corresponding control.

Fig. 3.11. PDE4A1 levels in the hippocampus, prefrontal cortex and striatum of wild type (Wt) and DISC1 mutant mice. PDE4A1 was not changed in the hippocampus (A), prefrontal cortex (B) or striatum (C) of DISC1 mutant mice compared with wild type mice. Values are means \pm SEM, $n=3-4$ per group. 
Fig. 3.12. PDE4A5 levels in the hippocampus, prefrontal cortex and striatum of wild type (Wt) and DISC1 mutant mice. PDE4A5 was not changed in the hippocampus (A), prefrontal cortex (B) or striatum (C) of DISC1 mutant mice compared with wild type mice. Values are means \pm SEM, $n=3-4$ per group.

Fig. 3.13. HARBS levels in the hippocampus, prefrontal cortex and striatum of wild type (Wt) and DISC1 mutant mice. HARBS was decreased in the hippocampus (A), prefrontal cortex (B) and striatum (C) in the DISC1 mutant mice compared with wild type mice. Values are means $\pm \mathrm{SEM}, \mathrm{n}=3-4$ per group. $* * \mathrm{P}<0.01, * \mathrm{P}<0.05$ vs. corresponding control. 
Figure 3.1

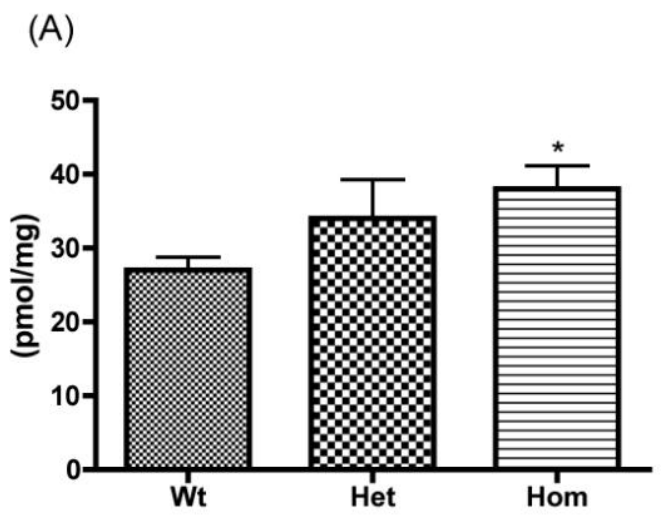

(B)

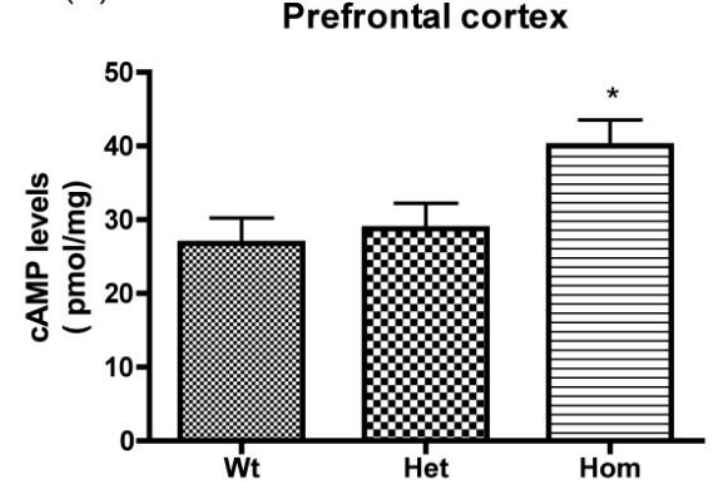

(C)

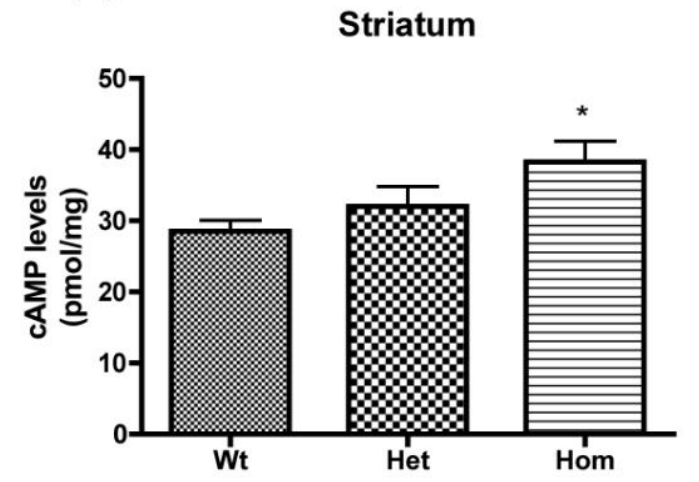


Figure 3.2

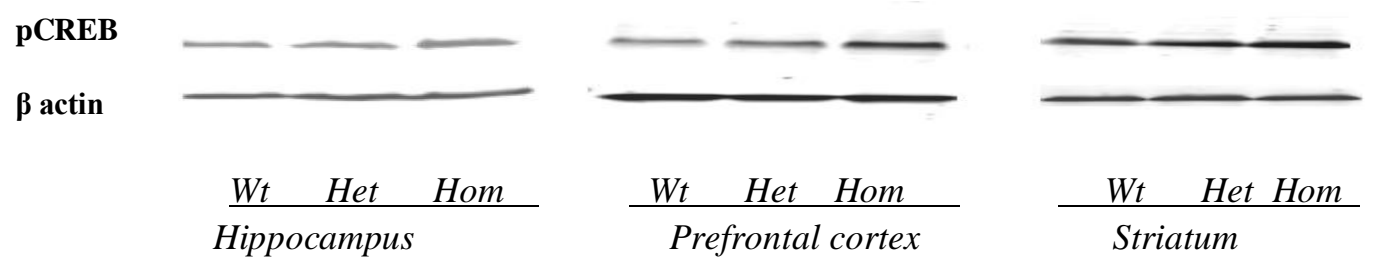

(A)

Hippocampus

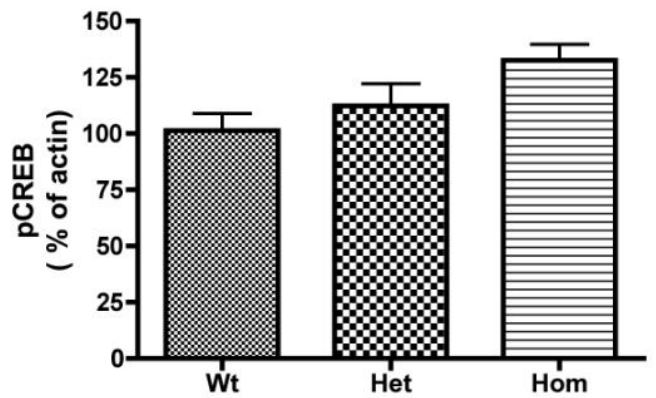

(B)

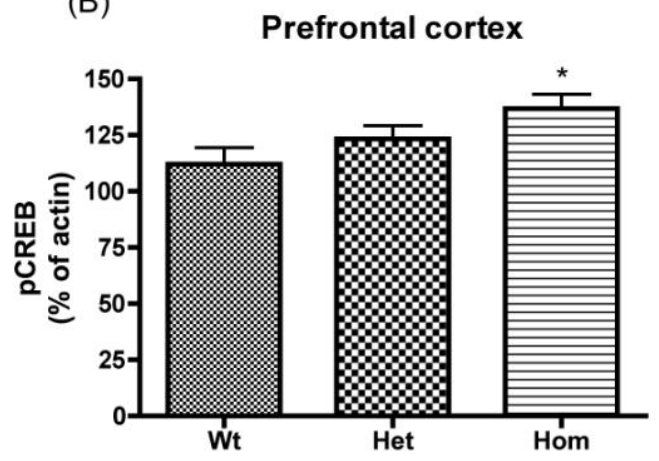

(B)

Striatum

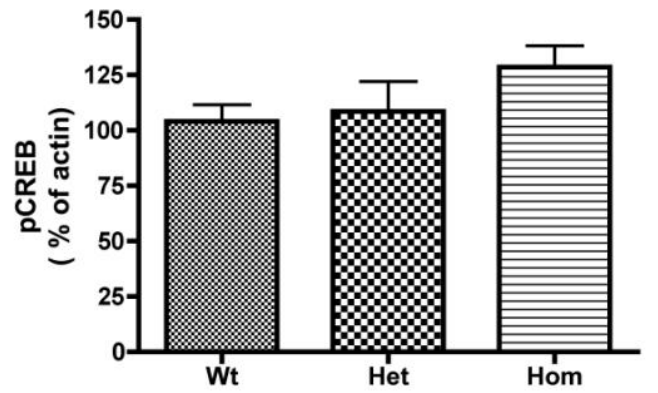


Figure 3.3

(A)

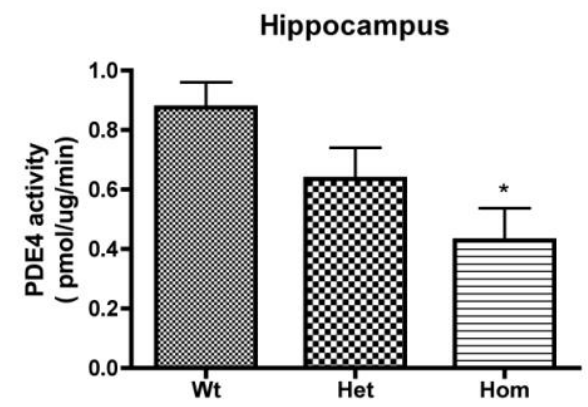

(B)

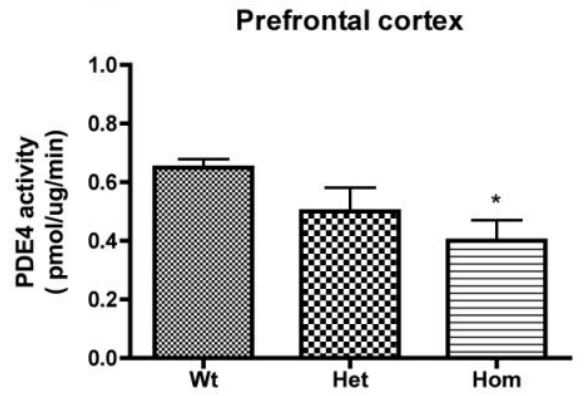

(C)

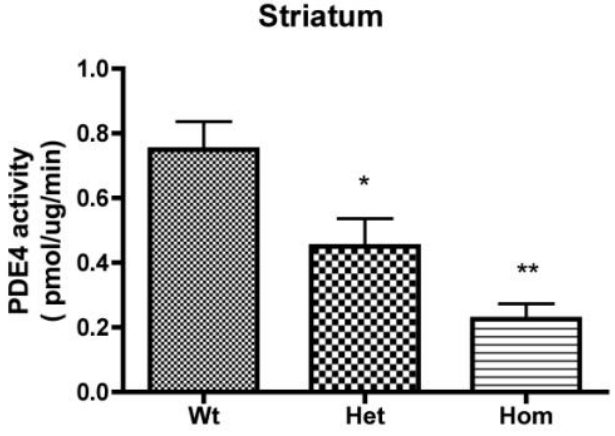


Figure 3.4

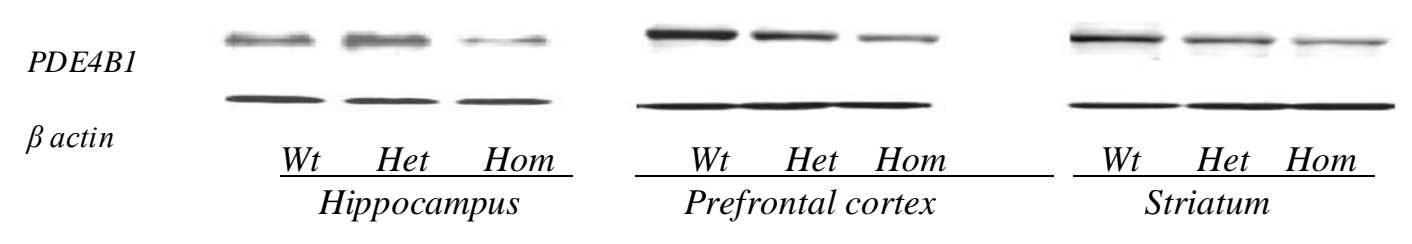

(A)

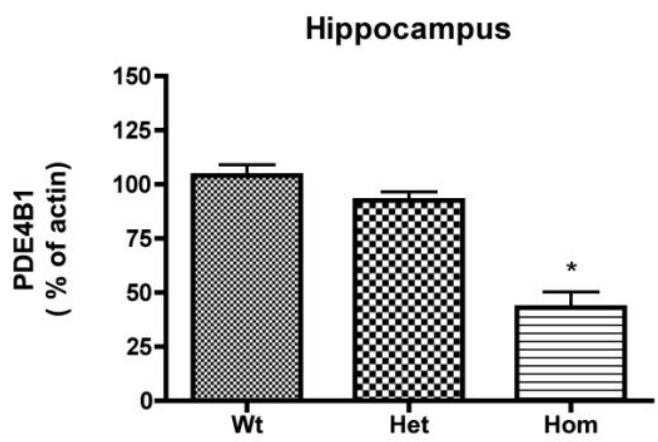

(B)

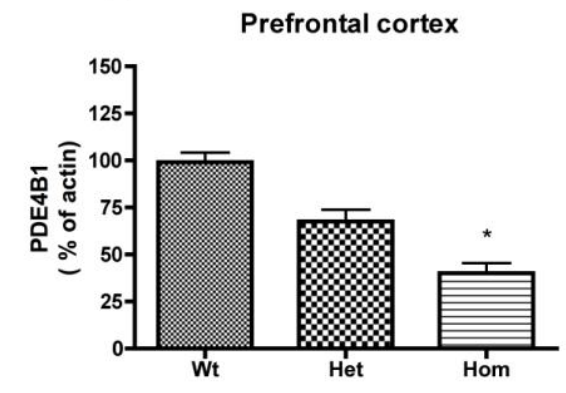

(C)

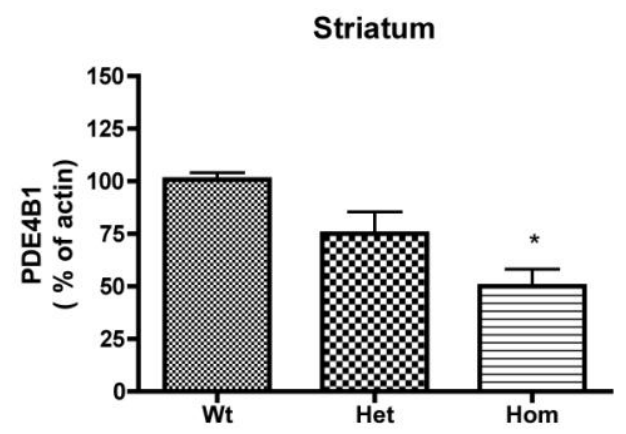


Figure 3.5

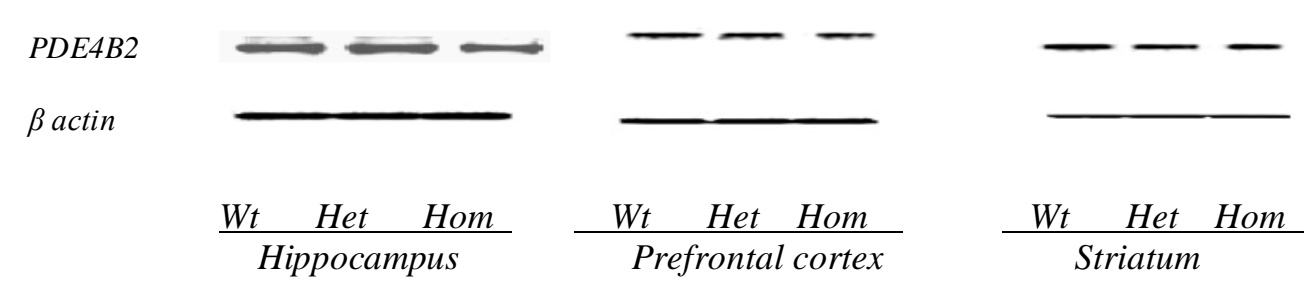

(A) Hippocampus

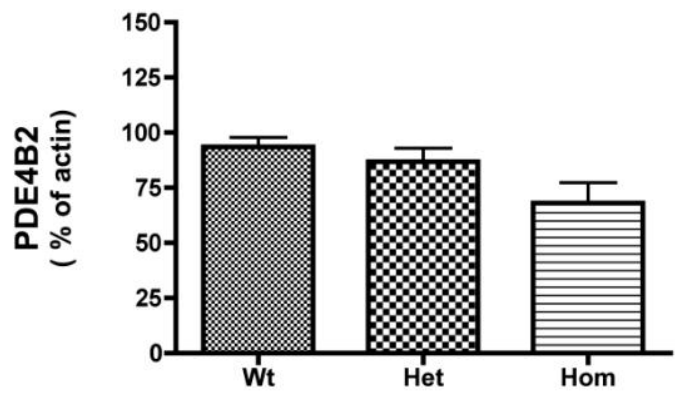

(B) Prefrontal cortex

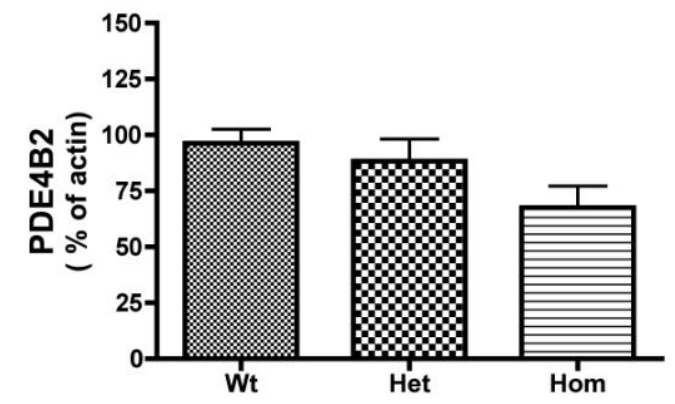

(C)

Striatum

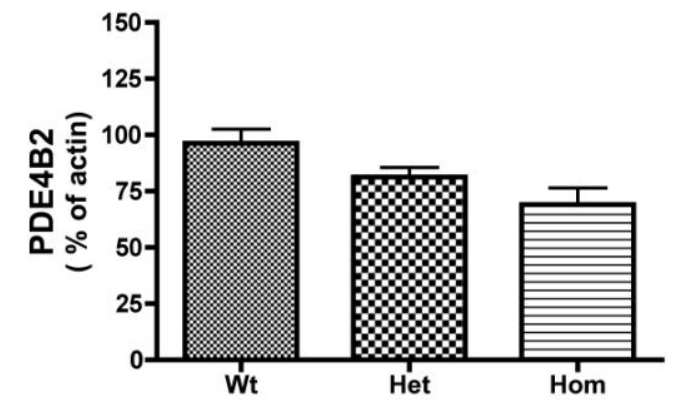


Figure 3.6

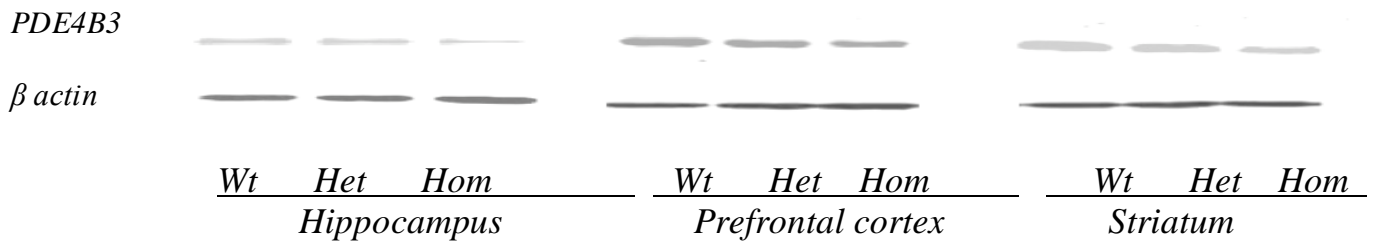

(A)

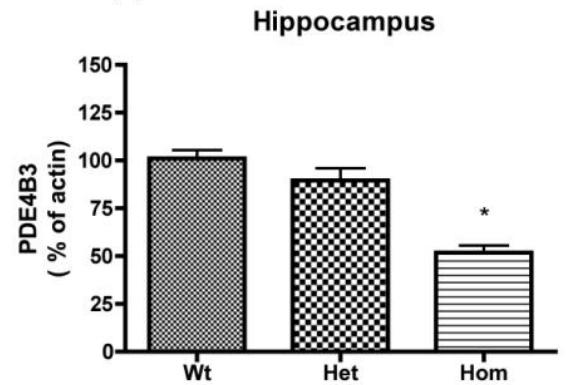

(B)

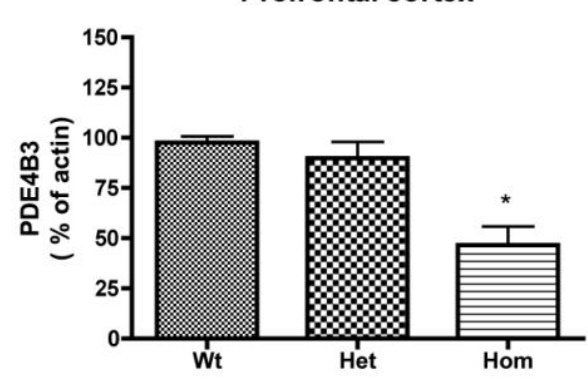

(C)

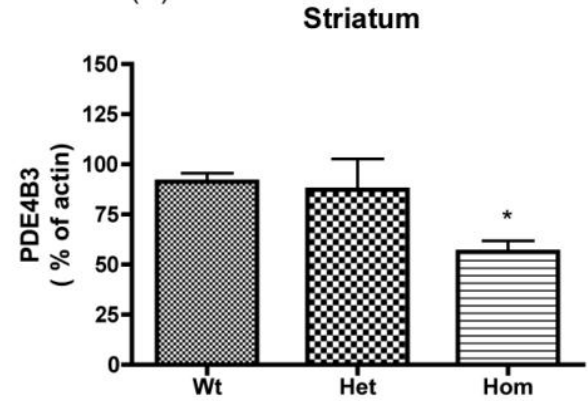


Figure 3.7

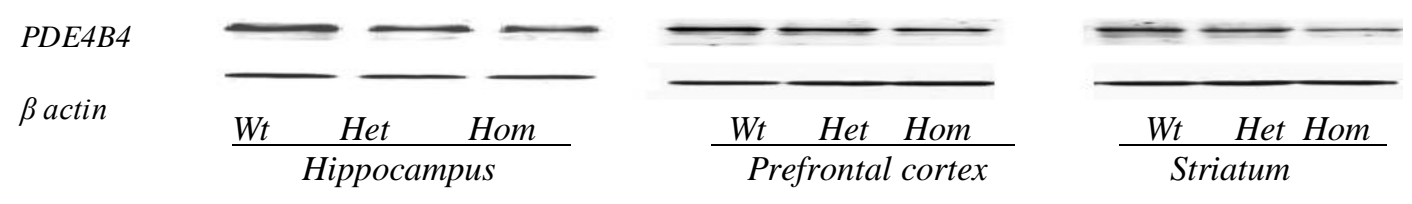

(A) Hippocampus

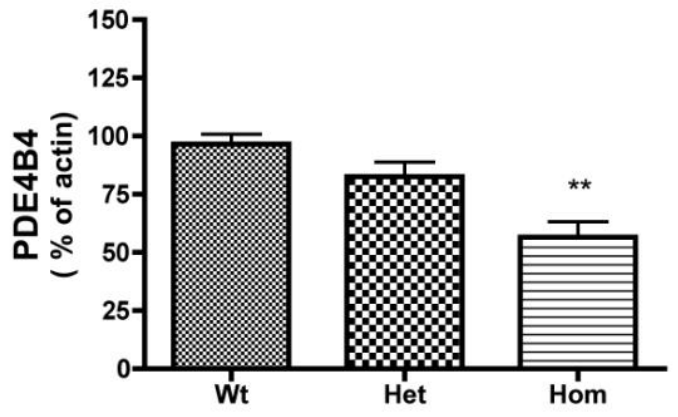

(B)

Prefrontal cortex

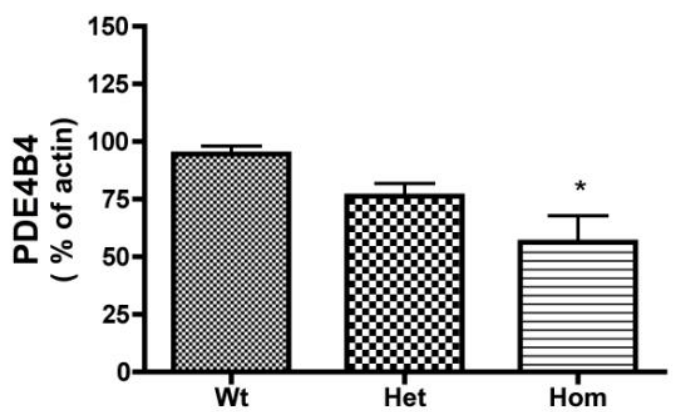

(C)

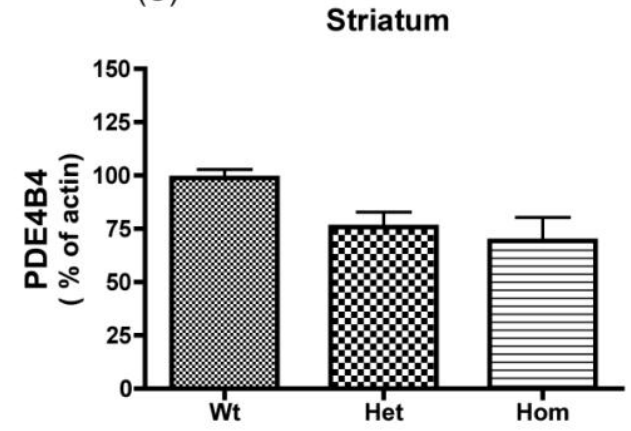


Figure 3.8

(A)

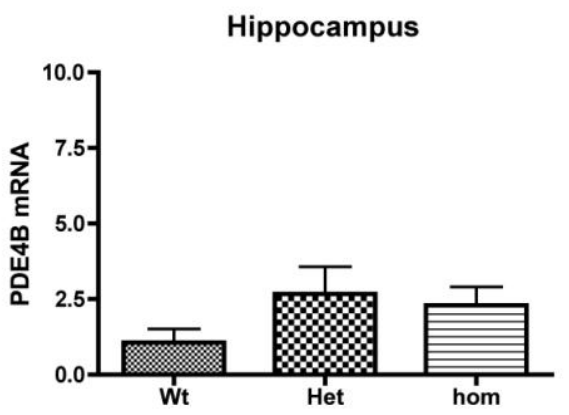

(B)

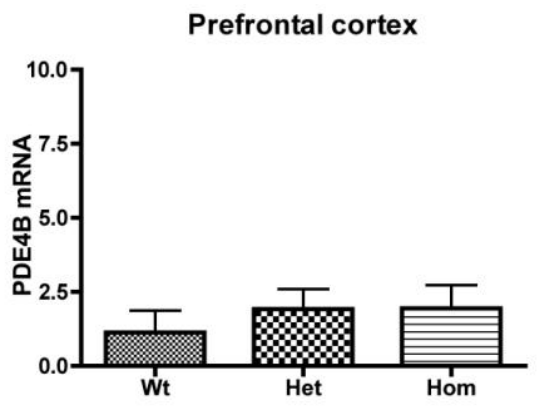

(C)

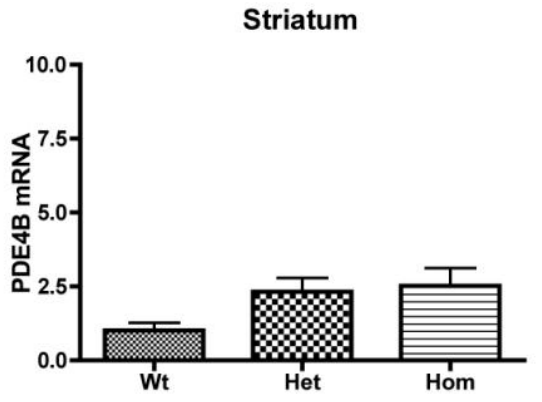


Figure 3.9

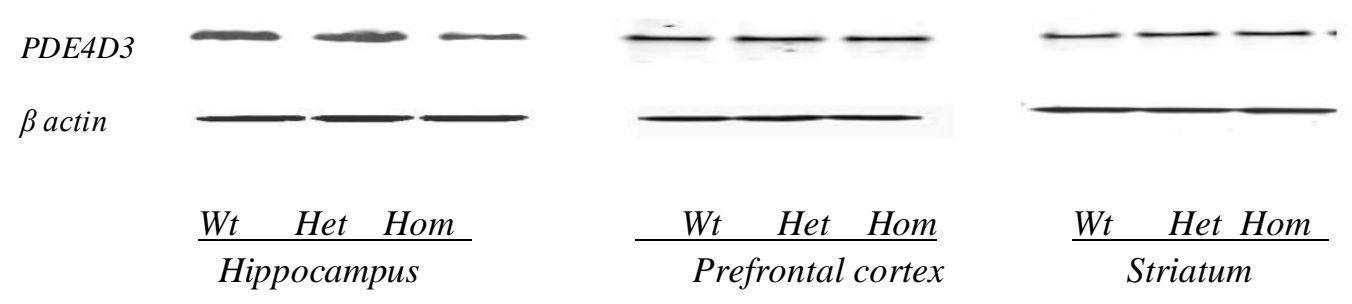

(A)

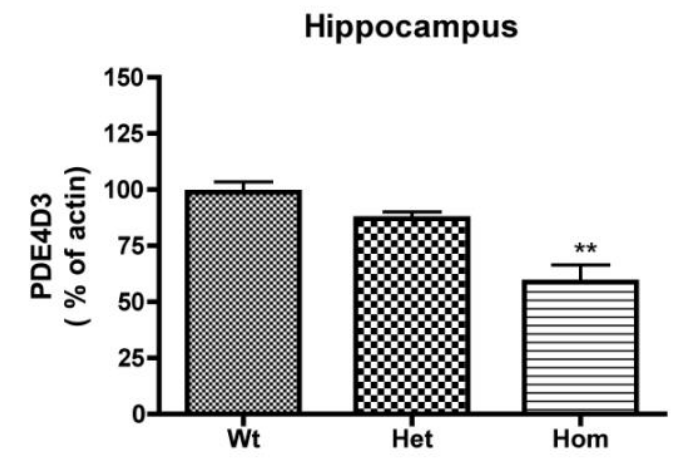

(B)

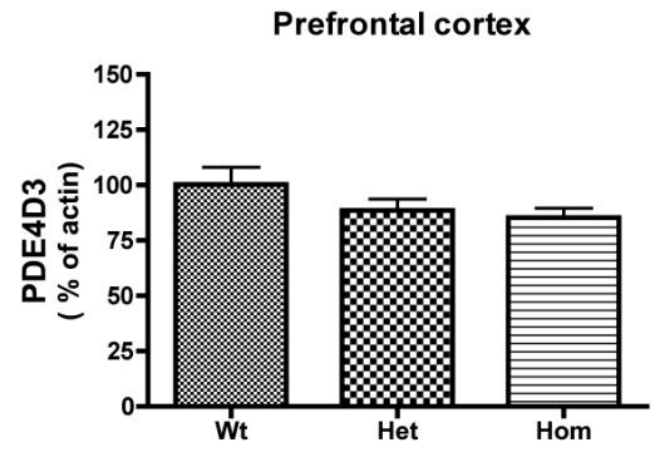

(C)

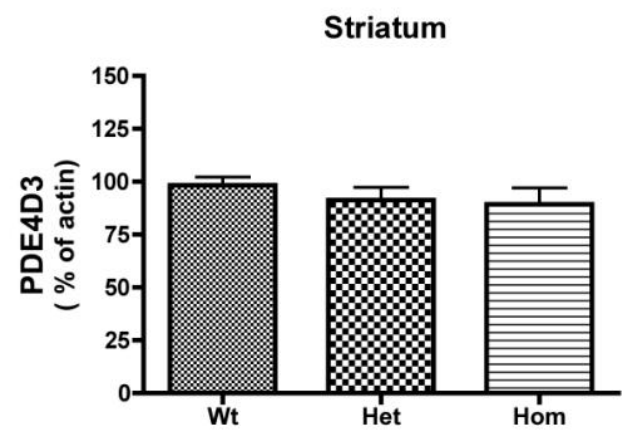


Figure 3.10

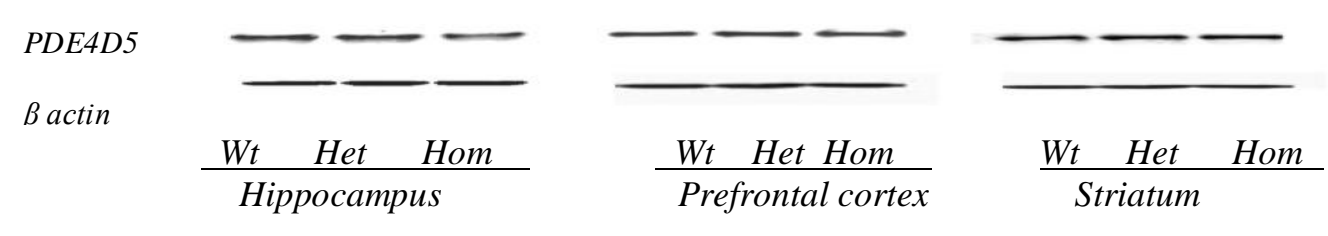

(A)

Hippocampus

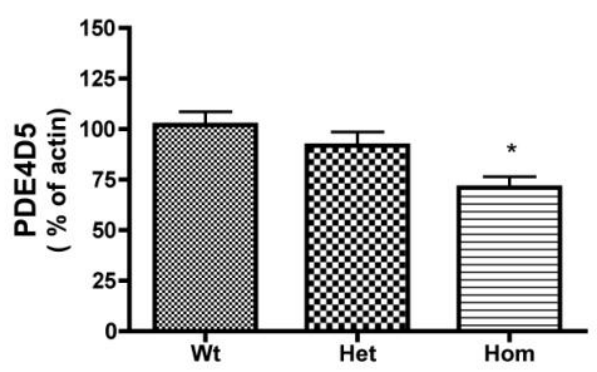

(B)

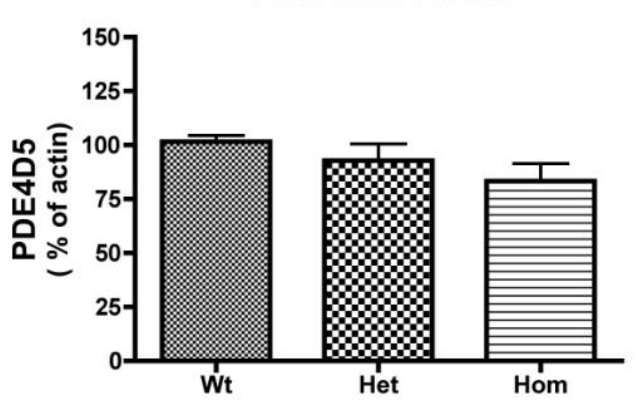

(C)

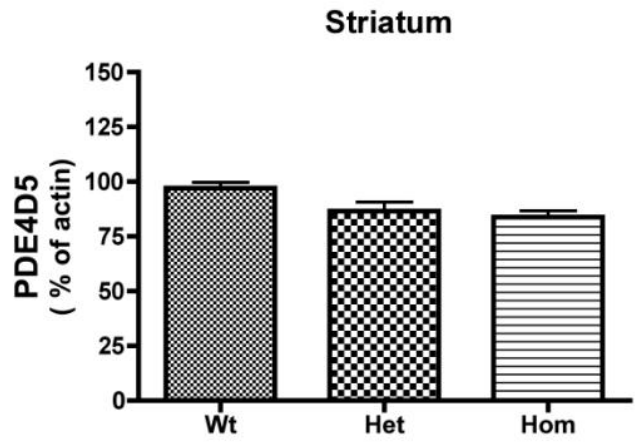


Figure 3.11

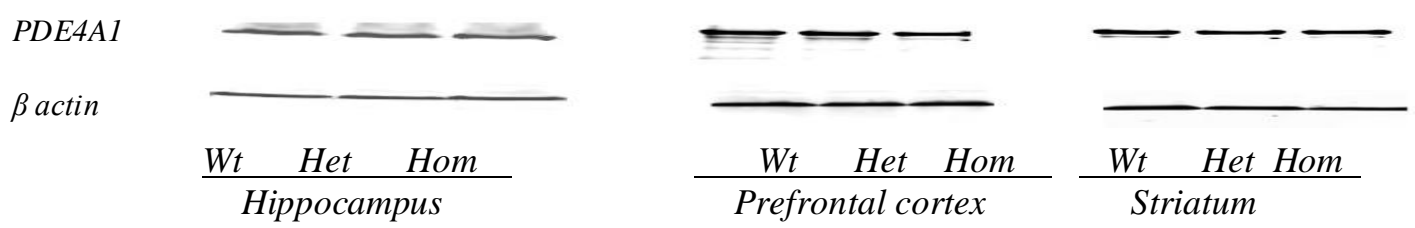

(A)

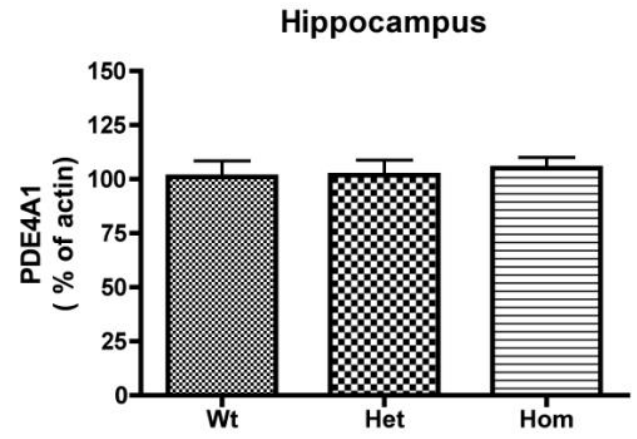

(B)

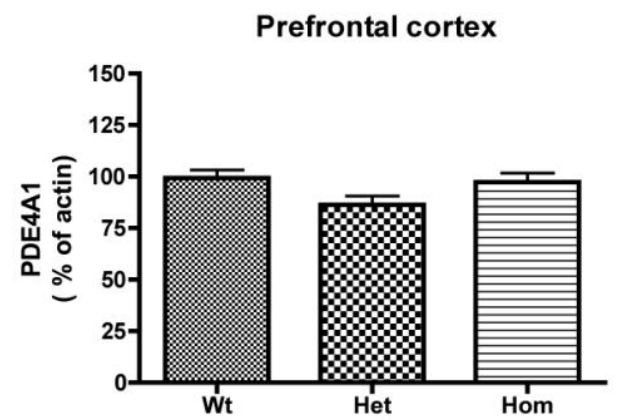

(C)

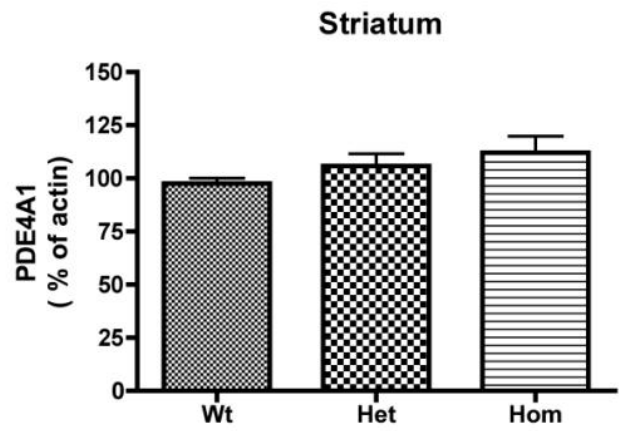


Figure 3.12

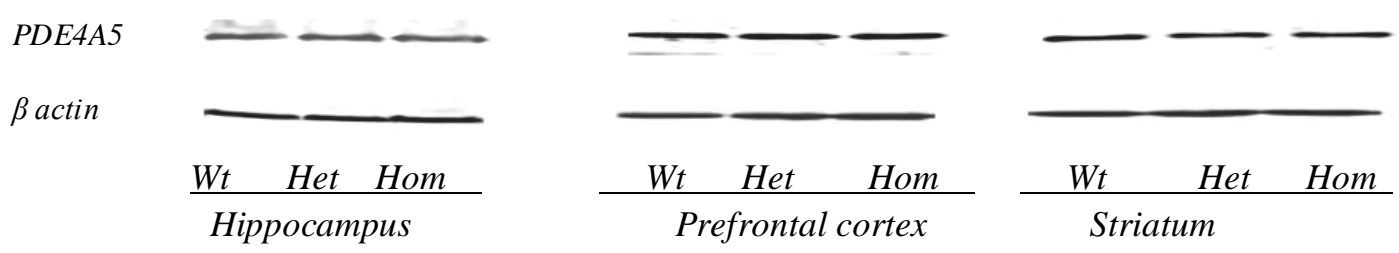

(A)

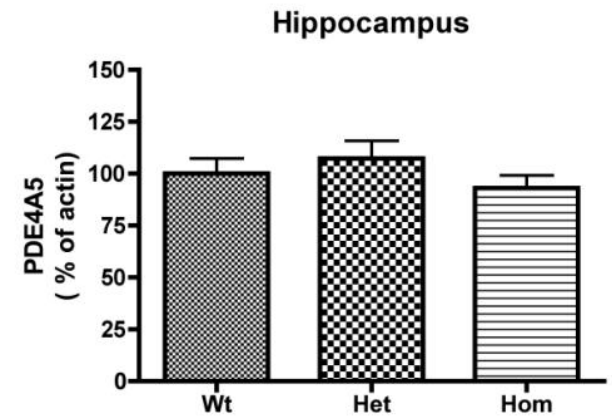

(B)

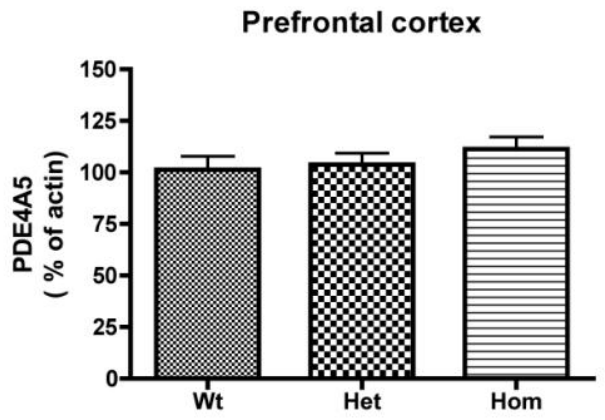

(C)

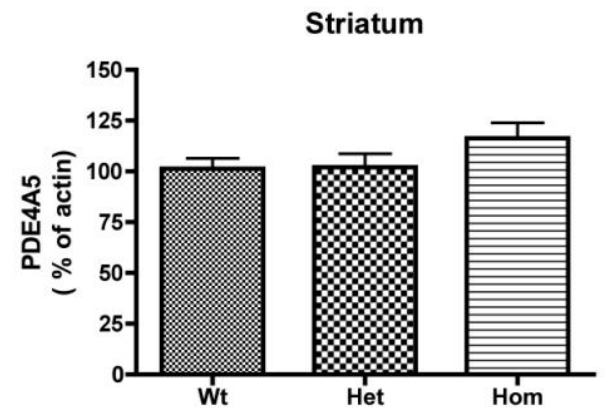


Figure 3.13

(A)

Saturation curves for $\mathrm{H}^{3}$-rolipram binding (Hippocampus)

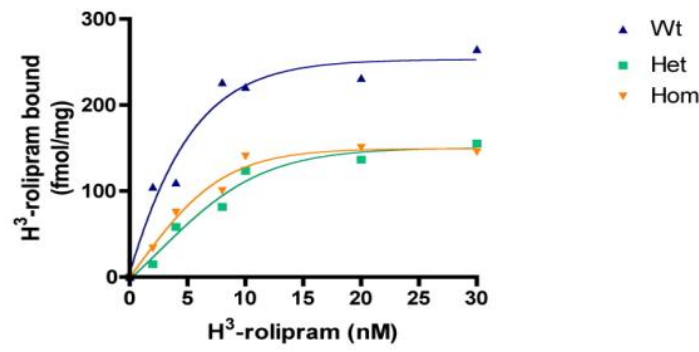

(B)

Saturation curves for $\mathrm{H}^{3}$-rolipram binding (Prefrontal cortex)

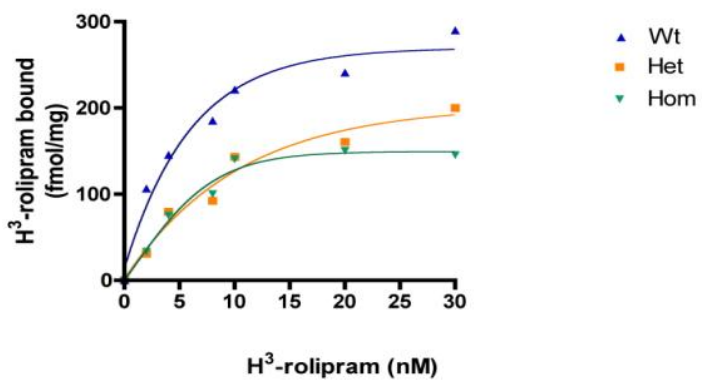

(C)

Saturation curves for $\mathrm{H}^{3}$-rolipram binding (Striatum)

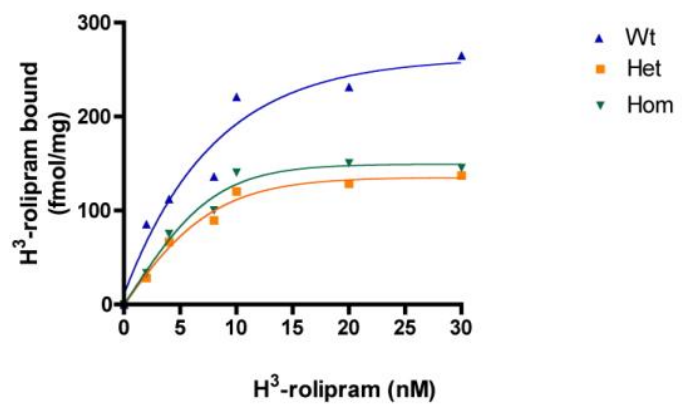




\section{Chapter 4}

Overall discussion and conclusion 
PDE4 plays a vital role in maintaining normal function of the central nervous system by modulating cAMP levels. Dysfunction of PDE4 contributes to the changes in cognitive function and impaired memory related to the symptoms in psychiatric patients (O'Donnell and Zhang, 2004). Previous studies have indicated that the specific PDE4 inhibitor rolipram has potent antidepressant effects in both animal models and patients with depression. However, despite the initial promise of PDE4 inhibitors as potent antidepressants, its clinical utility has not advanced significantly (O'Donnell and Zhang, 2004). This is due to an incomplete understanding of the function of PDE4 subtypes and the HARBS and LARBS in PDE4-mediated antidepressant-like effects. Therefore, it is of interest to know how HARBS and LARBS mediate their different pharmacological effects in the central nervous system. In the present study, we examined the differences in the effects of three PDE4 inhibitors, which have varying affinities for HARBS and LABRS, on cAMP signaling, hippocampal neurogenesis, immobility in forced-swim test, and PDE4 subtypes and the HARBS in DISC1 mutant mice.

To test the antidepressant-like effects in forced-swim test, both acute and repeated treatment were used. Acute treatment at higher doses did not produce any antidepressantlike effects as evidenced by an increase trend in immobility time likely due to the sedative effects. Repeated treatment with PDE4 inhibitors for 16 days decreased immobility significantly, compared with control groups. Compared with CDP840, which mainly interacts with the LARBS, lower doses of rolipram and piclamilast exerted greater effects in the forced-swim test. 
Compared with rolipram, piclamilast is about 1000 -fold more potent for binding to the LARBS and 40-fold more potent for binding to the HARBS (Zhao et al., 2003b). By contrast, CDP840 has a modest affinity for the LARBS and lower affinity to the HARBS. Consistent with their functions, HARBS is mainly located in the central nervous system, while LARBS in the peripheral tissues and the brain. In addition, antidepressant treatment increased HARBS but not LARBS in the brain (Zhao et al., 2003a). Taken together, the results suggest that the antidepressant-like effects of the PDE4 inhibitors are mediated predominantly by the HARBS.

In order to determine whether HARBS or LARBS is involved in the cAMP signaling and hippocampal neurogenesis, the differences in the effects of PDE4 inhibitors on cAMP/pCREB and neuronal proliferation were studied. Repeated treatment with three PDE4 inhibitors increased cAMP/pCREB signaling, but only rolipram and piclamilast enhanced hippocampal proliferation and survival. By contrast, CDP840, which has higher affinity to LARBS, failed to produce similar effects. All three compounds demonstrated antidepressant-like effects in forced-swim test, but not all of them enhanced hippocampal neurogenesis, indicating enhanced hippocampal neurogenesis is not necessary for the PDE4-inhibitor mediated antidepressant-like effects. In addition, HARBS seems to be more involved in the hippocampal neurogenesis, when compared with LARBS. These results suggest a close association between the HARBS and increased cyclic AMP signaling, neurogenesis, and antidepressant-like effects on behavior. Since side effects, including nausea and sedation, appeared to be mediated by the HARBS as well (O'Donnell and Zhang, 2004), simply modifying the affinity of PDE4 inhibitors for the HARBS might not be enough to develop better medication with fewer 
side effects. However, other alternative approaches, such as targeting the specific subtype of PDE4, might produce more desired pharmacological effects.

To determine the effects of a mutation of DISC1, one of the most important binding partners to PDE4, the PDE4 activity and PDE4 splice variants and HARBS were studied in the mouse strain carrying truncated DISC1. The mutation of DISC1 decreased PDE4 activity in three brain regions, hippocampus, prefrontal cortex and striatum, as well as increasing cAMP/pCREB levels. Similarly, previous studies have reported decreased binding of the mutant DISC1 with PDE4B in over-expression systems, coupled with decreased activity of PDE4 (Millar et al., 2005). In another DISC1 mutant line Q31L, PDE4 activity was also decreased by $50 \%$. When these mice were treated with rolipram, they seemed resistant (Clapcote et al., 2007). Rolipram resistance and decreased PDE4 activity suggest a strong correlation between an elevated cAMP signaling and the compromised DISC/PDE4 interaction. Currently, compelling biological evidence has shown that disrupted cAMP signaling mediated by the dysfunction of DISC1/PDE4B induces abnormal neurite outgrowth, axonal transport, neuronal migration (Porteous et al., 2003; Ross et al., 2006; Camargo et al., 2007; Shinoda et al., 2007; Taya et al., 2007) and thus contributes to compromised memory and learning function, and even psychotic symptoms in patients with schizophrenia (Pletnikov et al., 2007).

Though studies show that mutation of DISC1 compromised PDE4 function, it is still far from clear which subtype of PDE4 is mainly affected in the central nervous system. Molecular studies have demonstrated that DISC1 contains 2 binding sites for PDE4, 3 more specific binding sites for PDE4B (Millar et al., 2005; Murdoch et al., 2007). However, it is not clear whether DISC1 works the same way in the human central 
nervous system. In our DISC1 mutant mice, PDE4 splice variant levels, such as PDE4B1, B3 and B4, were decreased in three brain regions, and PDE4D were reduced only in the hippocampus, while no changes in PDE4A splice variants were observed. This suggests that among the PDE4 subtypes, PDE4B is a main binding partner for DISC1 and appears to be much more involved in the DISC1/PDE4 interaction. Interestingly, among the PDE4B splice variants, PDE4B2 was not decreased significantly. This may due to its structure as a short form of PDE4, which lacks of a UCR1 region. In addition, PDE4D was only altered in the hippocampus, suggesting its function is also brain region-dependent. In addition to studies showing differential regulation of PDE4 subtypes after antidepressant treatment, it appears that each PDE4 splice variants plays a variety of roles in the response to antidepressant treatment and in the development of mental disorders. However, due to the lack of specific PDE4 subtype inhibitors, the exact function of PDE4 subtypes needs more research to be fully understood.

In order to determine whether DISC1 mutation affects the HARBS, $\left[{ }^{3} \mathrm{H}\right]$-rolipram binding, which is used to label HARBS, was performed. In both homogenous and heterogeneous DISC1 mutant mice, the HARBS was decreased significantly compared with wild type mice. This suggests that the HARBS might be more sensitive to the dysfunction of DISC1 or more involved in the DISC1/PDE4 interaction. As certain PDE4 subtypes were also reduced in the same brain regions, it is very possible that most of these subtypes of PDE4 exist as HARBS in the CNS. It is also likely that the mutant DISC1 binds to any unknown cellular factors, and thus alters the conformation of PDE4, facilitating the transformation from HARBS to LARBS. 
Currently, there are several animal models of schizophrenia. In the DISC1 mutant mice used in the present study, mutation yielded a truncated DISC1 protein, which was rapidly degraded. Compared with wild type mice, these mice demonstrate deficits in working memory tasks (Koike et al., 2006; Kvajo et al., 2008), consistent with previous studies linking DISC1/PDE4 to cognition function. In other animal models, which express a dominant-negative mutant DISC1, abnormal spatial memory was also observed (Pletnikov et al., 2008). Other animal models with different DISC1 point mutations showed schizophrenia-like or depressive-like phenotypes respectively (Clapcote et al., 2007). Though these animal models revealed different behavioral abnormalities, it appears that these mouse models concur with the human genetic studies. It suggests that there are likely several routes by which DISC1 can perturb brain function leading to characteristics of human mental disorders. It is difficult to expect the phenotypes in the animal models of schizophrenia because it is believed to be the culmination of both genetic and environmentally elicited changes. Thus, these mouse models have advantages for the studying of both genetic effects and environmental impact for psychiatric disorders (Clapcote et al., 2007).

Collectively, these data characterize the function of HABRS on cAMP/pCREB signaling, hippocampal neurogenesis and its corresponding behaviors, as well as the interaction between DISC1 and PDE4. They shed light on the pharmacological effects of the HARBS and the complexity of DISC1/PDE4. However, the role of the HARBS in the central nervous system is still relatively unknown, and remains an interesting question for the future. Characterizing the alteration of downstream effectors of DISC1/PDE4 remains an important area of investigation and could provide us a better understanding of 
pathogenesis of mental disorders. It is intriguing that DISC1 interacts with PDE4, regulating cAMP signaling and altering PDE4 subtype levels. This suggests compromised cAMP signaling induced by the dysfunction of DISC1/PDE4 is critical for the development of mental disorder, and thus it will be very important to determine if the DISC1/PDE4 pathway is particularly vulnerable in neuropsychiatric disorders. 


\section{List of References}


Ahima RS and Osei SY (2001) Molecular regulation of eating behavior: new insights and prospects for therapeutic strategies. Trends Mol Med 7:205-213.

Airan RD, Meltzer LA, Roy M, Gong Y, Chen H and Deisseroth K (2007) High-speed imaging reveals neurophysiological links to behavior in an animal model of depression. Science 317:819-823.

Akiskal HS (2000) Temperament and mood disorders. Harv Ment Health Lett 16:5-6.

Altar CA (1999) Neurotrophins and depression. Trends Pharmacol Sci 20:59-61.

Arguello PA and Gogos JA (2006) Modeling madness in mice: one piece at a time. Neuron 52:179-196.

Austin CP, Ky B, Ma L, Morris JA and Shughrue PJ (2004) Expression of Disrupted-InSchizophrenia-1, a schizophrenia-associated gene, is prominent in the mouse hippocampus throughout brain development. Neuroscience 124:3-10.

Austin CP, Ma L, Ky B, Morris JA and Shughrue PJ (2003) DISC1 (Disrupted in Schizophrenia-1) is expressed in limbic regions of the primate brain. Neuroreport 14:951-954. 
Badner JA and Gershon ES (2002) Meta-analysis of whole-genome linkage scans of bipolar disorder and schizophrenia. Mol Psychiatry 7:405-411.

Balu DT, Hodes GE, Anderson BT and Lucki I (2009) Enhanced sensitivity of the MRL/MpJ mouse to the neuroplastic and behavioral effects of chronic antidepressant treatments. Neuropsychopharmacology 34:1764-1773.

Barnette MS, Bartus JO, Burman M, Christensen SB, Cieslinski LB, Esser KM, Prabhakar US, Rush JA and Torphy TJ (1996) Association of the anti-inflammatory activity of phosphodiesterase 4 (PDE4) inhibitors with either inhibition of PDE4 catalytic activity or competition for [3H]rolipram binding. Biochem Pharmacol 51:949-956.

Beavo JA and Brunton LL (2002) Cyclic nucleotide research -- still expanding after half a century. Nat Rev Mol Cell Biol 3:710-718.

Berke JD and Hyman SE (2000) Addiction, dopamine, and the molecular mechanisms of memory. Neuron 25:515-532.

Bilsland JG, Haldon C, Goddard J, Oliver K, Murray F, Wheeldon A, Cumberbatch J, McAllister G and Munoz-Sanjuan I (2006) A rapid method for the quantification of mouse hippocampal neurogenesis in vivo by flow cytometry. Validation with conventional and enhanced immunohistochemical methods. J Neurosci Methods 157:5463. 
Blackwood DH, Fordyce A, Walker MT, St Clair DM, Porteous DJ and Muir WJ (2001) Schizophrenia and affective disorders--cosegregation with a translocation at chromosome 1q42 that directly disrupts brain-expressed genes: clinical and P300 findings in a family. Am J Hum Genet 69:428-433.

Blazer DG, 2nd (2000) Controversies in community-based psychiatric epidemiology: let the data speak for themselves. Arch Gen Psychiatry 57:227-228.

Blier P (2001) Possible neurobiological mechanisms underlying faster onset of antidepressant action. J Clin Psychiatry 62 Suppl 4:7-11; discussion 37-40.

Blokland A, Schreiber R and Prickaerts J (2006) Improving memory: a role for phosphodiesterases. Curr Pharm Des 12:2511-2523.

Bolger GB, McPhee I and Houslay MD (1996) Alternative splicing of cAMP-specific phosphodiesterase mRNA transcripts. Characterization of a novel tissue-specific isoform, RNPDE4A8. J Biol Chem 271:1065-1071.

Bord L, Wheeler J, Paek M, Saleh M, Lyons-Warren A, Ross CA, Sawamura N and Sawa A (2006) Primate disrupted-in-schizophrenia-1 (DISC1): high divergence of a gene for major mental illnesses in recent evolutionary history. Neurosci Res 56:286-293.

Brandon NJ, Handford EJ, Schurov I, Rain JC, Pelling M, Duran-Jimeniz B, Camargo LM, Oliver KR, Beher D, Shearman MS and Whiting PJ (2004) Disrupted in 
Schizophrenia 1 and Nudel form a neurodevelopmentally regulated protein complex: implications for schizophrenia and other major neurological disorders. Mol Cell Neurosci 25:42-55.

Braun NN, Reutiman TJ, Lee S, Folsom TD and Fatemi SH (2007) Expression of phosphodiesterase 4 is altered in the brains of subjects with autism. Neuroreport 18:1841-1844.

Breuer ME, Groenink L, Oosting RS, Buerger E, Korte M, Ferger B and Olivier B (2009) Antidepressant effects of pramipexole, a dopamine D3/D2 receptor agonist, and 7-OHDPAT, a dopamine D3 receptor agonist, in olfactory bulbectomized rats. Eur $J$ Pharmacol 616:134-140.

Brown RW, Noel DM, Smith JJ, Smith ML, Huggins KN, Szebeni K, Szebeni A, Duffourc M, Chandley M and Ordway GA (2011) Eszopiclone facilitation of the antidepressant efficacy of fluoxetine using a social defeat stress model. Pharmacol Biochem Behav 99:648-658.

Burgin AB, Magnusson OT, Singh J, Witte P, Staker BL, Bjornsson JM, Thorsteinsdottir M, Hrafnsdottir S, Hagen T, Kiselyov AS, Stewart LJ and Gurney ME (2010) Design of phosphodiesterase 4D (PDE4D) allosteric modulators for enhancing cognition with improved safety. Nat Biotechnol 28:63-70. 
Burmeister M (1999) Basic concepts in the study of diseases with complex genetics. Biol Psychiatry 45:522-532.

Cahill L, Weinberger NM, Roozendaal B and McGaugh JL (1999) Is the amygdala a locus of "conditioned fear"? Some questions and caveats. Neuron 23:227-228.

Camargo LM, Collura V, Rain JC, Mizuguchi K, Hermjakob H, Kerrien S, Bonnert TP, Whiting PJ and Brandon NJ (2007) Disrupted in Schizophrenia 1 Interactome: evidence for the close connectivity of risk genes and a potential synaptic basis for schizophrenia. Mol Psychiatry 12:74-86.

Cameron HA and McKay RD (1999) Restoring production of hippocampal neurons in old age. Nat Neurosci 2:894-897.

Carlezon WA, Jr., Thome J, Olson VG, Lane-Ladd SB, Brodkin ES, Hiroi N, Duman RS, Neve RL and Nestler EJ (1998) Regulation of cocaine reward by CREB. Science 282:2272-2275.

Cecconi D, Mion S, Astner H, Domenici E, Righetti PG and Carboni L (2007) Proteomic analysis of rat cortical neurons after fluoxetine treatment. Brain Res 1135:41-51.

Chandrasekaran A, Toh KY, Low SH, Tay SK, Brenner S and Goh DL (2008) Identification and characterization of novel mouse PDE4D isoforms: molecular cloning, 
subcellular distribution and detection of isoform-specific intracellular localization signals. Cell Signal 20:139-153.

Chen AC, Shirayama Y, Shin KH, Neve RL and Duman RS (2001) Expression of the cAMP response element binding protein (CREB) in hippocampus produces an antidepressant effect. Biol Psychiatry 49:753-762.

Chiba S, Hashimoto R, Hattori S, Yohda M, Lipska B, Weinberger DR and Kunugi H (2006) Effect of antipsychotic drugs on DISC1 and dysbindin expression in mouse frontal cortex and hippocampus. J Neural Transm 113:1337-1346.

Chubb JE, Bradshaw NJ, Soares DC, Porteous DJ and Millar JK (2008) The DISC locus in psychiatric illness. Mol Psychiatry 13:36-64.

Clapcote SJ, Lipina TV, Millar JK, Mackie S, Christie S, Ogawa F, Lerch JP, Trimble K, Uchiyama M, Sakuraba Y, Kaneda H, Shiroishi T, Houslay MD, Henkelman RM, Sled JG, Gondo Y, Porteous DJ and Roder JC (2007) Behavioral phenotypes of Disc1 missense mutations in mice. Neuron 54:387-402.

Conti AC, Cryan JF, Dalvi A, Lucki I and Blendy JA (2002) cAMP response elementbinding protein is essential for the upregulation of brain-derived neurotrophic factor transcription, but not the behavioral or endocrine responses to antidepressant drugs. $J$ Neurosci 22:3262-3268. 
Conti M, Richter W, Mehats C, Livera G, Park JY and Jin C (2003) Cyclic AMP-specific PDE4 phosphodiesterases as critical components of cyclic AMP signaling. J Biol Chem 278:5493-5496.

D'Sa C and Duman RS (2002) Antidepressants and neuroplasticity. Bipolar Disord 4:183-194.

D'Sa C, Tolbert LM, Conti M and Duman RS (2002) Regulation of cAMP-specific phosphodiesterases type 4B and 4D (PDE4) splice variants by cAMP signaling in primary cortical neurons. J Neurochem 81:745-757.

David DJ, Klemenhagen KC, Holick KA, Saxe MD, Mendez I, Santarelli L, Craig DA, Zhong H, Swanson CJ, Hegde LG, Ping XI, Dong D, Marzabadi MR, Gerald CP and Hen R (2007) Efficacy of the MCHR1 antagonist N-[3-(1-\{[4-(3,4difluorophenoxy)phenyl]methyl\}(4-piperidyl))-4-methylphen yl]-2-methylpropanamide (SNAP 94847) in mouse models of anxiety and depression following acute and chronic administration is independent of hippocampal neurogenesis. J Pharmacol Exp Ther 321:237-248.

Davis M (1998) Are different parts of the extended amygdala involved in fear versus anxiety? Biol Psychiatry 44:1239-1247.

Davis RL, Cherry J, Dauwalder B, Han PL and Skoulakis E (1995) The cyclic AMP system and Drosophila learning. Mol Cell Biochem 149-150:271-278. 
Devon RS, Anderson S, Teague PW, Burgess P, Kipari TM, Semple CA, Millar JK, Muir WJ, Murray V, Pelosi AJ, Blackwood DH and Porteous DJ (2001) Identification of polymorphisms within Disrupted in Schizophrenia 1 and Disrupted in Schizophrenia 2, and an investigation of their association with schizophrenia and bipolar affective disorder. Psychiatr Genet 11:71-78.

Dlaboga D, Hajjhussein H and O'Donnell JM (2006) Regulation of phosphodiesterase-4 (PDE4) expression in mouse brain by repeated antidepressant treatment: comparison with rolipram. Brain Res 1096:104-112.

Dubarek W and Kucia K (2007) [Applications and safety of modern antidepressants in patients with liver diseases]. Wiad Lek 60:28-33.

Duman RS, Heninger GR and Nestler EJ (1997) A molecular and cellular theory of depression. Arch Gen Psychiatry 54:597-606.

Duman RS, Nakagawa S and Malberg J (2001) Regulation of adult neurogenesis by antidepressant treatment. Neuropsychopharmacology 25:836-844.

Duman RS and Vaidya VA (1998) Molecular and cellular actions of chronic electroconvulsive seizures. $J$ Ect 14:181-193.

Ekelund J, Hovatta I, Parker A, Paunio T, Varilo T, Martin R, Suhonen J, Ellonen P, Chan G, Sinsheimer JS, Sobel E, Juvonen H, Arajarvi R, Partonen T, Suvisaari J, 
Lonnqvist J, Meyer J and Peltonen L (2001) Chromosome 1 loci in Finnish schizophrenia families. Hum Mol Genet 10:1611-1617.

Everitt BJ, Parkinson JA, Olmstead MC, Arroyo M, Robledo P and Robbins TW (1999) Associative processes in addiction and reward. The role of amygdala-ventral striatal subsystems. Ann N Y Acad Sci 877:412-438.

Fatemi SH, Reutiman TJ, Folsom TD and Lee S (2008) Phosphodiesterase-4A expression is reduced in cerebella of patients with bipolar disorder. Psychiatr Genet 18:282-288.

Fava M and Kendler KS (2000) Major depressive disorder. Neuron 28:335-341.

Feighner JP (1999) Mechanism of action of antidepressant medications. J Clin Psychiatry 60 Suppl 4:4-11; discussion 12-13.

Finkbeiner S (2000) CREB couples neurotrophin signals to survival messages. Neuron 25:11-14.

Fleischhacker WW, Hinterhuber H, Bauer H, Pflug B, Berner P, Simhandl C, Wolf R, Gerlach W, Jaklitsch H, Sastre-y-Hernandez M and et al. (1992) A multicenter doubleblind study of three different doses of the new cAMP-phosphodiesterase inhibitor rolipram in patients with major depressive disorder. Neuropsychobiology 26:59-64. 
Francis SH, Turko IV and Corbin JD (2001) Cyclic nucleotide phosphodiesterases: relating structure and function. Prog Nucleic Acid Res Mol Biol 65:1-52.

Frechilla D, Otano A and Del Rio J (1998) Effect of chronic antidepressant treatment on transcription factor binding activity in rat hippocampus and frontal cortex. Prog Neuropsychopharmacol Biol Psychiatry 22:787-802.

Gonzalez MI, Vaziri S and Wilson CA (1996) Behavioral effects of alpha-MSH and MCH after central administration in the female rat. Peptides 17:171-177.

Hajjhussein H, Suvarna NU, Gremillion C, Chandler LJ and O'Donnell JM (2007) Changes in NMDA receptor-induced cyclic nucleotide synthesis regulate the agedependent increase in PDE4A expression in primary cortical cultures. Brain Res 1149:5868.

Hajszan T, Szigeti-Buck K, Sallam NL, Bober J, Parducz A, Maclusky NJ, Leranth C and Duman RS (2009) Effects of Estradiol on Learned Helplessness and Associated Remodeling of Hippocampal Spine Synapses in Female Rats. Biol Psychiatry.

Hall J, Thomas KL and Everitt BJ (2001) Fear memory retrieval induces CREB phosphorylation and Fos expression within the amygdala. Eur J Neurosci 13:1453-1458.

Hall RD, Bloom FE and Olds J (1977) Neuronal and neurochemical substrates of reinforcement. Neurosci Res Program Bull 15:131-314. 
Halpain S and Dehmelt L (2006) The MAP1 family of microtubule-associated proteins. Genome Biol 7:224.

Hashimoto A, Miyakoda G, Hirose Y and Mori T (2006) Activation of endothelial nitric oxide synthase by cilostazol via a cAMP/protein kinase A- and phosphatidylinositol 3kinase/Akt-dependent mechanism. Atherosclerosis 189:350-357.

Hattori T, Baba K, Matsuzaki S, Honda A, Miyoshi K, Inoue K, Taniguchi M, Hashimoto H, Shintani N, Baba A, Shimizu S, Yukioka F, Kumamoto N, Yamaguchi A, Tohyama M and Katayama T (2007) A novel DISC1-interacting partner DISC1-Binding Zinc-finger protein: implication in the modulation of DISC1-dependent neurite outgrowth. Mol Psychiatry 12:398-407.

Hayashi MA, Portaro FC, Bastos MF, Guerreiro JR, Oliveira V, Gorrao SS, Tambourgi DV, Sant'Anna OA, Whiting PJ, Camargo LM, Konno K, Brandon NJ and Camargo AC (2005) Inhibition of NUDEL (nuclear distribution element-like)-oligopeptidase activity by disrupted-in-schizophrenia 1. Proc Natl Acad Sci U S A 102:3828-3833.

Hitzemann R (2000) Animal models of psychiatric disorders and their relevance to alcoholism. Alcohol Res Health 24:149-158.

Hodgkinson CA, Goldman D, Jaeger J, Persaud S, Kane JM, Lipsky RH and Malhotra AK (2004) Disrupted in schizophrenia 1 (DISC1): association with schizophrenia, schizoaffective disorder, and bipolar disorder. Am J Hum Genet 75:862-872. 
Holick KA, Lee DC, Hen R and Dulawa SC (2008) Behavioral effects of chronic fluoxetine in $\mathrm{BALB} / \mathrm{cJ}$ mice do not require adult hippocampal neurogenesis or the serotonin 1A receptor. Neuropsychopharmacology 33:406-417.

Honda A, Miyoshi K, Baba K, Taniguchi M, Koyama Y, Kuroda S, Katayama T and Tohyama M (2004) Expression of fasciculation and elongation protein zeta-1 (FEZ1) in the developing rat brain. Brain Res Mol Brain Res 122:89-92.

Horger BA, Iyasere CA, Berhow MT, Messer CJ, Nestler EJ and Taylor JR (1999) Enhancement of locomotor activity and conditioned reward to cocaine by brain-derived neurotrophic factor. J Neurosci 19:4110-4122.

Houslay MD and Adams DR (2003) PDE4 cAMP phosphodiesterases: modular enzymes that orchestrate signalling cross-talk, desensitization and compartmentalization. Biochem J 370:1-18.

Houslay MD and Baillie GS (2005) Beta-arrestin-recruited phosphodiesterase-4 desensitizes the AKAP79/PKA-mediated switching of beta2-adrenoceptor signalling to activation of ERK. Biochem Soc Trans 33:1333-1336.

Houslay MD, Baillie GS and Maurice DH (2007) cAMP-Specific phosphodiesterase-4 enzymes in the cardiovascular system: a molecular toolbox for generating compartmentalized cAMP signaling. Circ Res 100:950-966. 
Huot RL, Thrivikraman KV, Meaney MJ and Plotsky PM (2001) Development of adult ethanol preference and anxiety as a consequence of neonatal maternal separation in Long Evans rats and reversal with antidepressant treatment. Psychopharmacology (Berl) 158:366-373.

Ikuta T, Furuta N, Kihara S, Okura M, Nagamine I, Nakayama H, Ishimoto Y, Kaneda Y, Tomotake M, Izaki Y and Ming X (2007) Differences in waveforms of cerebral evoked potentials among healthy subjects, schizophrenics, manic-depressives and epileptics. $J$ Med Invest 54:303-315.

Ishizuka K, Paek M, Kamiya A and Sawa A (2006) A review of Disrupted-InSchizophrenia-1 (DISC1): neurodevelopment, cognition, and mental conditions. Biol Psychiatry 59:1189-1197.

Itoh T, Tokumura M and Abe K (2004) Effects of rolipram, a phosphodiesterase 4 inhibitor, in combination with imipramine on depressive behavior, CRE-binding activity and BDNF level in learned helplessness rats. Eur J Pharmacol 498:135-142.

Jacobitz S, McLaughlin MM, Livi GP, Burman M and Torphy TJ (1996) Mapping the functional domains of human recombinant phosphodiesterase 4A: structural requirements for catalytic activity and rolipram binding. Mol Pharmacol 50:891-899. 
Jentsch JD, Olausson P, Nestler EJ and Taylor JR (2002) Stimulation of protein kinase a activity in the rat amygdala enhances reward-related learning. Biol Psychiatry 52:111118.

Jeon SH, Seong YS, Juhnn YS, Kang UG, Ha KS, Kim YS and Park JB (1997) Electroconvulsive shock increases the phosphorylation of cyclic AMP response element binding protein at Ser-133 in rat hippocampus but not in cerebellum. Neuropharmacology 36:411-414.

Johnston LA, Erdogan S, Cheung YF, Sullivan M, Barber R, Lynch MJ, Baillie GS, Van Heeke G, Adams DR, Huston E and Houslay MD (2004) Expression, intracellular distribution and basis for lack of catalytic activity of the PDE4A7 isoform encoded by the human PDE4A cAMP-specific phosphodiesterase gene. Biochem J 380:371-384.

Josselyn SA, Shi C, Carlezon WA, Jr., Neve RL, Nestler EJ and Davis M (2001) Longterm memory is facilitated by cAMP response element-binding protein overexpression in the amygdala. $J$ Neurosci 21:2404-2412.

Kamiya A, Kubo K, Tomoda T, Takaki M, Youn R, Ozeki Y, Sawamura N, Park U, Kudo C, Okawa M, Ross CA, Hatten ME, Nakajima K and Sawa A (2005) A schizophrenia-associated mutation of DISC1 perturbs cerebral cortex development. Nat Cell Biol 7:1167-1178. 
Kaulen P, Bruning G, Schneider HH, Sarter M and Baumgarten HG (1989) Autoradiographic mapping of a selective cyclic adenosine monophosphate phosphodiesterase in rat brain with the antidepressant [3H]rolipram. Brain Res 503:229245.

Kirkpatrick B, Xu L, Cascella N, Ozeki Y, Sawa A and Roberts RC (2006) DISC1 immunoreactivity at the light and ultrastructural level in the human neocortex. $J$ Comp Neurol 497:436-450.

Koike H, Arguello PA, Kvajo M, Karayiorgou M and Gogos JA (2006) Disc1 is mutated in the $129 \mathrm{~S} 6 / \mathrm{SvEv}$ strain and modulates working memory in mice. Proc Natl Acad Sci U S A 103:3693-3697.

Koob GF (1999) Stress, corticotropin-releasing factor, and drug addiction. Ann N Y Acad Sci 897:27-45.

Koob GF, Sanna PP and Bloom FE (1998) Neuroscience of addiction. Neuron 21:467476.

Kuroda Y and McEwen BS (1998) Effect of chronic restraint stress and tianeptine on growth factors, growth-associated protein-43 and microtubule-associated protein 2 mRNA expression in the rat hippocampus. Brain Res Mol Brain Res 59:35-39. 
Kvajo M, McKellar H, Arguello PA, Drew LJ, Moore H, MacDermott AB, Karayiorgou M and Gogos JA (2008) A mutation in mouse Disc1 that models a schizophrenia risk allele leads to specific alterations in neuronal architecture and cognition. Proc Natl Acad Sci U S A 105:7076-7081.

Li S, Wang C, Wang M, Li W, Matsumoto K and Tang Y (2007) Antidepressant like effects of piperine in chronic mild stress treated mice and its possible mechanisms. Life Sci 80:1373-1381.

Li YF, Huang Y, Amsdell SL, Xiao L, O'Donnell JM and Zhang HT (2009) Antidepressant- and anxiolytic-like effects of the phosphodiesterase-4 inhibitor rolipram on behavior depend on cyclic AMP response element binding protein-mediated neurogenesis in the hippocampus. Neuropsychopharmacology 34:2404-2419.

Lipska BK, Mitkus SN, Mathew SV, Fatula R, Hyde TM, Weinberger DR and Kleinman JE (2006) Functional genomics in postmortem human brain: abnormalities in a DISC1 molecular pathway in schizophrenia. Dialogues Clin Neurosci 8:353-357.

Liu YL, Fann CS, Liu CM, Chen WJ, Wu JY, Hung SI, Chen CH, Jou YS, Liu SK, Hwang TJ, Hsieh MH, Ouyang WC, Chan HY, Chen JJ, Yang WC, Lin CY, Lee SF and Hwu HG (2006) A single nucleotide polymorphism fine mapping study of chromosome 1q42.1 reveals the vulnerability genes for schizophrenia, GNPAT and DISC1: Association with impairment of sustained attention. Biol Psychiatry 60:554-562. 
Lucki I (2001) A prescription to resist proscriptions for murine models of depression. Psychopharmacology (Berl) 153:395-398.

Lugnier C (2006) Cyclic nucleotide phosphodiesterase (PDE) superfamily: a new target for the development of specific therapeutic agents. Pharmacol Ther 109:366-398.

Lynch MJ, Hill EV and Houslay MD (2006) Intracellular targeting of phosphodiesterase4 underpins compartmentalized cAMP signaling. Curr Top Dev Biol 75:225-259.

Lynex CN, Li Z, Chen ML, Toh KY, Low RW, Goh DL and Tay SK (2008) Identification and molecular characterization of a novel PDE4D11 cAMP-specific phosphodiesterase isoform. Cell Signal 20:2247-2255.

MacKenzie SJ, Baillie GS, McPhee I, MacKenzie C, Seamons R, McSorley T, Millen J, Beard MB, van Heeke G and Houslay MD (2002) Long PDE4 cAMP specific phosphodiesterases are activated by protein kinase A-mediated phosphorylation of a single serine residue in Upstream Conserved Region 1 (UCR1). Br J Pharmacol 136:421433.

Mackie S, Millar JK and Porteous DJ (2007) Role of DISC1 in neural development and schizophrenia. Curr Opin Neurobiol 17:95-102. 
Maeda K, Nwulia E, Chang J, Balkissoon R, Ishizuka K, Chen H, Zandi P, McInnis MG and Sawa A (2006) Differential expression of disrupted-in-schizophrenia (DISC1) in bipolar disorder. Biol Psychiatry 60:929-935.

Manji HK, Quiroz JA, Sporn J, Payne JL, Denicoff K, N AG, Zarate CA, Jr. and Charney DS (2003) Enhancing neuronal plasticity and cellular resilience to develop novel, improved therapeutics for difficult-to-treat depression. Biol Psychiatry 53:707-742.

Mao Y, Ge X, Frank CL, Madison JM, Koehler AN, Doud MK, Tassa C, Berry EM, Soda T, Singh KK, Biechele T, Petryshen TL, Moon RT, Haggarty SJ and Tsai LH (2009) Disrupted in schizophrenia 1 regulates neuronal progenitor proliferation via modulation of GSK3beta/beta-catenin signaling. Cell 136:1017-1031.

Marx J (2007) Behavioral genetics. Evidence linking DISC1 gene to mental illness builds. Science 318:1062-1063.

McCahill A, McSorley T, Huston E, Hill EV, Lynch MJ, Gall I, Keryer G, Lygren B, Tasken K, van Heeke G and Houslay MD (2005) In resting COS1 cells a dominant negative approach shows that specific, anchored PDE4 cAMP phosphodiesterase isoforms gate the activation, by basal cyclic AMP production, of AKAP-tethered protein kinase A type II located in the centrosomal region. Cell Signal 17:1158-1173. 
Middleton FA, Peng L, Lewis DA, Levitt P and Mirnics K (2005) Altered expression of 14-3-3 genes in the prefrontal cortex of subjects with schizophrenia. Neuropsychopharmacology 30:974-983.

Millar JK, Christie S, Semple CA and Porteous DJ (2000a) Chromosomal location and genomic structure of the human translin-associated factor X gene (TRAX; TSNAX) revealed by intergenic splicing to DISC1, a gene disrupted by a translocation segregating with schizophrenia. Genomics 67:69-77.

Millar JK, James R, Brandon NJ and Thomson PA (2004) DISC1 and DISC2: discovering and dissecting molecular mechanisms underlying psychiatric illness. Ann Med 36:367-378.

Millar JK, Mackie S, Clapcote SJ, Murdoch H, Pickard BS, Christie S, Muir WJ, Blackwood DH, Roder JC, Houslay MD and Porteous DJ (2007) Disrupted in schizophrenia 1 and phosphodiesterase 4B: towards an understanding of psychiatric illness. J Physiol 584:401-405.

Millar JK, Pickard BS, Mackie S, James R, Christie S, Buchanan SR, Malloy MP, Chubb JE, Huston E, Baillie GS, Thomson PA, Hill EV, Brandon NJ, Rain JC, Camargo LM, Whiting PJ, Houslay MD, Blackwood DH, Muir WJ and Porteous DJ (2005) DISC1 and PDE4B are interacting genetic factors in schizophrenia that regulate cAMP signaling. Science 310:1187-1191. 
Millar JK, Wilson-Annan JC, Anderson S, Christie S, Taylor MS, Semple CA, Devon RS, St Clair DM, Muir WJ, Blackwood DH and Porteous DJ (2000b) Disruption of two novel genes by a translocation co-segregating with schizophrenia. Hum Mol Genet 9:1415-1423.

Miyoshi K, Honda A, Baba K, Taniguchi M, Oono K, Fujita T, Kuroda S, Katayama T and Tohyama M (2003) Disrupted-In-Schizophrenia 1, a candidate gene for schizophrenia, participates in neurite outgrowth. Mol Psychiatry 8:685-694.

Monti B, Berteotti C and Contestabile A (2006) Subchronic rolipram delivery activates hippocampal CREB and arc, enhances retention and slows down extinction of conditioned fear. Neuropsychopharmacology 31:278-286.

Monzon ME, Varas MM and De Barioglio SR (2001) Anxiogenesis induced by nitric oxide synthase inhibition and anxiolytic effect of melanin-concentrating hormone (MCH) in rat brain. Peptides 22:1043-1047.

Morris JA, Kandpal G, Ma L and Austin CP (2003) DISC1 (Disrupted-In-Schizophrenia 1) is a centrosome-associated protein that interacts with MAP1A, MIPT3, ATF4/5 and NUDEL: regulation and loss of interaction with mutation. Hum Mol Genet 12:1591-1608.

Murdoch H, Mackie S, Collins DM, Hill EV, Bolger GB, Klussmann E, Porteous DJ, Millar JK and Houslay MD (2007) Isoform-selective susceptibility of 
DISC1/phosphodiesterase-4 complexes to dissociation by elevated intracellular cAMP levels. J Neurosci 27:9513-9524.

Nakagawa S, Kim JE, Lee R, Malberg JE, Chen J, Steffen C, Zhang YJ, Nestler EJ and Duman RS (2002) Regulation of neurogenesis in adult mouse hippocampus by cAMP and the cAMP response element-binding protein. J Neurosci 22:3673-3682.

Nelson JC (1997) Safety and tolerability of the new antidepressants. J Clin Psychiatry 58 Suppl 6:26-31.

Nemoz G, Sette C and Conti M (1997) Selective activation of rolipram-sensitive, cAMPspecific phosphodiesterase isoforms by phosphatidic acid. Mol Pharmacol 51:242-249.

Nestler EJ (2001) Molecular neurobiology of addiction. Am J Addict 10:201-217.

Nestler EJ, Barrot M, DiLeone RJ, Eisch AJ, Gold SJ and Monteggia LM (2002) Neurobiology of depression. Neuron 34:13-25.

Nibuya M, Morinobu S and Duman RS (1995) Regulation of BDNF and trkB mRNA in rat brain by chronic electroconvulsive seizure and antidepressant drug treatments. $J$ Neurosci 15:7539-7547. 
Nibuya M, Nestler EJ and Duman RS (1996) Chronic antidepressant administration increases the expression of cAMP response element binding protein (CREB) in rat hippocampus. J Neurosci 16:2365-2372.

O'Callaghan JP and Sriram K (2004) Focused microwave irradiation of the brain preserves in vivo protein phosphorylation: comparison with other methods of sacrifice and analysis of multiple phosphoproteins. J Neurosci Methods 135:159-168.

O'Donnell JM (1993) Antidepressant-like effects of rolipram and other inhibitors of cyclic adenosine monophosphate phosphodiesterase on behavior maintained by differential reinforcement of low response rate. J Pharmacol Exp Ther 264:1168-1178.

O'Donnell JM, Marek GJ and Seiden LS (2005) Antidepressant effects assessed using behavior maintained under a differential-reinforcement-of-low-rate (DRL) operant schedule. Neurosci Biobehav Rev 29:785-798.

O'Donnell JM and Seiden LS (1983) Differential-reinforcement-of-low-rate 72-second schedule: selective effects of antidepressant drugs. J Pharmacol Exp Ther 224:80-88.

O'Donnell JM, Wolfe BB and Frazer A (1984) Agonist interactions with beta adrenergic receptors in rat brain. J Pharmacol Exp Ther 228:640-647.

O'Donnell JM and Zhang HT (2004) Antidepressant effects of inhibitors of cAMP phosphodiesterase (PDE4). Trends Pharmacol Sci 25:158-163. 
Ozeki Y, Tomoda T, Kleiderlein J, Kamiya A, Bord L, Fujii K, Okawa M, Yamada N, Hatten ME, Snyder SH, Ross CA and Sawa A (2003) Disrupted-in-Schizophrenia-1 (DISC-1): mutant truncation prevents binding to NudE-like (NUDEL) and inhibits neurite outgrowth. Proc Natl Acad Sci U S A 100:289-294.

Pacher P and Kecskemeti V (2004) Trends in the development of new antidepressants. Is there a light at the end of the tunnel? Curr Med Chem 11:925-943.

Page ME, Detke MJ, Dalvi A, Kirby LG and Lucki I (1999) Serotonergic mediation of the effects of fluoxetine, but not desipramine, in the rat forced swimming test. Psychopharmacology (Berl) 147:162-167.

Pickard BS, Millar JK, Porteous DJ, Muir WJ and Blackwood DH (2005) Cytogenetics and gene discovery in psychiatric disorders. Pharmacogenomics J 5:81-88.

Pickard BS, Thomson PA, Christoforou A, Evans KL, Morris SW, Porteous DJ, Blackwood DH and Muir WJ (2007) The PDE4B gene confers sex-specific protection against schizophrenia. Psychiatr Genet 17:129-133.

Pletnikov MV, Ayhan Y, Nikolskaia O, Xu Y, Ovanesov MV, Huang H, Mori S, Moran TH and Ross CA (2008) Inducible expression of mutant human DISC1 in mice is associated with brain and behavioral abnormalities reminiscent of schizophrenia. Mol Psychiatry 13:173-186, 115. 
Pletnikov MV, Xu Y, Ovanesov MV, Kamiya A, Sawa A and Ross CA (2007) PC12 cell model of inducible expression of mutant DISC1: new evidence for a dominant-negative mechanism of abnormal neuronal differentiation. Neurosci Res 58:234-244.

Pliakas AM, Carlson RR, Neve RL, Konradi C, Nestler EJ and Carlezon WA, Jr. (2001) Altered responsiveness to cocaine and increased immobility in the forced swim test associated with elevated cAMP response element-binding protein expression in nucleus accumbens. J Neurosci 21:7397-7403.

Porsolt RD (2000) Animal models of depression: utility for transgenic research. Rev Neurosci 11:53-58.

Porteous DJ, Evans KL, Millar JK, Pickard BS, Thomson PA, James R, MacGregor S, Wray NR, Visscher PM, Muir WJ and Blackwood DH (2003) Genetics of schizophrenia and bipolar affective disorder: strategies to identify candidate genes. Cold Spring Harb Symp Quant Biol 68:383-394.

Reeves ML, Leigh BK and England PJ (1987) The identification of a new cyclic nucleotide phosphodiesterase activity in human and guinea-pig cardiac ventricle. Implications for the mechanism of action of selective phosphodiesterase inhibitors. Biochem J 241:535-541.

Roberts RC (2007) Schizophrenia in translation: disrupted in schizophrenia (DISC1): integrating clinical and basic findings. Schizophr Bull 33:11-15. 
Rodgers RJ and Dalvi A (1997) Anxiety, defence and the elevated plus-maze. Neurosci Biobehav Rev 21:801-810.

Ross CA, Margolis RL, Reading SA, Pletnikov M and Coyle JT (2006) Neurobiology of schizophrenia. Neuron 52:139-153.

Rutten K, Misner DL, Works M, Blokland A, Novak TJ, Santarelli L and Wallace TL (2008) Enhanced long-term potentiation and impaired learning in phosphodiesterase 4Dknockout (PDE4D) mice. Eur J Neurosci 28:625-632.

Saccomano NA, Vinick FJ, Koe BK, Nielsen JA, Whalen WM, Meltz M, Phillips D, Thadieo PF, Jung S, Chapin DS and et al. (1991) Calcium-independent phosphodiesterase inhibitors as putative antidepressants: [3-(bicycloalkyloxy)-4-methoxyphenyl]-2imidazolidinones. J Med Chem 34:291-298.

Sahay A and Hen R (2007) Adult hippocampal neurogenesis in depression. Nat Neurosci 10:1110-1115.

Santarelli L, Saxe M, Gross C, Surget A, Battaglia F, Dulawa S, Weisstaub N, Lee J, Duman R, Arancio O, Belzung C and Hen R (2003) Requirement of hippocampal neurogenesis for the behavioral effects of antidepressants. Science 301:805-809. 
Scharf MT, Mackiewicz M, Naidoo N, O'Callaghan JP and Pack AI (2008) AMPactivated protein kinase phosphorylation in brain is dependent on method of killing and tissue preparation. J Neurochem 105:833-841.

Schmiechen R, Schneider HH and Wachtel H (1990) Close correlation between behavioural response and binding in vivo for inhibitors of the rolipram-sensitive phosphodiesterase. Psychopharmacology (Berl) 102:17-20.

Schneider HH, Schmiechen R, Brezinski M and Seidler J (1986) Stereospecific binding of the antidepressant rolipram to brain protein structures. Eur J Pharmacol 127:105-115.

Schurov IL, Handford EJ, Brandon NJ and Whiting PJ (2004) Expression of disrupted in schizophrenia 1 (DISC1) protein in the adult and developing mouse brain indicates its role in neurodevelopment. Mol Psychiatry 9:1100-1110.

Semple CA, Devon RS, Le Hellard S and Porteous DJ (2001) Identification of genes from a schizophrenia-linked translocation breakpoint region. Genomics 73:123-126.

Sette C and Conti M (1996) Phosphorylation and activation of a cAMP-specific phosphodiesterase by the cAMP-dependent protein kinase. Involvement of serine 54 in the enzyme activation. J Biol Chem 271:16526-16534.

Shaw-Lutchman TZ, Barrot M, Wallace T, Gilden L, Zachariou V, Impey S, Duman RS, Storm D and Nestler EJ (2002) Regional and cellular mapping of cAMP response 
element-mediated transcription during naltrexone-precipitated morphine withdrawal. $J$ Neurosci 22:3663-3672.

Shinoda T, Taya S, Tsuboi D, Hikita T, Matsuzawa R, Kuroda S, Iwamatsu A and Kaibuchi K (2007) DISC1 regulates neurotrophin-induced axon elongation via interaction with Grb2. J Neurosci 27:4-14.

Siuciak JA (2008) The role of phosphodiesterases in schizophrenia : therapeutic implications. CNS Drugs 22:983-993.

Siuciak JA, Chapin DS, McCarthy SA and Martin AN (2007) Antipsychotic profile of rolipram: efficacy in rats and reduced sensitivity in mice deficient in the phosphodiesterase-4B (PDE4B) enzyme. Psychopharmacology (Berl) 192:415-424.

Smith MA, Makino S, Kvetnansky R and Post RM (1995) Stress and glucocorticoids affect the expression of brain-derived neurotrophic factor and neurotrophin-3 mRNAs in the hippocampus. J Neurosci 15:1768-1777.

Smith PK, Krohn RI, Hermanson GT, Mallia AK, Gartner FH, Provenzano MD, Fujimoto EK, Goeke NM, Olson BJ and Klenk DC (1985) Measurement of protein using bicinchoninic acid. Anal Biochem 150:76-85.

Souness JE and Rao S (1997) Proposal for pharmacologically distinct conformers of PDE4 cyclic AMP phosphodiesterases. Cell Signal 9:227-236. 
St Clair D, Blackwood D, Muir W, Carothers A, Walker M, Spowart G, Gosden C and Evans HJ (1990) Association within a family of a balanced autosomal translocation with major mental illness. Lancet 336:13-16.

Stahl SM (1998) Basic psychopharmacology of antidepressants, part 1: Antidepressants have seven distinct mechanisms of action. J Clin Psychiatry 59 Suppl 4:5-14.

Takahashi M, Palmer TD, Takahashi J and Gage FH (1998) Widespread integration and survival of adult-derived neural progenitor cells in the developing optic retina. Mol Cell Neurosci 12:340-348.

Takahashi M, Terwilliger R, Lane C, Mezes PS, Conti M and Duman RS (1999) Chronic antidepressant administration increases the expression of cAMP-specific phosphodiesterase 4A and 4B isoforms. J Neurosci 19:610-618.

Tanis KQ and Duman RS (2007) Intracellular signaling pathways pave roads to recovery for mood disorders. Ann Med 39:531-544.

Tao X, Finkbeiner S, Arnold DB, Shaywitz AJ and Greenberg ME (1998) Ca2+ influx regulates $\mathrm{BDNF}$ transcription by a CREB family transcription factor-dependent mechanism. Neuron 20:709-726. 
Taya S, Shinoda T, Tsuboi D, Asaki J, Nagai K, Hikita T, Kuroda S, Kuroda K, Shimizu M, Hirotsune S, Iwamatsu A and Kaibuchi K (2007) DISC1 regulates the transport of the NUDEL/LIS1/14-3-3epsilon complex through kinesin-1. J Neurosci 27:15-26.

Thompson WJ and Appleman MM (1971a) Cyclic nucleotide phosphodiesterase and cyclic AMP. Ann N Y Acad Sci 185:36-41.

Thompson WJ and Appleman MM (1971b) Multiple cyclic nucleotide phosphodiesterase activities from rat brain. Biochemistry 10:311-316.

Thomson PA, Wray NR, Millar JK, Evans KL, Hellard SL, Condie A, Muir WJ, Blackwood DH and Porteous DJ (2005) Association between the TRAX/DISC locus and both bipolar disorder and schizophrenia in the Scottish population. Mol Psychiatry 10:657-668, 616 .

Vaidya VA, Marek GJ, Aghajanian GK and Duman RS (1997) 5-HT2A receptormediated regulation of brain-derived neurotrophic factor mRNA in the hippocampus and the neocortex. J Neurosci 17:2785-2795.

van Hest A, van Drimmelen M and Olivier B (1992) Flesinoxan shows antidepressant activity in a DRL 72-s screen. Psychopharmacology (Berl) 107:474-479.

van Praag H, Shubert T, Zhao C and Gage FH (2005) Exercise enhances learning and hippocampal neurogenesis in aged mice. J Neurosci 25:8680-8685. 
Wachtel H and Loschmann PA (1986) Effects of forskolin and cyclic nucleotides in animal models predictive of antidepressant activity: interactions with rolipram. Psychopharmacology (Berl) 90:430-435.

Wachtel H and Schneider HH (1986) Rolipram, a novel antidepressant drug, reverses the hypothermia and hypokinesia of monoamine-depleted mice by an action beyond postsynaptic monoamine receptors. Neuropharmacology 25:1119-1126.

Wang JW, David DJ, Monckton JE, Battaglia F and Hen R (2008) Chronic fluoxetine stimulates maturation and synaptic plasticity of adult-born hippocampal granule cells. $J$ Neurosci 28:1374-1384.

Willie JT, Chemelli RM, Sinton CM and Yanagisawa M (2001) To eat or to sleep? Orexin in the regulation of feeding and wakefulness. Annu Rev Neurosci 24:429-458.

Willner P (1995) Animal models of depression: validity and applications. Adv Biochem Psychopharmacol 49:19-41.

Willner P, Towell A, Sampson D, Sophokleous S and Muscat R (1987) Reduction of sucrose preference by chronic unpredictable mild stress, and its restoration by a tricyclic antidepressant. Psychopharmacology (Berl) 93:358-364.

Wise RA (1996) Addictive drugs and brain stimulation reward. Annu Rev Neurosci 19:319-340. 
Ye Y, Jackson K and O'Donnell JM (2000) Effects of repeated antidepressant treatment of type 4A phosphodiesterase (PDE4A) in rat brain. J Neurochem 74:1257-1262.

Zeller E, Stief HJ, Pflug B and Sastre-y-Hernandez M (1984) Results of a phase II study of the antidepressant effect of rolipram. Pharmacopsychiatry 17:188-190.

Zhang HT (2009) Cyclic AMP-specific phosphodiesterase-4 as a target for the development of antidepressant drugs. Curr Pharm Des 15:1688-1698.

Zhang HT, Huang Y, Jin SL, Frith SA, Suvarna N, Conti M and O'Donnell JM (2002) Antidepressant-like profile and reduced sensitivity to rolipram in mice deficient in the PDE4D phosphodiesterase enzyme. Neuropsychopharmacology 27:587-595.

Zhang HT, Huang Y, Masood A, Stolinski LR, Li Y, Zhang L, Dlaboga D, Jin SL, Conti M and O'Donnell J M (2007) Anxiogenic-Like Behavioral Phenotype of Mice Deficient in Phosphodiesterase 4B (PDE4B). Neuropsychopharmacology.

Zhang HT, Huang Y, Masood A, Stolinski LR, Li Y, Zhang L, Dlaboga D, Jin SL, Conti M and O'Donnell JM (2008) Anxiogenic-like behavioral phenotype of mice deficient in phosphodiesterase 4B (PDE4B). Neuropsychopharmacology 33:1611-1623.

Zhang HT, Zhao Y, Huang Y, Deng C, Hopper AT, De Vivo M, Rose GM and O'Donnell JM (2006) Antidepressant-like effects of PDE4 inhibitors mediated by the high-affinity 
rolipram binding state (HARBS) of the phosphodiesterase-4 enzyme (PDE4) in rats. Psychopharmacology (Berl) 186:209-217.

Zhao Y, Zhang HT and O'Donnell JM (2003a) Antidepressant-induced increase in highaffinity rolipram binding sites in rat brain: dependence on noradrenergic and serotonergic function. J Pharmacol Exp Ther 307:246-253.

Zhao Y, Zhang HT and O'Donnell JM (2003b) Inhibitor binding to type 4 phosphodiesterase (PDE4) assessed using [3H]piclamilast and $[3 \mathrm{H}]$ rolipram. $J$ Pharmacol Exp Ther 305:565-572. 


\section{Lan Xiao, M.D., Ph.D.}

Department of Pharmacology and Pharmaceutical Sciences

West Virginia University

1 Medical Center Drive

Morgantown, WV 26506

laxiao@hsc.wvu.edu

\section{Curriculum Vitae}

\section{Education}

2011 Ph.D. West Virginia University, Morgantown, WV, USA

2003 M.S. Norman Bethune Medical School, Jilin University, China

2000 M.D. Norman Bethune University of Medical Sciences, Jilin Province, China

\section{Professional Society Memberships}

(2007-present) Member of Neuroscience Society

\section{Work Experiences}

2011-present Postdoctoral Research Fellow

Department of Psychiatry, Johns Hopkins University, Baltimore,

MD, 21210

2004-2011 Research Assistant

Department of Behavioral Medicine \& Psychiatry, West Virginia University, Morgantown, WV, 26505

\section{Professional Society Memberships}

(2007-present) Member of Neuroscience Society 


\section{Publications}

Xiao L, O'Callaghan JP, O'Donnell JM (2011) Effects of repeated treatment with phosphodiesterase-4 inhibitors on cyclic AMP signaling, hippocampal neurogenesis, and behavior in the forced-swim test. J Pharmacol Exp Ther. 338(2):641-7

Mirna Kvajo, Heather McKellar, Liam J. Drew, Aude-Marie Lepagnol-Bestel, Xiao L, P. Alexander Arguello, Clay O. Lacefield, Michel Simonneau, James M. O’Donnell, Amy B. MacDermott, Maria Karayiorgou, and Joseph A. Gogos Aberrant connectivity, excitability and short-term synaptic plasticity of a hippocampal circuit in a genetic mouse model of schizophrenia. PNAS. In review

Masood A, Huang Y, Hajjhussein H, Xiao L, Li H, Wang W, Hamza A, Zhan CG, O'Donnell JM (2009) Anxiolytic effects of phosphodiesterase-2 inhibitors associated with increased cGMP signaling J Pharmacol Exp Ther. 331(2):690-9

Li YF, Huang Y, Amsdell SL, Xiao L, O'Donnell JM, Zhang HT (2009) Antidepressant- and Anxiolyticlike Effects of the Phosphodiesterase-4 Inhibitor Rolipram on Behavior Depend on Cyclic AMP Response Element Binding Protein-Mediated Neurogenesis in the Hippocampus (2009) Neuropsychopharmacology. 34(11):2404-19

\section{Posters}

Xiao L, Gogos J, O'Donnell JM. The effect of DISC1 mutation on the PDE4 isoforms and cAMP/pCREBsignaling cascade. GOR of PDE meeting 2010, NH

Xiao L, Gogos J, O'Donnell JM. The effects of DISC1 mutation on cAMP/pCREB signaling and highaffinity rolipram binding state. West Virginia University Health Science Center 2009 E.J.Van Liere Convocation and Research day

Xiao L, Felton CM, O'Callaghan JP, O'Donnell JM. PDE4 inhibitors exert an antidepressant-like effect via increased cAMP/CREB signaling and and increased neurogenesis in hippocampus: Importance of the high-affinity binding state. Society for Neuroscience 2008 annual meeting, Washington, DC

Xiao L, Felton CM, O'Callaghan JP, O'Donnell JM. Effects of phosphodiesterase-4 (PDE4) inhibitor on cAMP levels and CREB phosphorylation in rat brain. Society for Neuroscience 2007 annual meeting, San Diego, $C A$

Xiao L, O'Donnell JM. Effects of phosphodiesterase-4 (PDE4) inhibitor rolipram on cAMP levels and CREB phosphorylation in rat brain. West Virginia University Health Science Center 2007 E.J.Van Liere Convocation and Research day.

Xiao L, Masood A, and O'Donnell JM. Behavioral and Neurochemical Effects of the PDE2 Inhibitor Bay 60-7550 Suggest an Anxiolytic Profile. West Virginia University Health Science Center 2006 E.J.Van Liere Convocation and Research day. 